\title{
SIMULATION OF ENERGY EFFICIENCY IMPROVEMENTS ON
}

\author{
COMMUTER RAILWAYS
}

by

\section{GAVIN JOHN HuLL}

A thesis submitted to The University of Birmingham for the degree of

MASTER OF Philosophy: RAILWAy SYSTEMS EngineERING

Department of Birmingham Centre for Railway Research and Education

School of Electrical, Electronic and Computer Engineering

The University of Birmingham

August 2009 


\section{UNIVERSITYOF BIRMINGHAM}

\section{University of Birmingham Research Archive \\ e-theses repository}

This unpublished thesis/dissertation is copyright of the author and/or third parties. The intellectual property rights of the author or third parties in respect of this work are as defined by The Copyright Designs and Patents Act 1988 or as modified by any successor legislation.

Any use made of information contained in this thesis/dissertation must be in accordance with that legislation and must be properly acknowledged. Further distribution or reproduction in any format is prohibited without the permission of the copyright holder. 


\begin{abstract}
Railway networks consume large amounts of energy and, as a result, are the cause of a significant amount of $\mathrm{CO}_{2}$ and other harmful gas emissions. British railways strive to comply with objectives set by the European Rail Research Advisory Council and the Committee on Climate Change. Improvements in the operation of railway networks through the use of energy efficiency regimes can decrease the operational costs and $\mathrm{CO}_{2}$ emissions. Existing and industry proven methods include regeneration, coasting allowances and driver training. The use of a simulator allows railway organisations to understand and quantify the benefits of the various methods for their particular rolling stock and networks.
\end{abstract}

This thesis describes the development of a multi-train simulator for the Merseyrail network. The simulator is based on a pre-existing single train simulator. Results from the simulator show that a combination of regeneration, introduction of coasting points and improved driving style have the potential to provide up to a $50 \%$ increase in energy efficiency. In particular, the study shows that a $23 \%$ reduction in energy consumption through regeneration; a $22 \%$ energy reduction with the strategic placement of coasting points; and a 4\% reduction in energy when an improved driving style is adopted, are possible. These improvements have the potential to eliminate 12 kilotonnes of $\mathrm{CO}_{2}$ emissions from Merseyrail per year. 


\section{ACKNOWLEDGEMENTS}

Throughout this Master of Philosophy, Dr Clive Roberts has overseen the progress of this thesis and helped me develop my appreciation and understanding of research in the area of railway systems engineering. I would like to thank $\mathrm{Dr}$ Clive Roberts for the support he has given me during the time to complete my thesis. I would also like to thank Dr Stuart Hillmansen for providing support on understanding the STS and also for giving me supervision. The thesis has been helped by information provided by a number of companies. This information has been vital in developing the Merseyrail Simulator. I would like to express my appreciation to Angel Trains, ATKINS, CORUS, and GEC for the use of unpublished information on railway properties. The thesis has been supported by a Doctoral Training Account grant from the Engineering and Physical Sciences Research Council. Last, but not least, I am grateful for all the support I have received from my family and friends. 


\section{TABLE OF CONTENTS}

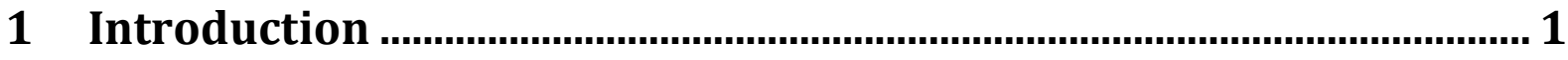

1.1 Motivation ........................................................................................................................... 1

1.2 Modelling and Environmental Objectives ..................................................................... 2

1.3 Methodology and Modelling Parameters ………………………………………………...... 4

1.4 Contributions to Research and Modelling..................................................................... 5

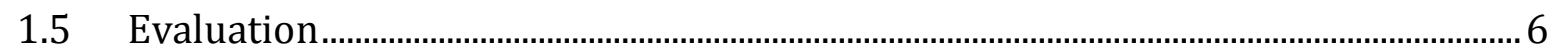

1.6 Thesis Outline .....................................................................................................................

2 DC Railways and Merseyrail: Background and Case Study …............. 9

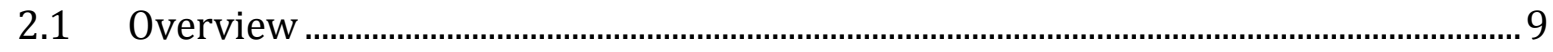

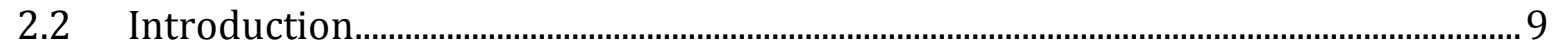

2.3 DC Railway Power Distribution Systems.................................................................... 11

2.4 DC Machines ................................................................................................................ 18

2.5 Merseyrail Case Study ....................................................................................................... 40

2.6 Discussion and Conclusion ............................................................................................. 49

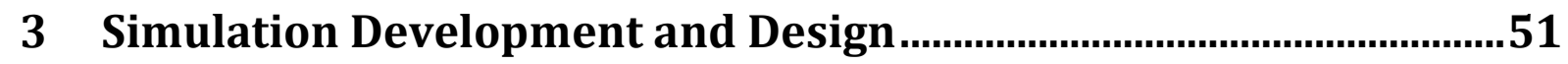

3.1 Introduction............................................................................................................ 51

3.2 Mathematical Representation of Train Kinematics..................................................... 51

3.3 Extraction and Input of Route Information................................................................. 55

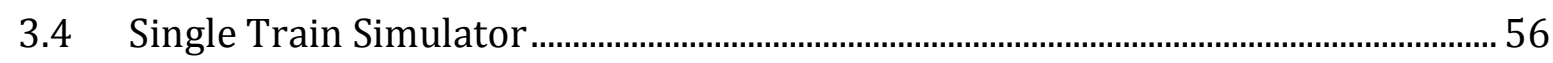

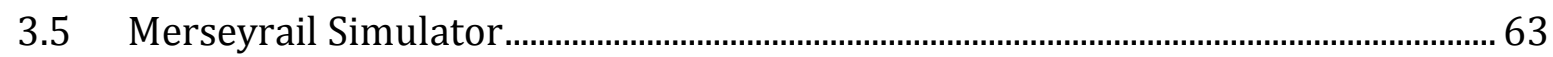

3.6 Assumptions and Limitations of the Merseyrail Simulator .......................................77

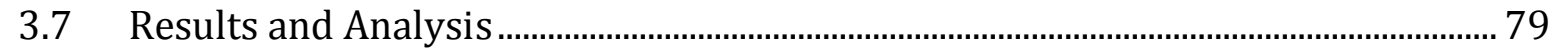

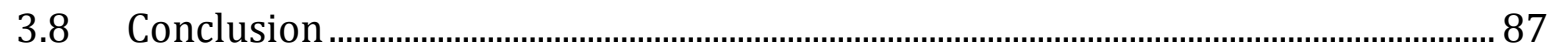

4 Verification and Reliability of the Merseyrail Simulator...................90

4.1 Introduction.............................................................................................................. 90

4.2 Docklands Light Railway Rolling Stock and Distribution Network ......................... 91

4.3 Simulators for the Docklands Light Railway Route...................................................... 92

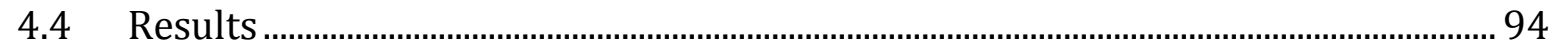

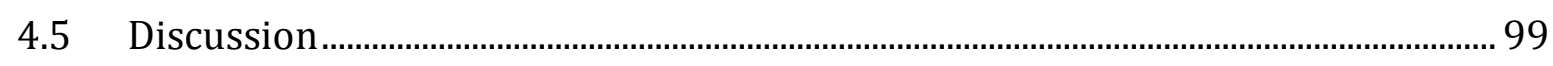

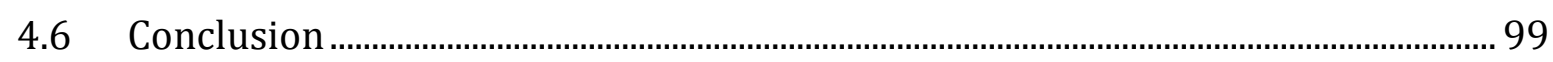

5 Simulation and Results of Energy Efficiency Schemes...................101

5.1 Introduction .................................................................................................................101 


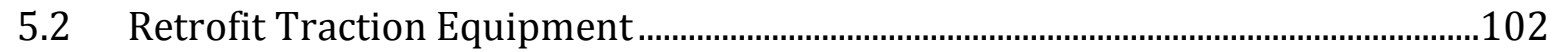

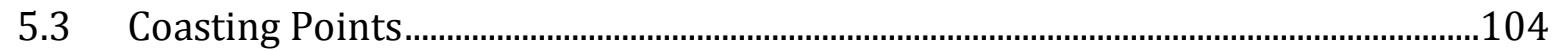

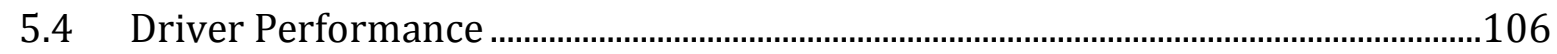

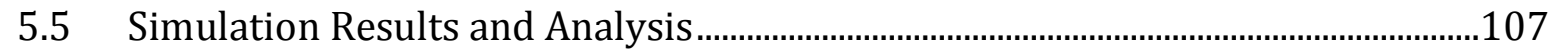

5.6 Conclusion and Further Work ................................................................................130

6 Conclusion and Further Work......................................................... 132

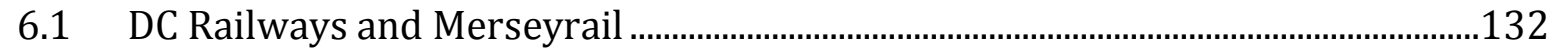

6.2 Single Train Simulator and Merseyrail Simulator.....................................................133

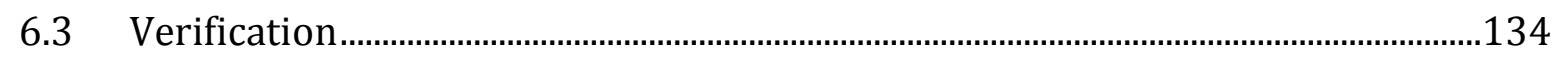

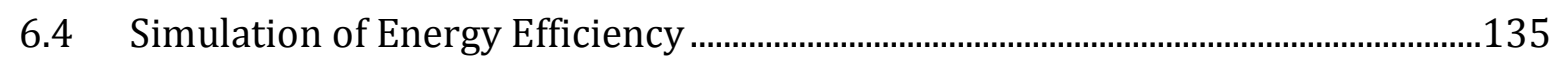

6.5 Further Work: Simulator Developments................................................................136

6.6 Further Work: Merseyrail Project................................................................................137

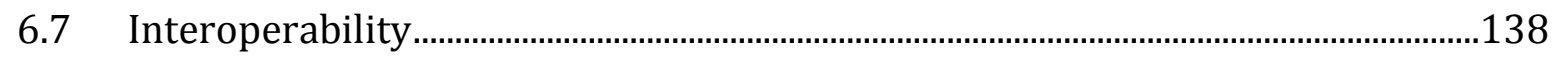

7 Bibliography .................................................................................. 140

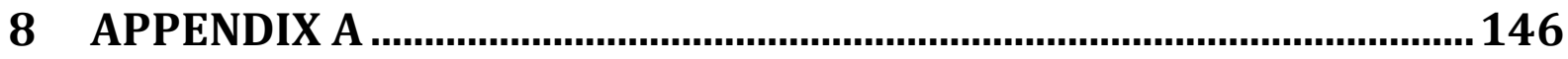

9 APPENDIX B ............................................................................................... 147

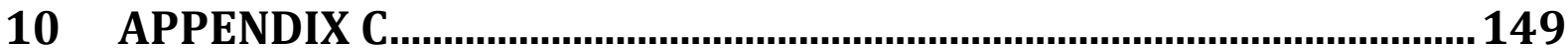




\section{LIST OF ILLUSTRATIONS}

Figure 1: Railway power network between two substations distributing power to trains via third rails.

Figure 2: Full bridge rectifier with smoothing inductor loaded with a DC motor 15

Figure 3: Three-phase full wave rectifier with a smoothing inductor loaded with a DC motor. 16

Figure 4: 12-pulse rectifier with secondary windings in a delta and star configuration that connect to two parallel rectifiers 17

Figure 5: Three-phase bridge rectifier-inverter with LC filter 18

Figure 6: Plan view of bogie equipment including DC motors, third rail, shoe gear, power controller, gears, earth return brush, wheels and rails

Figure 7: Single-coil DC machine with two commutator segments and brushes 21

Figure 8: Equivalent circuit diagram of a series DC motor 25 Figure 9: Variation of flux with magneto-motive force showing the saturation of flux in a

DC motor. 26

Figure 10: Effect of armature reaction in a DC machine. 28

Figure 11: Inter-poles placed between poles to reduce sparking on brush-commutator contact

Figure 12: Camshaft controlled $\mathrm{V}_{\mathrm{T}}$ with series and parallel rheostats loaded with either four series DC motors, or two pairs of DC motors in parallel 33

Figure 13: DC-DC converter in the boost configuration with a high-frequency switch $\mathrm{T}_{1}$

smoothing inductor $\left(\mathrm{L}_{F}\right)$ and capacitor $\left(\mathrm{C}_{1}\right)$, and a fly-back diode $\left(\mathrm{D}_{1}\right)$ 34

Figure 14: DC converter in a buck configuration with LC filter. 35 
Figure 15: Capacitors switch on starting resistors depending on a time constant

Figure 16: Hysteresis curve of DC motor

Figure 17: Sample from Merseyrail substation wiring diagram between Liverpool Central and Brunswick

Figure 18: Equivalent circuit diagram for one coach of the $C 507 / 8$ trains showing the rheostat controller and motor configuration 44

Figure 19: The amount of brake power available from electric motors and the proportion of the total brake rate desired 47

Figure 20: Motion of a train with forward force from traction, resistive force from resistance and effect of the track gradient due to the force from gravity. 52

Figure 21: Specific Traction, Resistance and Acceleration curve of an accelerating train 53

Figure 22: Cross-sectional height and speed limit between Moorfields and Southport on the Merseyrail Northern Line 56

Figure 23 : Flow diagram of processes required to calculate the power versus time of a single train 57

Figure 24: The flat-out case simulation results of a C507/8 on a test track 61

Figure 25: The proportional case simulation results of a C507/8 on a test track 62 Figure 26: The proportional and notched case simulation results of a C507/8 on a test track 63

Figure 27: Flow diagram showing operations, conditionals and data storage of the MERS program from start to end 67 
Figure 28: Train $(\mathrm{M})$ between substations $\left(\mathrm{V}_{1}\right.$ and $\left.\mathrm{V}_{2}\right)$ with losses on conductors and rails ahead $\left(\mathrm{R}_{C} l\right.$ and $\left.\mathrm{R}_{\mathrm{T}} l\right)$ and behind $\left(\mathrm{R}_{\mathrm{C}}\left(\mathrm{x}_{\mathrm{T}}-l\right)\right.$ and $\mathrm{R}_{\mathrm{T}}\left(\mathrm{x}_{\mathrm{T}}-l\right)$ including current ahead $\left(\mathrm{I}_{1}\right)$ and behind $\left(\mathrm{I}_{2}\right)$

Figure 29: Two trains (M) in opposite direction between substations $\left(\mathrm{V}_{1}\right.$ and $\left.\mathrm{V}_{2}\right)$ with losses on conductors and rails ahead Train 1 and Train $2\left(\mathrm{R}_{C} l, \mathrm{R}_{\mathrm{T}} l\right.$ and $\left.\mathrm{R}_{C} X, \mathrm{R}_{\mathrm{T}} X\right)$ and behind $\left(\mathrm{R}_{\mathrm{C}}\left(\mathrm{x}_{\mathrm{T}}-l\right), \mathrm{R}_{\mathrm{T}}\left(\mathrm{x}_{\mathrm{T}}-l\right)\right.$ and $\left.\mathrm{R}_{\mathrm{C}}\left(\mathrm{x}_{\mathrm{T}}-x\right), \mathrm{R}_{\mathrm{T}}\left(\mathrm{x}_{\mathrm{T}}-x\right)\right)$ current ahead $\left(\mathrm{I}_{3}\right.$ and $\left.\mathrm{I}_{2}\right)$ and behind $\left(\mathrm{I}_{4}\right.$ and $\mathrm{I}_{1}$ ) Train 1 and Train 2 72

Figure 30: Motoring Curves for C507/8 with operating ranges of series (solid, A sequentially to $\mathrm{K}$ ), parallel (dashed, L sequentially to $\mathrm{Q}$ ) and field weakening (dotted, $\mathrm{R}$ sequentially to T)

Figure 31: Digitised tractive effort versus current curve indicating field weakening percentages, trend-line, and equation of trend-line. .76

Figure 32: Simulated speed-distance graph for C507/8 80

Figure 33: Simulated acceleration versus distance graph for C507/8 80

Figure 34: Simulated speed versus current graph for $\mathrm{C507/8}$ with operating regions series A to B, parallel B to $C$ and field weakening $C$ and above 81

Figure 35: Simulated current for C507/8 with series, parallel and field weakening operating regions 82

Figure 36: Simulated tractive effort and resistance versus speed. Indications of operating regions series (A to $B$ ), parallel (B to $C$ ) and field weakening ( $C$ to $D$ ). 83 Figure 37: Simulated average power flow of two trains in opposite direction between two substations, where average power in Pav In, average power out Pav Out and average power on the track Pav Track 84 
Figure 38: Simulated power loss versus time for C507/8 with operating regions indicated, torque loss $\mathrm{M}$, power controller loss $\mathrm{L}$ and total power loss $\mathrm{P}$ 85

Figure 39: Simulated voltage on shoe, voltage on rail and current behind and before Train 1 86

Figure 40: Simulated voltage on shoe, voltage on rail and current behind and before Train 2

Figure 41: DLR route between Canning Town and Beckton showing the speed limit and cross-sectional height. 91

Figure 42: Speed-distance graph for OSLO between Canning Town and Beckton 96

Figure 43: Speed-distance graph for MTS between Canning Town and Beckton 96

Figure 44: Speed-distance graph for MERS between Canning Town and Beckton 96

Figure 45: Train Voltage and Current for MTS and OSLO between Canning Town and Beckton 98

Figure 46: Train Voltage and Current for MERS between Canning Town and Beckton.... 98 Figure 47: Merseyrail route map showing the Wirral and Northern lines including other routes not operated by Merseyrail (Merseytravel 2005) 108

Figure 48: The MERS simulating one train from Chester to Liverpool Central 109

Figure 49: The average power of C507/8 trains with a driving style of flat-out travelling between Chester and Liverpool Central 113 Figure 50: The MERS result between Chester and Liverpool Central of the average power from C507/8 trains operated in the proportional driving style "Driver (prop)" 116 Figure 51: The MERS results of the average power of a proportional and notched controlled C507/8 between Chester and Liverpool Central 118 
Figure 52: Simulation results of C507/8 with coasting points showing the decrease in energy consumption and increase of time

Figure 53: Energy against time graph showing percentage of energy saved for an increase of running time because of coasting points 120

Figure 54: The MERS results of the average power of trains travelling between Chester and Liverpool Central with coasting points placed at 37\% between stations

Figure 55: The MERS simulated speed-distance of a train travelling from Chester to Liverpool Central.

Figure 56: The MERS simulated speed-distance of a train travelling from Liverpool Central to Chester. 121

Figure 57: Simulation results of C507/8 with boost converter, regeneration and coasting points showing the decrease in energy consumption and increase of run time 122 Figure 58: The average power of regenerating trains travelling between Chester and Liverpool Central 123

Figure 59: Regeneration against coasting showing the decrease in regenerated energy with an increase in energy saved by coasting 124

Figure 60: Simulation results of $\mathrm{C} 507 / 8$ with buck converter and coasting points showing the decrease in energy consumption and increase of time compared to the C507/8 travelling flat-out 125

Figure 61: Energy against time graph of a C507/8 with a buck converter, showing percentage of energy saved for an increase of running time because of coasting points

Figure 62: Simulation results of C507/8 with buck and boost converters, regeneration, and coasting points showing the energy consumption decrease and time increase....... 127 
Figure 63: Regeneration against coasting of the C507/8 with buck and boost converters, showing regenerated energy decrease with energy saved by coasting increase 128

Figure 64: The average power results from the MERS between Chester and Liverpool Central for a C507/8 retrofitted with buck and boost converters with regeneration and coasting points at $35.5 \%$

Figure 65: Class 507 Motoring Curves (C507MC) with calculation of motor constant (K) for lap and frog-leg windings, 1 to 11 turns on armature conductors and multiplex..... 146 Figure 66: Tractive Effort versus Current and Speed versus Current with indicated field weakening percentages

Figure 67: Speed versus Current curves for each camshaft position from A to T, with indicated resistance and field weakening percentages 148

Figure 68: The MERS simulating one train from Ellesmere Port to Hooton. 149

Figure 69: The MERS simulating one train from Hunts Cross to Moorfields 149

Figure 70: The MERS simulating one train from Kirkby to Liverpool Central 150

Figure 71: The MERS simulating one train from Ormskirk to Kirkdale. 150

Figure 72: The MERS simulating one train from West Kirby to Birkenhead North 151

Figure 73: The MERS simulating one train from New Brighton to Liverpool Central .... 151

Figure 74: The MERS simulating one train from Southport to Moorfields. 152 


\section{INTRODUCTION}

\subsection{Motivation}

It is well known that railway transport is the most environmentally friendly mass transportation system available. Nonetheless, as recently reported by the European Union (2008), British railway emissions amounted to 2.4 megatonnes of $\mathrm{CO}_{2}$ equivalent. Many previous research projects have provided methods to improve the energy efficiency of railways, primarily to reduce carbon emissions. There are two environmental objectives set by international organisations that influence British policy in this area. The first is a proposed 50\% energy efficiency improvement between 2001 and 2020 from the European Rail Research Advisory Council (ERRAC) (ERRAC 2001). The second is a $42 \%$ reduction in $\mathrm{CO}_{2}$ and other pollutant gases from the Committee on Climate Change (CCC) in Britain from 1990 to 2020 (Commitee on Climate Change 2008). The objectives set by ERRAC and CCC are important, particularly given Network Rail's (2007a) forecast of an increase in railway traffic due to increased passenger loading and freight traffic. Any increase in railway traffic will inevitably increase $\mathrm{CO}_{2}$ emissions in the sector. The majority of British electric railways are powered by gas and coal power stations (Department of Trade and Industry 2007). Therefore, in order to reduce the emission of pollutants and have a sustainable energy source, the ratio of electricity generation should increase to favour nuclear, regenerative, or environmentally friendly energy sources (Wen 2007).

Research into developing technologies that improve the energy efficiency of railways include hybrid systems (Ogawa 2007, Hillmansen 2006), Energy Storage 
Systems (ESS) (Fletcher 1991, Açikbas 2007, Flinders 1995), and driving style (Bocharnikov 2007, Wong 2004, Golovitcher 2001). However, there has not been extensive research into the proficiency of these energy efficient schemes to improve railways, nor into the quantification of their effect when used together.

This thesis describes the creation of a simulator, the Merseyrail Simulator (MERS). It has been used to simulate the Merseyrail network as a case study to test the potential of improving energy efficiency using the various efficiency schemes available. The work assesses the potential of meeting the objectives set by ERRAC and CCC. The results also indicate the potential operational savings that Merseyrail would have from the adoption of energy saving strategies. The findings of this thesis suggest that networks similar to Merseyrail, such as Southern Region, Docklands Light Railway (DLR), London Underground, and Glasgow Subway have the potential to improve their energy efficiency.

This thesis is associated with a condition monitoring project undertaken by the Birmingham Centre for Railway Research and Education. This entails the monitoring of Class 507 and 508 (C507/8) rolling stock. The MERS could be used in further work to analyse the data from the monitoring project. The method of analysis would be the correlation of collected data with simulated data.

\subsection{Modelling and Environmental Objectives}

The objective of this thesis is to explain the development of the MERS and how it has been used to evaluate the potential benefits of different energy efficiency approaches. 
Furthermore, the simulator is compared with other industrially recognised simulators in order to verify the results.

In every railway, there are many areas where developments could improve energy efficiency. Electrified railways are only used for the busiest routes in Britain because infrastructure costs and passenger numbers are suitably balanced (see Chapter 2). Britain has 39\% of the national railway system electrified (DFT 2007). The majority of Britain's railway operators do not have energy efficient schemes such as regeneration or coasting (see Chapter 5). On commuter railways, stations are spaced relatively close together, therefore a train will use its brakes regularly. The use of regenerative braking on commuter railways, whereby the traction equipment generates electricity from the kinetic energy of the train, has significant potential to improve overall the energy efficiency under conditions of regular brake utilisation.

The timetable specifies the time that a train has to travel between stations. Slight allowances in the timetable has the potential to increase the energy efficiency when the train travels at a decreased constant speed or operates according to a strategically positioned coasting point (Wong 2004).

In terms of energy efficiency, the ideal operation of a train is in a sequence of: maximum tractive effort up to a speed limit (Schmid 2007), constant speed, coasting from a pre-defined location, and braking at the precise moment to stop at the station (Bocharnikov 2007). The train driver can operate the train without any traction control error and brake in the correct sequence, which gives the ideal operation of the train. 
The energy efficiency improvement of commuter railways is simulated in the MERS to discover the effect of energy efficient schemes and their potential when used together.

\subsection{Methodology and Modelling Parameters}

Industrial railway simulators (Taskin 1991, Yu 1998, Martin 1999, Siu 1994) allow the development of network specific scenarios by combining models of railway subsystems. Each component of the subsystem has a set of generalised equations that describes its behaviour. The design of the MERS also started from subsystem models with generalised equations, which are integrated in order to simulate the Merseyrail system. The generalised equations are solved to form sets of equations, sometimes involving differential equations. The design of the MERS required detailed information provided by Merseyrail and other sources to make the model specific. A comparison of the MERS with two other simulators enabled the verification of results from the simulation over a Docklands Light Railway (DLR) route. The simulators used for this comparison were the Multi-train Simulator (MTS) developed by the University of Birmingham and Overhead Electrical System Loading (OSLO) used by ATKINS.

The important parameters and components that have been modelled in the MERS are:

- Interaction of trains

- Multiple train power dynamics

- Resistance of conductors and rails

- Speed restrictions 
- Station distributions

- Static payload

- Substation spacing/ locations

- Track geometry

- Traction equipment

This enables an estimation of acceleration, speed, displacement, energy consumption, and timetabling of operating trains.

\subsection{Contributions to Research and Modelling}

This thesis has contributed to the railway research sector in many ways; three significant accomplishments are described below:

- The MERS is compared and verified with two other industrial simulators and annual consumption reports. The three simulators give comparable results, which indicates that the MERS is capable of simulating other DC railway networks.

- The design of the MERS included an equivalent circuit diagram of the power network that was solved using current mesh analysis and a Traction Equipment (TEm) model for a C507/8. This contributed to the design of simulators, where a model of the $\mathrm{C} 507 / 8$ is presently unavailable.

- There is a contribution to the evaluation of three energy efficient schemes for commuter railways. Merseyrail is used as a case study, where the energy efficiency schemes are implemented to see how much energy is saved. If Merseyrail developed its network with these schemes then their energy efficiency should improve and operational costs decrease. The simulated total 
energy efficiency improvement is sufficient for Merseyrail to comply with the objectives defined by ERRAC and CCC.

\subsection{Evaluation}

An aspect of the project is the comparison of the schemes and the assignment of a rating to each in terms of energy efficiency improvement. A proposal for Merseyrail would be to develop the best scheme, so they could benefit from reduced operating costs and comply with international environmental objectives. However, the proficiency of the energy efficient schemes is different for each railway network. Specific evaluation of the parameters is needed to determine the effect of each scheme, since the effect of regeneration is dependent on station spacing, coasting on gradient changes, and driver strategies on performance and controls. Railway companies benefit from the development when the incurred costs are less than the savings from reduced energy expenditure. The point at which that happens can be evaluated in a cost budget analysis.

A railway company may use more than one energy efficiency technique at the same time. It is important to consider possible secondary effects arising from interactions between the techniques. For instance, the use of regeneration with coasting points decreases the amount of kinetic energy available at the point of braking. Therefore, the amount of energy recuperated decreases with an earlier coasting point. For example, to gain $50 \%$ energy efficiency, the coasting point needs to be chosen while considering the amount of kinetic energy the train will have when it needs to brake. When several developments are used together, it is essential to include their interactions to show the total net benefit. 


\subsection{Thesis Outline}

\section{Chapter 2 DC Railways: Background Information and Case Study}

This starts with an overview of DC commuter railways including an analysis of the railway power distribution system, the traction equipment of DC commuter trains and operational procedures. It then continues onto a case study of Merseyrail and calculation of parameters for their railway.

\section{Chapter 3 Simulation Development and Design}

The Single Train Simulator (STS) is introduced and there is description on how it works and the developments taken to make it specific to Merseyrail. The design and development of the equivalent distribution network circuit diagram using mesh analysis is shown. This follows onto the design and development of the Traction Equipment (TEm) model. The results from the MERS involved a power flow calculation, which show the network energy consumption, current in traction equipment, acceleration and power losses in the conductors/ rails, motor and torque.

\section{Chapter 4 Verification and Reliability of the Merseyrail Simulator}

Three simulators are compared; the MERS, MTS and OSLO. These are compared on parameters of running time, energy consumption, and train voltage and current. The verification procedure is analysed to show the parameter variation and boundary conditions. It concludes the results with relations to the programming methods in each simulator.

\section{Chapter 5 Simulation and Results of Energy Efficient Schemes}


There is an introduction of energy efficiency schemes that are widely accepted in research. The retrofit of traction equipment is described, highlighting issues on the efficiency of regeneration, losses in the inverter, in the motor (flux linkages), along the line to storage and increased weight. Coasting is introduced, with description of algorithms "Fibonacci", "Gradient" and "Golden". The MERS will use fixed coasting points between stations. Driving technique is described including detail on fatigue and the different driving style from the STS. There is a comparison between the energy efficient scenarios of the energy consumption, and there is a determination of the best method. The chapter concludes with potential savings Merseyrail has with three energy efficiency schemes combined.

\section{Chapter 6 Conclusion and Further Work}

There is a conclusion on the simulation of energy efficiency schemes and the ideal method to develop the Class 507 and 508 rolling stock and distribution network. Further developments to the MERS are identified, including description of the flexibility of the assumptions and constraints, and limitations in the generalisations. The Merseyrail project is further work, which has potential to monitor driver style, payload dynamics, and investigate cause for delays 


\section{DC RAILWAYS AND MERSEYRAIL: BACKGROUND AND CASE}

\section{STUDY}

\subsection{Overview}

In this chapter a literature review was carried out to obtain the relevant information required to design the MERS and to analyse the results. The review starts with an introduction to the history of DC Railways and a comparison with other commuter railways. A study of the traction equipment, supports the modelling process with a detailed description of the fundamentals of controlling DC machines. There is an examination of the problems associated with DC motor control summarised by an evaluation of the present industrial techniques. The power distribution system is described including the conversion and transmission of power from industrial power supplies to the current collector system onboard the train.

This review then focuses on Merseyrail as a case study. Background information relevant to Merseyrail is analysed to identify parameters of their railway system. The case study then examines the possible values of these parameters using information gathered from various sources.

\subsection{Introduction}

The first DC railway had a third rail power distribution system and was built in 1879 . The same design is now present in many countries across the globe, particularly for urban transport. DC railways are better suited to busy commuter railways, compared to AC railways and diesel traction. One advantage of DC railways compared to diesel 
traction is that, independent from the weight of the traction equipment, there is less weight on the train as there is no onboard fuel. Another is that environmental emissions are not local to the train, so it does not spread pollutants into the surrounding environment. DC railways also provide a suitable infrastructure to build underground routes because of the absence of local pollution and ease of construction compared to the difficulties associated with diesel traction and overhead line catenary structures, as used for AC railway power networks.

There are a large number of substations contained within a DC railway. These convert AC power from industrial utility supplies into DC for locomotives and multiple units. The transmission medium between substations and trains is either third rail, fourth rail or overhead line catenary. Third and forth rail systems offer a simple construction method. Safety regulations require low voltage levels for third and fourth rail systems because of the possibility of power arcs across the short separation distance between conductor and rail. This, in addition to the power demand from a train $(656 \mathrm{~kW}$

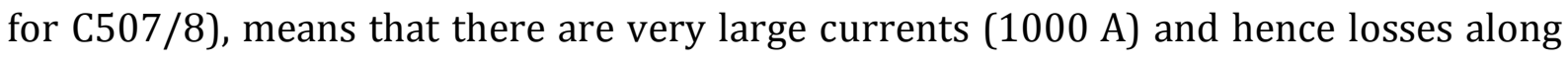
the line. Accordingly to avoid power shortages, the distances between substations are shorter substation distributions on AC railways. The DC railway requires more substations compared to AC railways, which increases the cost of building a commuter railway (Morrison-Knudsen 1992).

Within the substations and the trains are electronic power converters, with the exception of some trains having power controllers. In the substations the power converters are for the conversion of AC into DC power and on the trains they are for the regulation of voltage for traction requirements. The older, heavier, and less reliable 
power converters and controllers have replacements that are lighter, require less maintenance and have improved power factors.

The C507/8 is powered using DC series motors, which have a high starting torque and simple methods for control. The operation of the motors have different performance depending on the construction. Field coils in the motor create magnetic fields, which induce voltage in the armature coils to produce a torque. This motor is primarily used in DC railways because of its higher starting torque compared to separately excited, shunt, and compounded DC motors.

\subsection{Railway Power Distribution Systems}

Industrial utility supplies distribute power over the power grid into substations, which have transformers, rectifiers, and circuit breakers. Modern substations have the ability to convert and invert from $\mathrm{AC}$ to $\mathrm{DC}$ and $\mathrm{DC}$ to $\mathrm{AC}$, the latter for regeneration, control the power factor and utilise power filtering (Dixon 2005).

As shown in Figure 1, an AC industrial utility supply transmits power to the railway power network; the voltage is stepped down and rectified to supply DC power to the DC machines on the train. The rectifier has an inductor that is large enough to minimise the ripple of the rectified current. Either side of the transformer and rectifier are two circuit breakers that sense over-currents and protect the rectifier and traction equipment. The motoring coaches of the train have shoe gear. These are hydraulic arms that have a sliding electrical contact with the third rail (see Section 2.4). The return path for the electricity is through the wheel-rail contact or earth return brush. Since there is power dissipation in the conductors and rails, the substations are positioned according 
to a maximum separation distance to make sure the trains have enough power at all times (see Equation<2-1>).

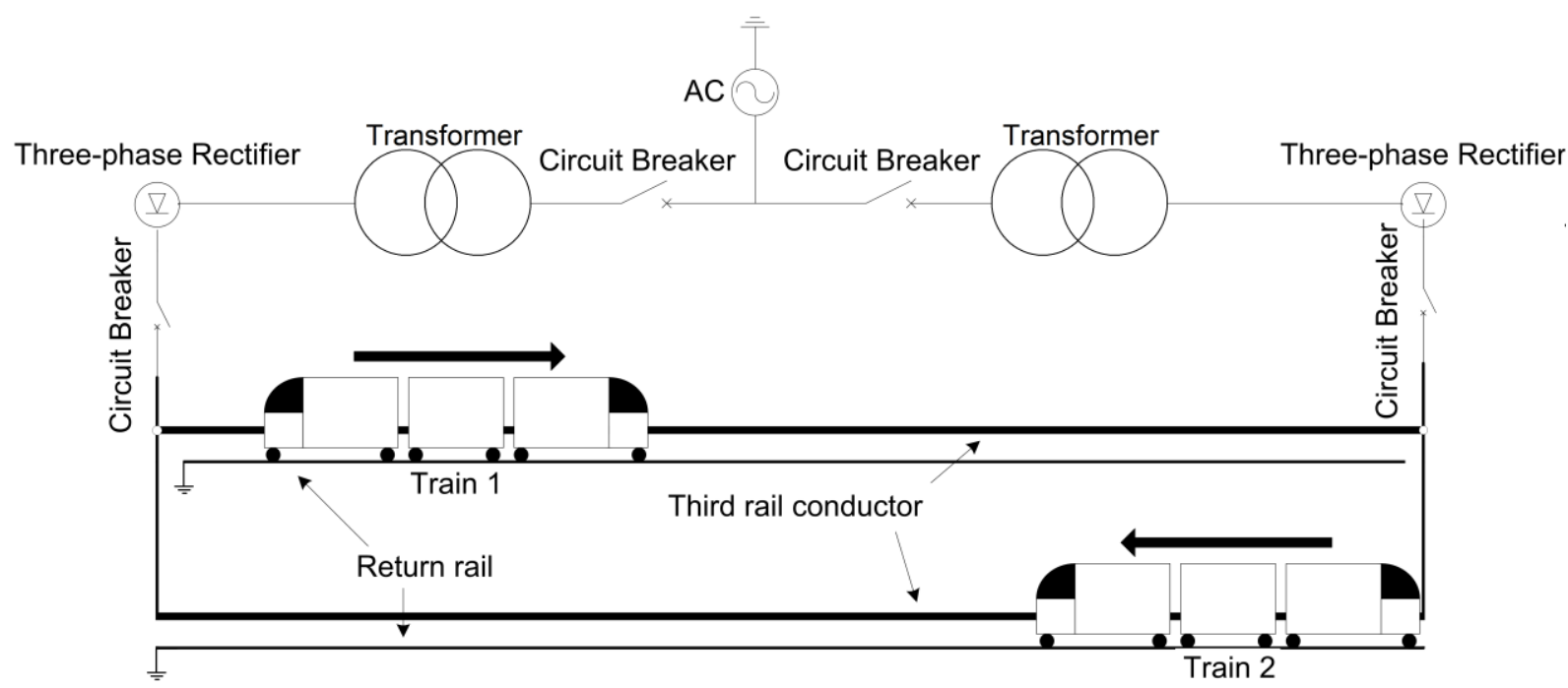

Figure 1: Railway power network between two substations distributing power to trains via third rails

$$
\mathrm{x}_{\mathrm{T}} \leq \frac{\mathrm{V}^{2}}{\mathrm{R}_{\mathrm{L}} \mathrm{P}_{\mathrm{T}}}
$$

where $x_{T}$ is the distance between series substations, $V$ is the output voltage from the substation, $R_{L}=R_{C}+R_{T}$ is the equivalent resistance of the conductors and track respectively and $\mathrm{P}_{\mathrm{T}}$ is the rated power of the train.

Transformers are devices that step-up or step-down the magnitude of voltage for an AC supply without affecting the frequency (Chapman 2005). High voltage is required to distribute power with fewer losses over long distances. A power distribution system with a low voltage and high current will have high conductor losses unless the distribution of the substations is sufficiently dense. The calculation of the resistance of the conductors and rails requires knowledge of the resistivity $(\rho)$, cross-sectional area 
$\left(A_{L}\right)$, and length of the conductor or rail $\left(I_{S}\right)$ (see Equation<2-2>). Since the train is moving, the resistance is calculated as a product of displacement in $\Omega \mathrm{km}^{-1}$.

$$
\mathrm{R}_{\mathrm{L}}=\frac{\rho I_{\mathrm{S}}}{\mathrm{A}_{\mathrm{L}}}
$$

On the rail track there is also a voltage drop. Safety limitations specify it has to be low enough to make sure there is no risk of damaging surrounding objects and passengers. According to IEC standard for DC railways, the fluctuation on the conductor needs to be within $-30 \%$ and $+20 \%$ of the nominal.

DC urban railways require a low voltage for two reasons; power arcs are more likely to occur due to the smaller separation of the conductor and rail compared to the overhead catenary, and is hazardous to the public because it is close to the ground. Therefore, to meet the power demands of the train and for health and safety reasons, the voltage is stepped-down and current stepped-up. A DC substation can typically supply 600 to $3000 \mathrm{~V}_{\mathrm{DC}}$ (Schmid 2007). The distribution of the substations is determined by a calculation to ensure that, after accounting for the power loss from the resistance of the conductor and return rail, there is adequate power for the demands of the train. The overhead line catenary infrastructure compared to third and fourth rail systems, requires a greater clearance height for underground routes and has greater resistance due to the smaller cross-sectional contact patch.

Third and fourth rail systems are easier to construct, but as previously mentioned they are hazardous. Within Britain, the majority of DC railways are third and fourth rail systems. However, within Europe there is a greater percentage of overhead 
line catenary systems. These have a greater magnitude of voltage in the power supply due to the decreased risk of causing injury. Thus, the substations can be further apart.

Rectifiers convert AC to DC power through a configuration of diodes, thyristors, or other current blocking devices. Their different configurations are either half-wave or full-wave, which convert single or three-phase AC power (see Section 2.3.1). As discussed by Mohan (2003), the power factor and the number of harmonics present in the rectified signal are important to filter because other electrical facilities connected are affected. A better rectifier would utilise a diode-bridge configuration connected to a large inductor, called a smoothing inductor (see Section 2.3.1).

\subsubsection{AC to DC: Utility Supply to Substations}

A configuration of diodes, arranged as a bridge, gives a DC output of single phase AC power. As shown in Figure 2, the diodes are arranged to conduct for the full cycle of the AC waveform. The positive current cycle conducts through $\mathrm{D}_{2}$ and returns through $\mathrm{D}_{3}$, while the negative current cycle conducts through $\mathrm{D}_{4}$ and returns through $\mathrm{D}_{1}$. As explained in Chapman (2005), the inductor is assumed to be sufficiently large to smooth the current ripple, providing a constant current output. 


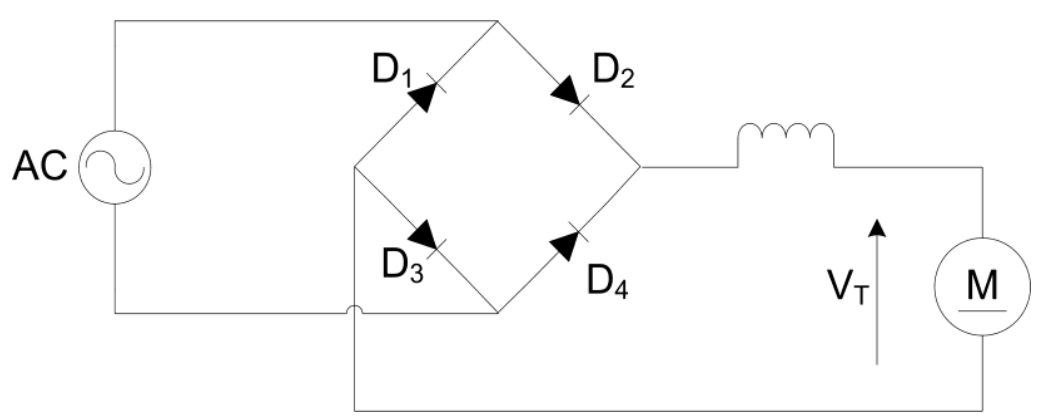

Figure 2: Full bridge rectifier with smoothing inductor loaded with a DC motor

Three-phase AC power supplies can also be rectified using half-wave and full-wave rectifiers. A three-phase full-wave rectifier, also known as the 6-pulse rectifier shares half a full bridge for each phase, which connects to the terminals of the DC motor via a smoothing inductor, see Figure 3. Mohan (2003) explains that the commutation of each diode turns on when the phase current becomes the greatest out of the three phases. The conducting diode will stay on until the magnitude of the phase current becomes less than either two of the other phases. This will turn on a different diode, which turns off the previously conducting diode with natural commutation. Natural commutation is when the current through a diode becomes reverse biased and blocks current flow. However as shown in Chapman (2005), natural commutation in the diode is relatively slow compared to triggered or timed capacitors, which are used in industry to force commutation. 


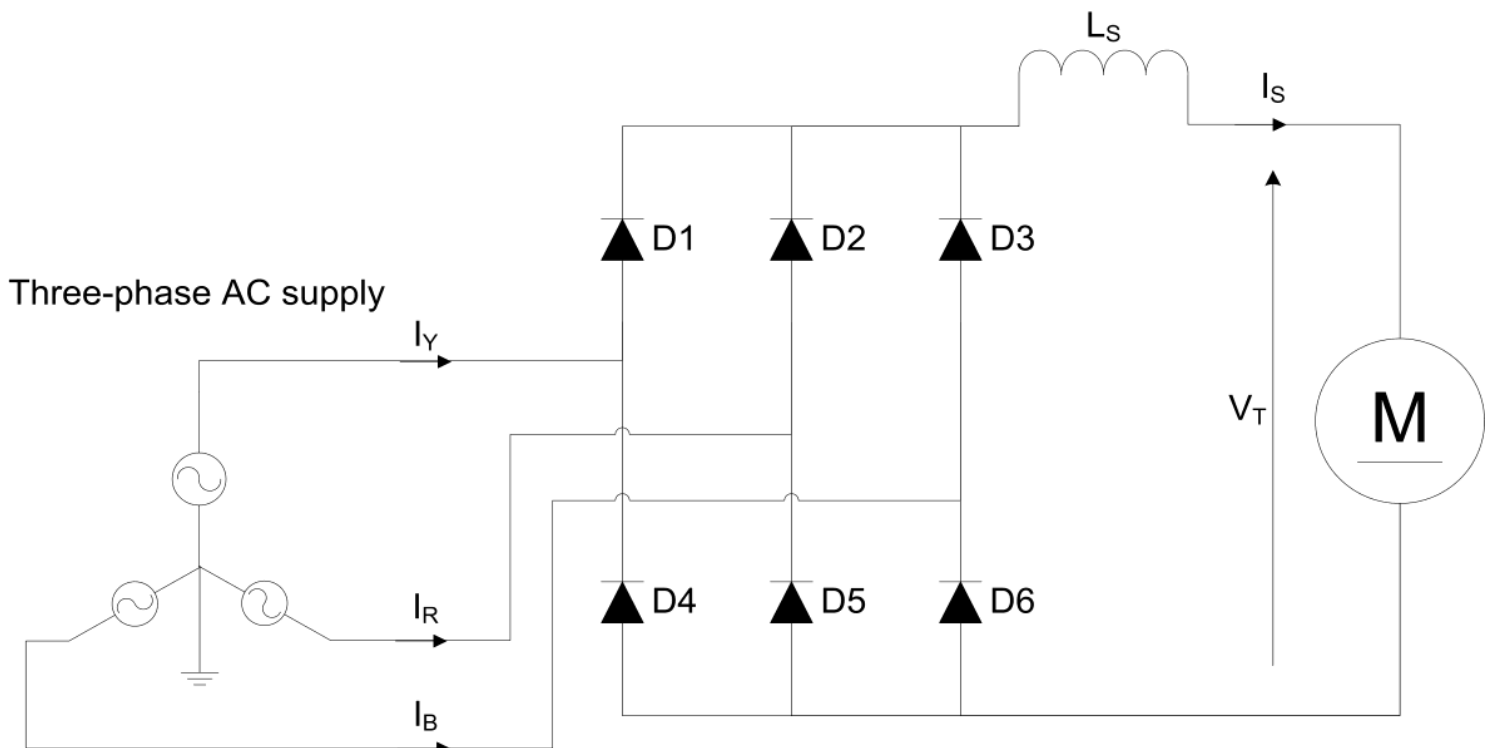

Figure 3: Three-phase full wave rectifier with a smoothing inductor loaded with a DC motor

The rectified signal from the 6-pulse rectifier will have a ripple, which is because of additional harmonics to the fundamental. To gain a better power factor, 12-pulse rectifiers are used in industry. This takes delta and star connected three-phase sources in series and uses two 6-pulse rectifiers connected in parallel. The magnitude of each phase from the delta and star three-phase sources will conduct when it has a greater current magnitude than the phases of the others. The phase difference of the delta lags $30^{\circ}$ behind the star. This makes all phases out-of-phase from each other and produces a smoother output. 

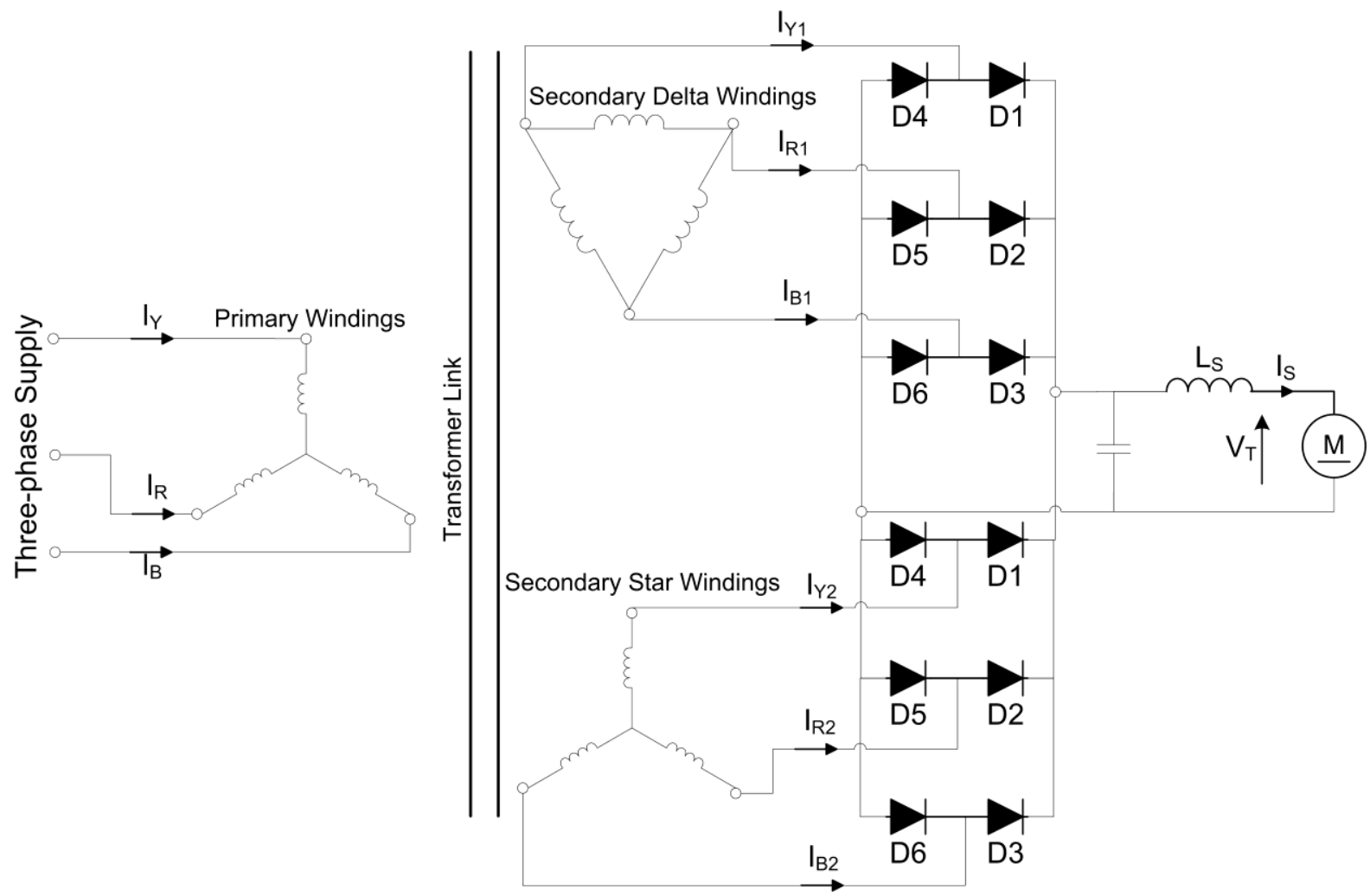

Figure 4: 12-pulse rectifier with secondary windings in a delta and star configuration that connect to two parallel rectifiers

Figure 4 shows a configuration of a 12-pulse rectifier supplying a DC motor with a inductor-capacitor filtered DC power. The three-phase supply is connected to the primary windings of the transformer link. On the right hand side of the transformer link are the delta and star connected secondary windings. These supply the parallel rectifiers, which at the output produces a DC power with less ripple than the 6-pulse rectifiers (Kuphaldt 2008).

\subsubsection{DC to AC: Substation to Utility Supply}

A three-phase bridge rectifier-inverter can invert from DC to AC power. When the DC motor is in generation mode, the rectifier-inverter inverts the DC power into threephase AC power for industrial utility supplies, as shown in Figure 5. Thyristors invert the DC power into three-phase AC, which are labelled G1 to G6. The thyristors turn off by 
natural commutation however, as explained by Schmid (2007) and Chapman (2005), forced commutation is preferred.

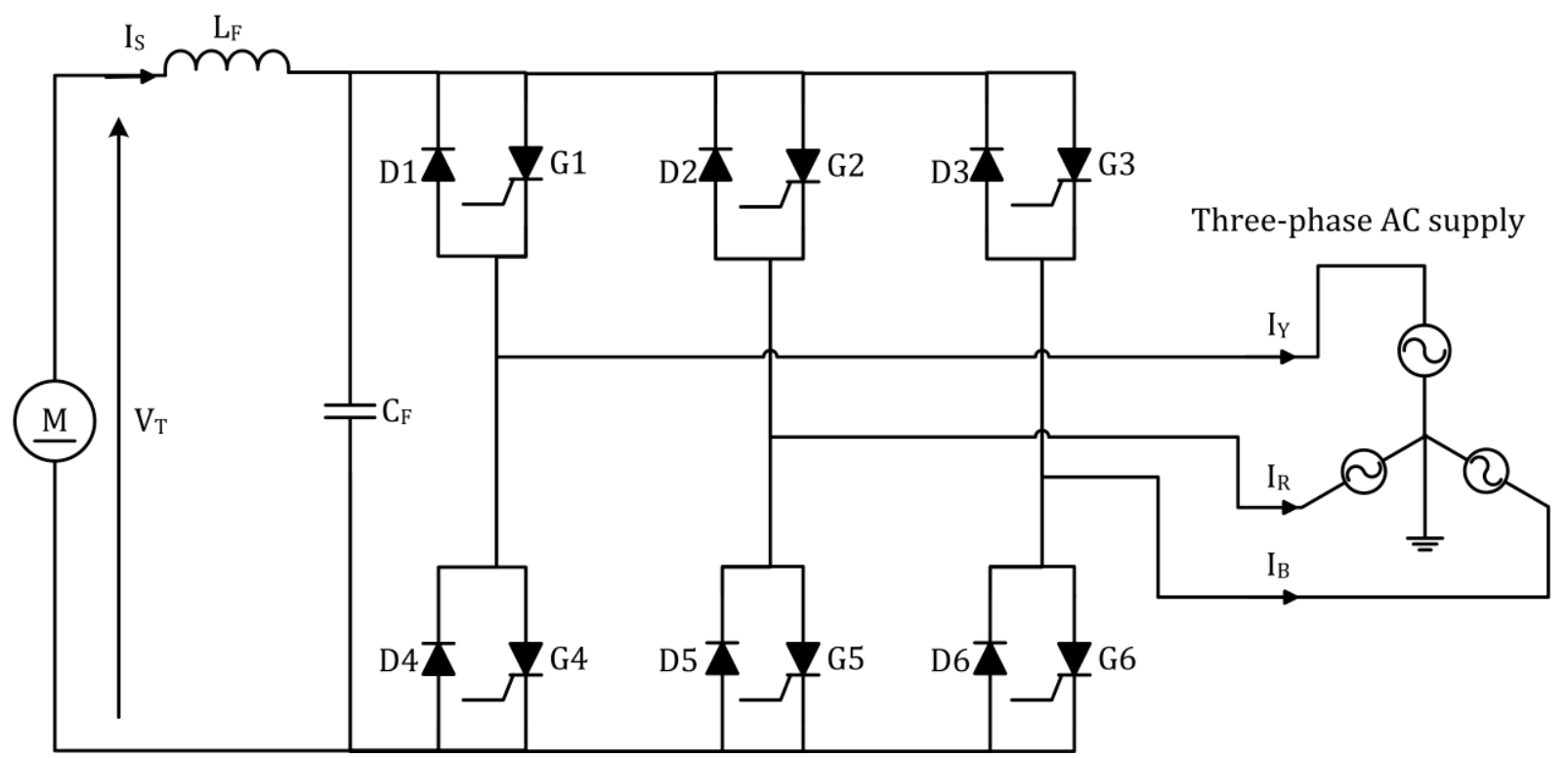

Figure 5: Three-phase bridge rectifier-inverter with LC filter

A substation with a rectifier-inverter is also known as an inverting substation. Inverting substations can convert and transmit regenerated electricity from the train back into the power grid. The voltage of the generator is stepped-up using a chopper (see Section 2.4.6). This uses a high frequency switching device, which adds harmonics to the regenerated electricity decreasing the power factor and affecting utilities connected to the power grid. Davis (2005) explains that the phase difference can be improved using an active filter. It is evident that the implementation of an inverting substation is a complex design issue, hence they are not common in railway power networks.

\subsection{Machines}

DC motors convert electricity into kinetic energy. There are several DC motor configurations, with each having individual operating characteristics. This thesis only considers DC series motors because they are used for the C507/8 on Merseyrail. Figure 
6 shows a typical layout of traction equipment on the bogie of a third rail DC train. Not shown in the diagram are the brakes and the frame of the bogie, which holds the equipment into place. The diagram includes shoe gear that slides along the third rail and supplies power to the power controller. The driver sends commands to the power controller, which controls the operation of the DC motors. The motors supply a torque to the gears and these turn the wheels. The return current flows from the motor, back to the power controller and to an earth return brush, which slides along the rails.

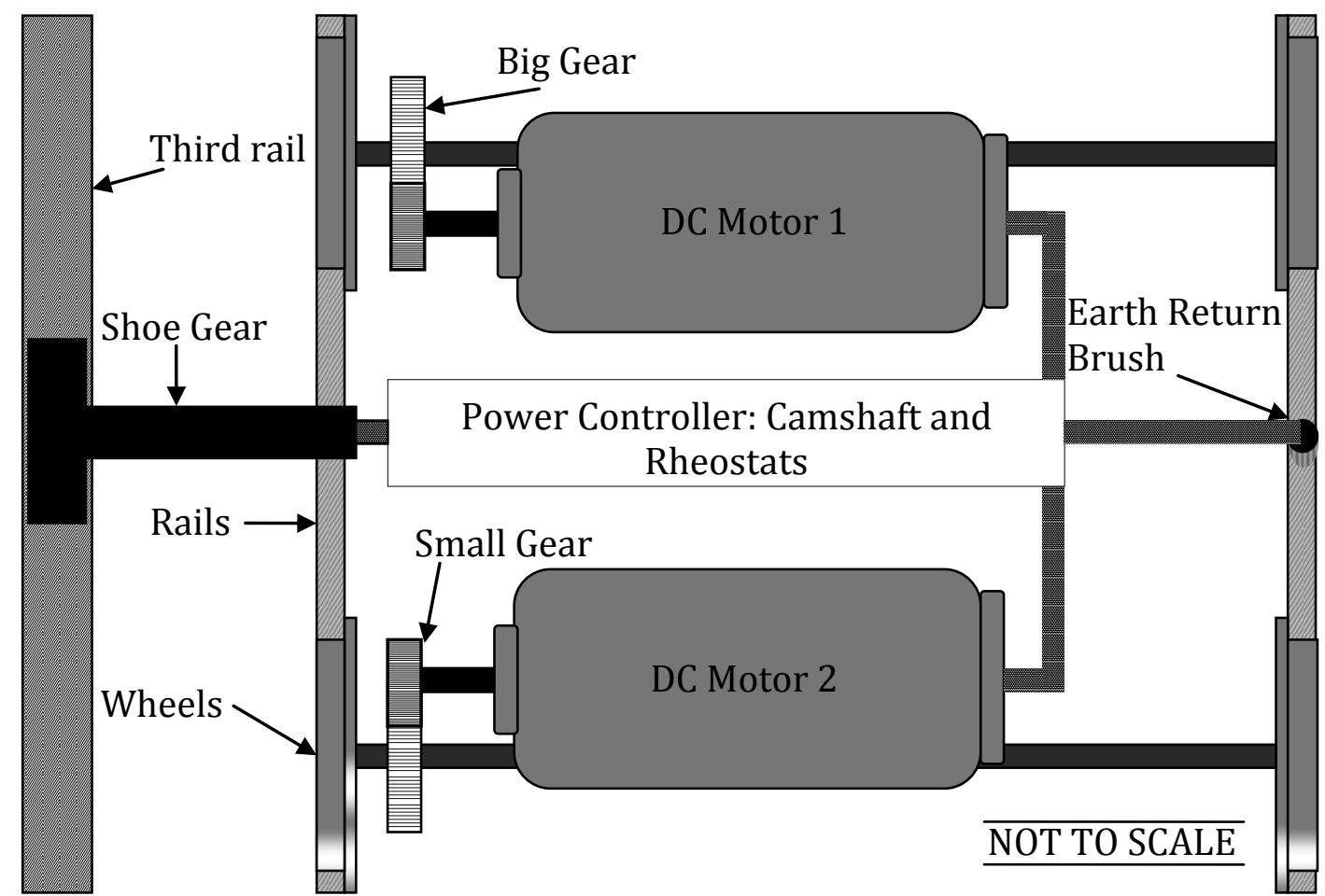

Figure 6: Plan view of bogie equipment including DC motors, third rail, shoe gear, power controller, gears, earth return brush, wheels and rails

This thesis models a railway using physical equations that describe the behaviour of DC machines. These originate from André-Marie Ampère (1775 - 1836), Michael Faraday (1791 - 1867), and Hendrik Lorentz (1853 - 1928). The solid-state general equation of voltage and current from the terminals of the DC machine is a combination of a 
derivation of those equations, Ohm's Law and Kirchoff's Voltage Law (see Equation $<2-3>$ ).

$$
V_{\mathrm{T}}=I_{\mathrm{a}} R_{\mathrm{a}}+\mathrm{K}_{\mathrm{e}} \varphi \omega
$$

where $V_{\mathrm{T}}$ is the terminal voltage, $I_{\mathrm{a}}$ is the armature current, $R_{\mathrm{a}}$ is the armature resistance, $\mathrm{K}_{\mathrm{e}}$ is the motor constant, $\varphi$ is the flux of the machine, and $\omega$ is the angular speed.

\subsubsection{Machines: Properties and Characteristics}

A DC machine has two modes of operation for the conversion of electrical energy to mechanical energy for motoring and the inverse conversion for electrical generation. The performance of a DC machine varies depending on the type of construction, and the magnitude of the voltage, torque, and armature current (Chapman 2005).

A simple DC machine is shown in Figure 7; this has a single coil with two poles. The magnetic field comes from the North and South poles of the stator (not shown in the diagram), which surround the rotor. The magnetic field lines are evenly distributed and perpendicular to the surface of the rotor, creating a uniform magnetic flux. 


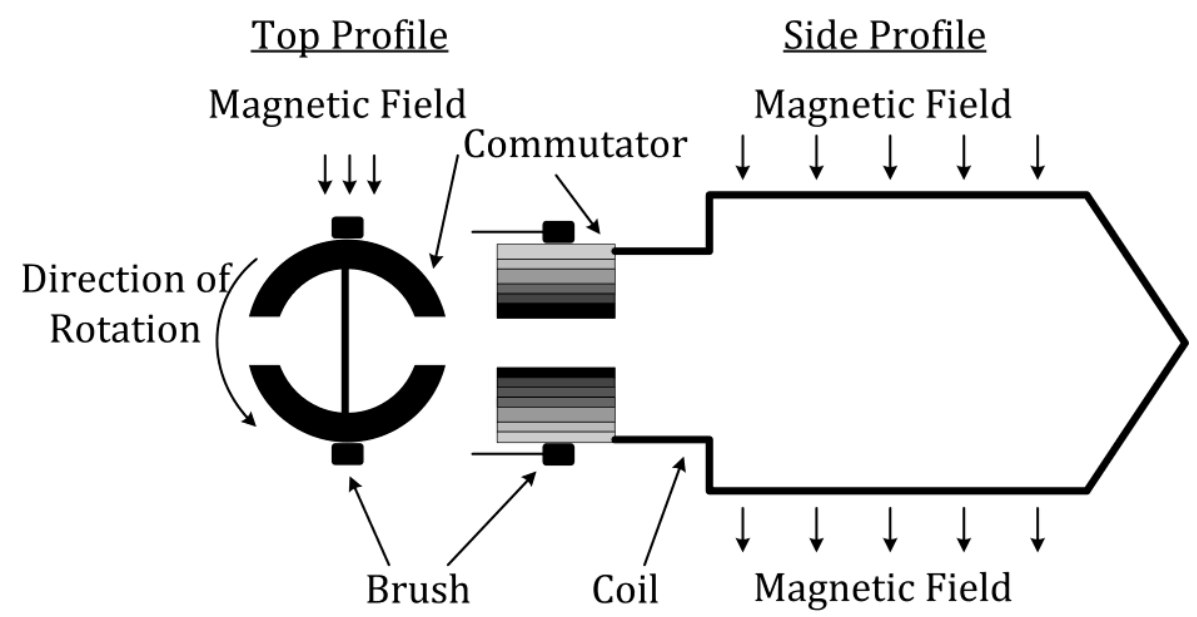

Figure 7: Single-coil DC machine with two commutator segments and brushes

As demonstrated by Wildi (2006), Chapman (2005) and Slemon (1992), a coil that has an attached load surrounded by a uniform magnetic field will create a torque. This causes the coil to move and thus induces voltage, which is uniform for both sides of the coil. The speed will continue to increase until the machine torque equals the torque of the load.

The coil has two polarities either side of the poles, which increase as it approaches the pole face (Chapman 2005). Hence, the coil develops an AC current, which is converted into DC using a commutator.

As shown in Wildi (2006), Chapman (2005), and Slemon (1992), the induced voltage $\left(e_{\text {ind }}\right)$ for DC machines is proportional to the flux and angular speed. The unit of proportionality is determined by a motor constant $\left(\mathrm{K}_{\mathrm{e}}\right)$, which is calculated from the physical properties of the DC machine (see Section 2.4.2) see Equation<2-4>.

$$
e_{\text {ind }}=\mathrm{K}_{\mathrm{e}} \varphi \omega
$$

As demonstrated in Wildi (2006), Chapman (2005) and Slemon (1992) the torque $(\tau)$ for large coil machines is proportional to the flux and armature current. The unit of 
proportionality is similar to the induced voltage as it is determined by the motor constant $\left(K_{t}\right)$, see Equation $<2-5>$.

$$
\tau=\mathrm{K}_{\mathrm{t}} \varphi I_{\mathrm{a}}
$$

Reliable sources (Angel Trains 2008, GEC 2008) provided information on the physical properties of the C507/8 traction equipment, which enabled it to be modelled. However, not all the information required for modelling was obtained, such as the motor constant. The unknown properties were approximated using a detailed analysis and background knowledge on the construction of DC machines.

\subsubsection{Machine Construction}

The construction of a DC motor determines its rated power and speed. As described by Faraday's law of voltage induction, in a uniformly distributed flux, the more turns on the rotor, the greater the amount of induced voltage and hence speed. The number of windings on the armature affects the number of current paths, induced voltage, and the number of poles.

The value of the motor constant $\left(K_{e}\right.$ and $\left.K_{t}\right)$, as described by Chapman (2005), is a constant that represents the shape of the conductors, the number of current paths and the number of poles $(P)$, as shown in Equation $<2-6>$. The values of $K_{e}$ and $K_{t}$ in this study have the same value, which is represented as K.

$$
\mathrm{K}=\frac{\mathrm{ZP}}{2 \pi \mathrm{a}}
$$

The motor constant can be determined by testing the motor and monitoring the induced torque and voltage. The comparison of these will result in a value for the motor constant. 
The motor constant can also be found with the use of equations and knowledge of the general physical properties of the DC motor. The following is a detailed description of the different winding types of DC motors and their effect on the number of current paths. The load current $\left(i_{\text {load }}\right)$ is shared between the conducting coils, which decreases as the number of current paths (a) increase, see Equation $<2-7>$ (Chapman 2005).

$$
i_{\text {load }}=\frac{I_{\mathrm{a}}}{\mathrm{a}}
$$

The winding configuration can be different for each machine with the connections between the coils having a different multiplex. The sequences of the connections are classified as lap, wave, or frog-leg windings, the latter being a combination of lap and wave. A lap winding has a large number of current paths, which are determined by the amount of poles and multiplex, see Equation $<2-8>$. This is good because a large current is created from a small voltage.

$$
\mathrm{a}=\mathrm{mP}
$$

where $\mathrm{m}$ is the degree of multiplex (simplex $\mathrm{m}=1$, duplex $\mathrm{m}=2$, and so on). In a wave wound simplex machine, there are twice as many current paths as there are multiplexes, see Equation<2-9>.

$$
\mathrm{a}=2 \mathrm{~m}
$$

Wave windings are better for supplying large voltages, as demonstrated in Chapman (2005). A frog-leg winding is a combination of lap and wave wound. The number of current paths is:

$$
\mathrm{a}=2 \mathrm{Pm}_{\mathrm{lap}}
$$


where $\mathrm{m}_{\text {lap }}$ is the degree of multiplex of the lap winding.

The way that a DC motor is constructed determines the value of the motor constant and the number of current paths. All these different construction methods are important for modelling the behaviour of a DC machine. The physical properties of a DC machine can be estimated from an analysis of data from an operating DC machine. Therefore, if some properties are unknown, an approximation is possible using knowledge and equations.

The physical properties of a DC machine limit the maximum acceleration and its energy efficiency. Operators choose a DC machine that has a specification sufficient to haul the train with an acceleration great enough to transport passengers between stations within a reasonable time.

\subsubsection{Series Motors: Parameters and Characteristics}

The DC series motor is useful for applications requiring a high starting torque and good speed-torque characteristics. It is relatively simple to control compared to other DC machines. Railway operators have chosen the DC series motor for its simple control and speed-torque characteristics.

As shown in Figure 8 the DC series motor has field windings connected in series with the armature, thus the armature current equals the series current. The armature windings have an equivalent resistance $\left(R_{A}\right)$, which is fixed. The field windings denoted $\mathrm{R}_{\mathrm{S}}$ and $\mathrm{L}_{\mathrm{S}}$ are an equivalent resistance and inductance respectively that as Wildi (2006) shows, are connected to the armature in series. 


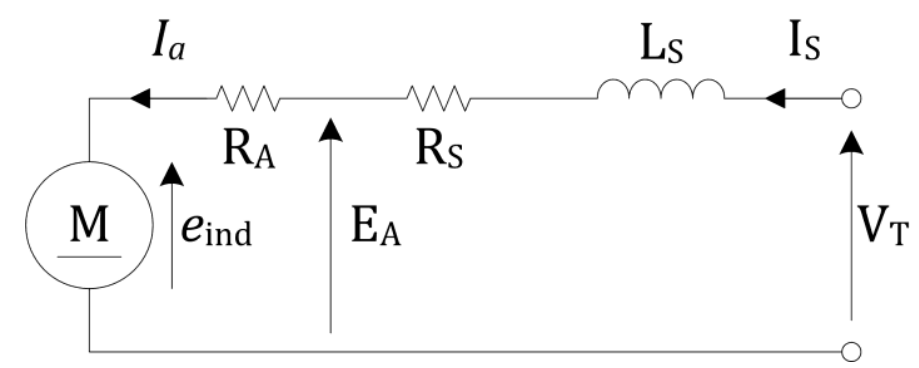

\section{Figure 8: Equivalent circuit diagram of a series DC motor}

The flux is proportional to the armature current as long as the core of the motor has not saturated, see Equation<2-10>.

$$
\varphi=c I_{\mathrm{a}}
$$

where $c$ is the saturation variable. Thus from Equation $<2-5>$ the induced torque is:

$$
\tau_{\text {ind }}=\mathrm{K} I_{\mathrm{a}}^{2} c
$$

There only needs to be a small amount of current to produce a torque in the machine and as the current increases so does the torque.

Using Equations $<2-3>,<2-10>,<2-11>$ and substituting $R_{\mathrm{a}}=\mathrm{R}_{\mathrm{S}}+\mathrm{R}_{\mathrm{A}}$ the terminal voltage can be written eliminating $I_{\mathrm{a}}$, and $\varphi$ :

$$
V_{\mathrm{T}}=\mathrm{K} \sqrt{\frac{\tau_{\text {ind }} c}{\mathrm{~K}}} \omega+\sqrt{\frac{\tau_{\text {ind }}}{\mathrm{K} c}}\left(\mathrm{R}_{\mathrm{S}}+\mathrm{R}_{\mathrm{A}}\right)
$$

Re-arranging for $\omega$ :

$$
\omega=\frac{V_{\mathrm{T}}}{\sqrt{\tau_{\text {ind }} \mathrm{K} c}}-\frac{\left(\mathrm{R}_{\mathrm{A}}+\mathrm{R}_{\mathrm{s}}\right)}{\mathrm{K} c}
$$

As shown in Equation<2-12> and demonstrated in Chapman (2005), the angular speed is proportional to the reciprocal square-root of the torque. This means as long as the operation of the motor is before the saturation point, the DC series motor has a high 
starting torque. In addition, when the speed increases the torque proportionally decreases. The advantage of having a flux that is directly proportional to the armature current is that it gives high torque, which is useful for heavy rolling stock (Chapman 2005).

The saturation curve of magneto-motive force (mmf) versus flux ( $\Phi$ ) determines the rate of flux induction into the motor, see Figure 9. As demonstrated in Chapman (2005), this curve is equal to the saturation curve of field current versus armature voltage.

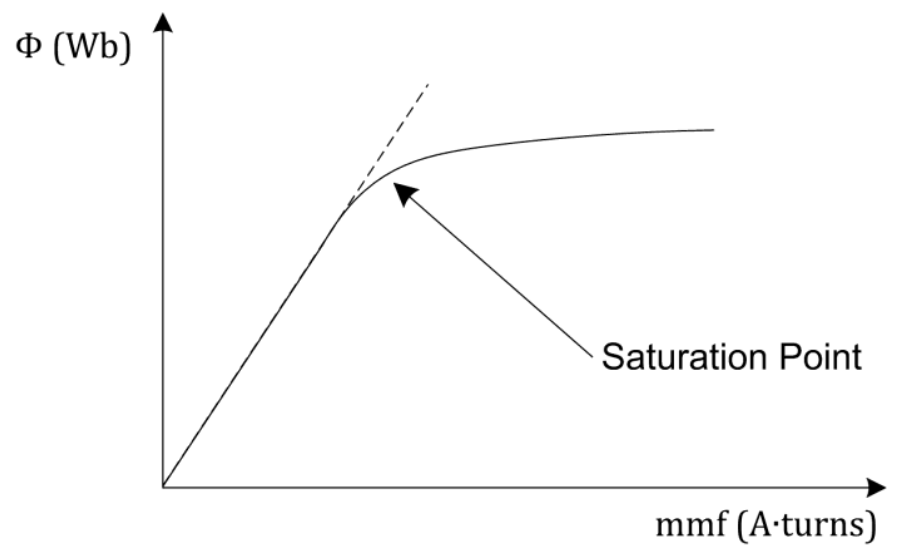

Figure 9: Variation of flux with magneto-motive force showing the saturation of flux in a DC motor

\subsubsection{Armature Reaction in DC Series Motors}

The armature reaction and effect of voltage build-up due to the inductance of the armature windings creates sparking on the brush-commutator contact and neutral line shifting (Chapman 2005). A DC generator with a load attached to the commutator has current flowing in the armature coils. This creates an armature mmf that opposes the mmf applied by the flux of the poles (Chapman 2005, Wildi 2006). The armature flux and flux of the poles will add to produce a residual flux in the air gap (see Figure 10). This adds to the flux at the south pole and subtracts at the north pole, resulting in a flux 
increase and decrease respectively across the air gap. The flux increase on the south pole will also saturate due to the permeability of the ferrite-iron core (Chapman 2005, Wildi 2006). This has two effects: it changes the neutral flux line and weakens the magnetic field of the field windings (field weakening). Field weakening happens when the field saturates at the teeth of the pole, resulting in a smaller rate of increase in flux for an increase in mmf from the poles. The problem with changing the neutral flux line is that the brushes, which are positioned to short out the commutator bars conducting in the neutral flux line, will not be in the correct place. They would be in the right place for shorting out the machine at no load. Therefore, a voltage will be conducted across the brushes at the original neutral flux line. At the shifted neutral flux line, as shown in Chapman (2005), there will be a voltage build-up on the brush-commutator contact, which will create a power arc because the brushes are not aligned with the neutral flux line. This damages the brushes and creates corrosion, so is more expensive to maintain over longer operating periods (Chapman 2005). 


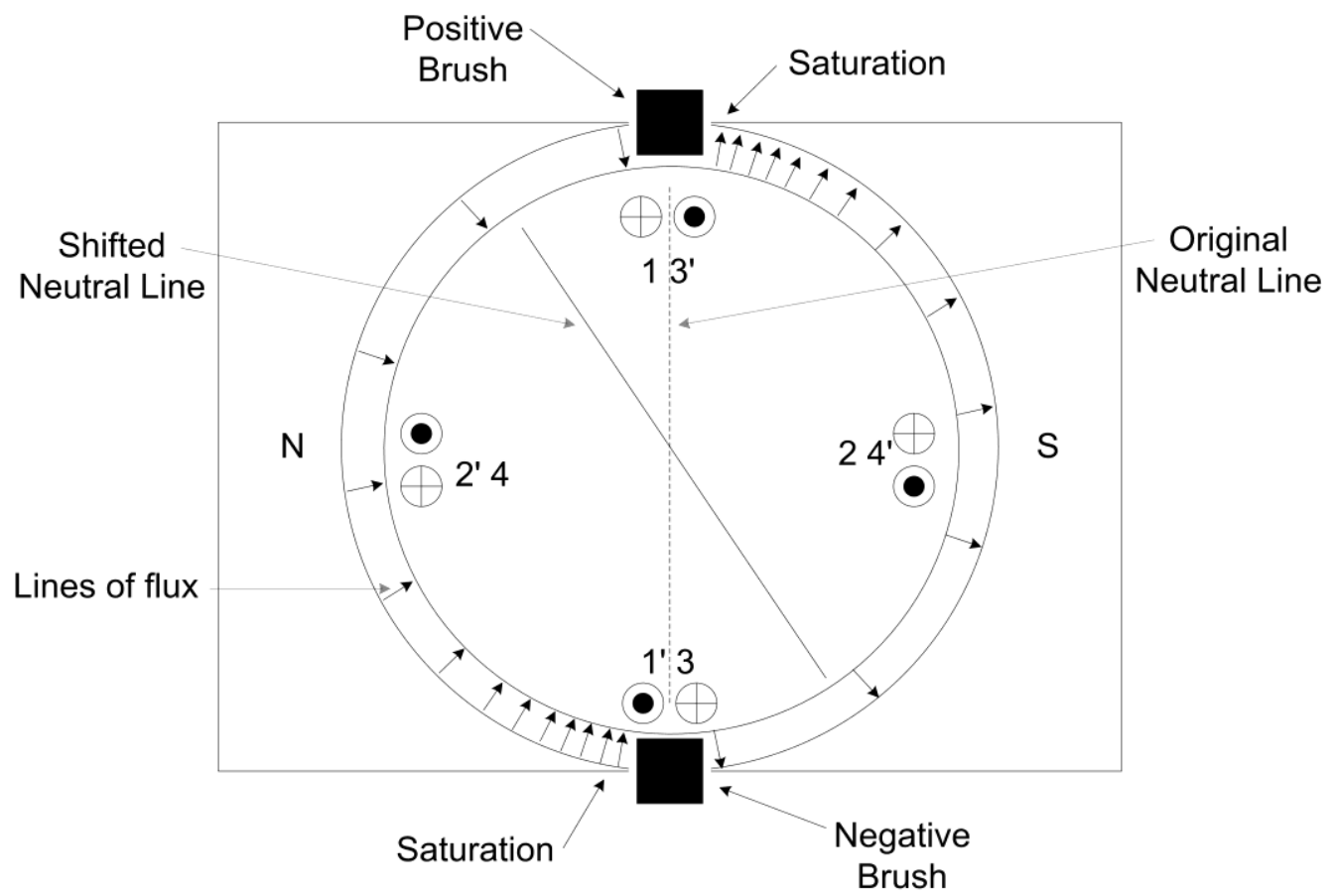

Figure 10: Effect of armature reaction in a DC machine

The positions of the brushes are specific to short out the conductor coils that are passing between the north and south poles. The current flows through the brush and along each commutator segment at a magnitude defined by the inductance and rate of change in current. When one brush is over one segment there are two coils conducting and the flow of current is neutral. A problem arises when the brush is in between two segments, shorting-out the coil that is already charged. The current will now flow around one coil, which has to change polarity in order to keep the output DC. The time taken for the brushes to pass one segment is given in Equation<2-13>. For the C507/8 motor moving at $1390 \mathrm{rpm}$, passing 184 commutator segments, with rated armature current at $275 \mathrm{~A}$, 1 segment passes a brush every $235 \mu$ s (see Equation $<2-14>$ ), which has a rate of change in current of $1 \times 10^{6} \mathrm{As}^{-1}$ (see Equation<2-15>):

$$
t=\frac{\text { displacement }[r]}{\text { speed }[r p s]}
$$




$$
\begin{aligned}
& t=\frac{(1 / 184)}{(1390 / 60)}=235 \times 10^{-6} \mathrm{~s} \\
& \frac{d I_{\mathrm{a}}}{d t}=\frac{275}{23.5 \times 10^{-3}}=1.17 \times 10^{6}
\end{aligned}
$$

Therefore, the voltage build up due to inductance $\left(V_{L}\right)$ will be large even with a small armature inductance $(L)$ (see Equation<2-16>).

$$
V_{L}=L \frac{d I_{\mathrm{a}}}{d t}
$$

This results in an arcing over the brush and commutator segments.

There are several methods to minimise the effect of armature reaction, such as implementing brush shifting, inter-poles, or compensation windings. All these methods improve the efficiency of the motor, with the latter minimising the effect of neutral flux line shifting. Chapman (2005) suggests that manufacturers should have inter-pole and compensation windings on their DC motors, and that the brush shifting method is not suitable for applications with a variable load.

Implementation of inter-poles is a method that stops sparking over the brushcommutator contact, without any moving parts. These poles are placed directly above the coils that are on the original neutral flux line (see Figure 11). They have an equal and opposite flux to that of the coils, which neutralises the flux and induced voltage. This method works for dynamic loads because the terminal voltage directly connects to their input terminals (Chapman 2005). Therefore, when the load increases so does the terminal voltage and more current flows into the armature and inter-poles. In addition, this method works in both modes of operation (motor or generator) because the windings on the inter-poles are in the opposite direction to that of the armature 
windings. Therefore, the inter-pole field will always be opposite and equal. Inter-poles do not solve the problem of saturation because the inter-poles are thin and only influence the flux around the original neutral flux line.

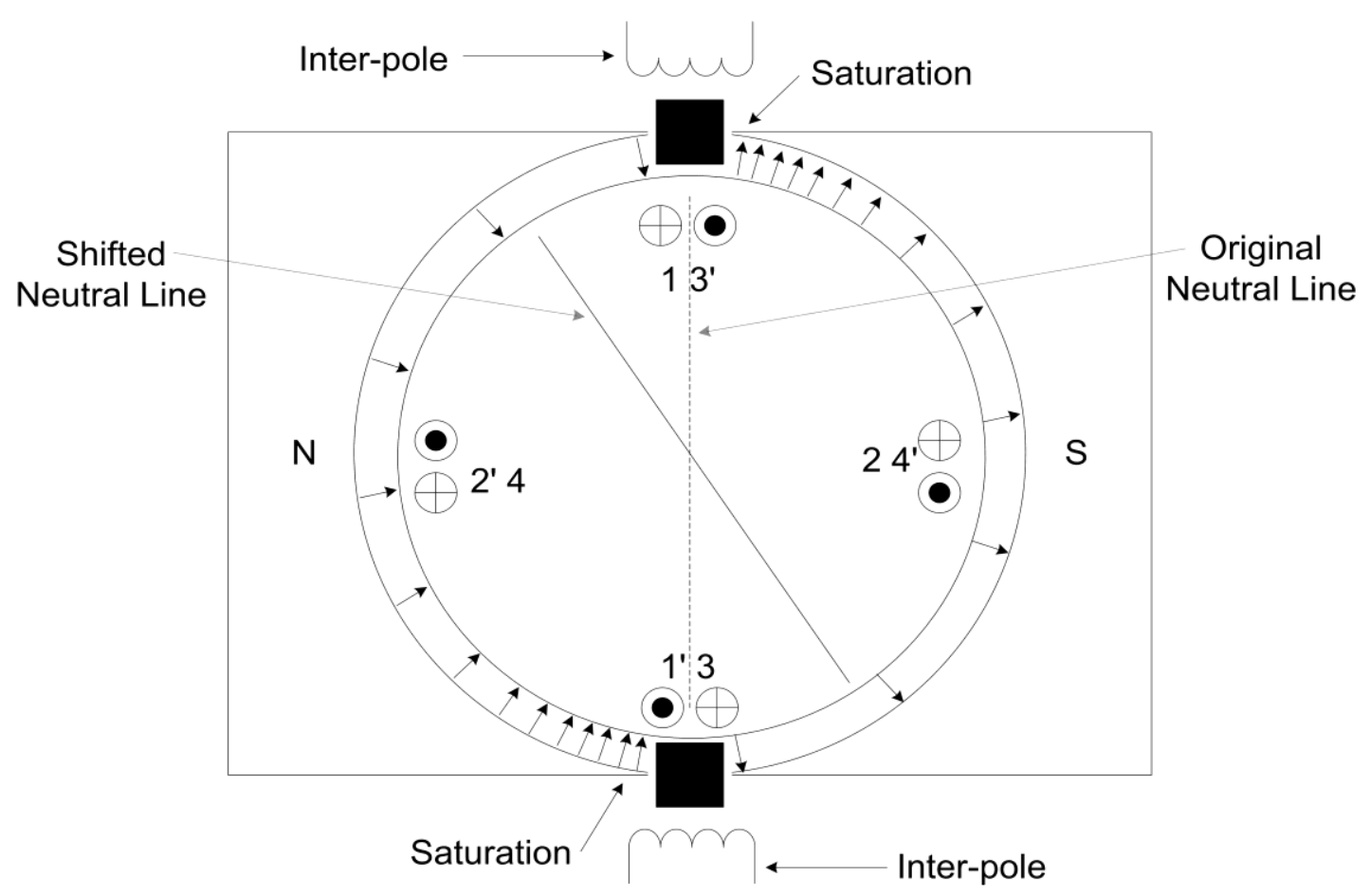

Figure 11: Inter-poles placed between poles to reduce sparking on brushcommutator contact

Compensation windings placed on the main poles stop neutral flux line shifting and hence the associated saturation (Chapman 2005). These have the same amount of windings and conductors as the rotor. The mmf produced from the compensation windings is equal and opposite to that of the rotor. Thus this method eliminates the effect of the mmf of the rotors on the residual flux and returns the neutral flux line to its original position. Most large DC machines have inter-poles and compensation windings because the armature reaction effect is greater at high speed (Chapman 2005). 


\subsubsection{Control Methods for DC Series Motors}

There are three main methods of speed control for a series DC motor; varying field current; varying terminal voltage; and varying armature resistance. The latter is commonly used for starting up the motor.

The series DC machine can be controlled by varying the field current when it is connected in a configuration, such as in Figure 12. The increase in parallel resistance decreases the field current and flux. The decrease of field current proportionally decreases the armature voltage relative to the magnetisation curve shown in Figure 9. This increases the armature current and hence the induced torque increases (see Equation $<2-3>$ and Equation $<2-5>$ ). Of particular note, as demonstrated in Chapman (2005), even though the flux decreases from an increased field resistance, the magnitude of the difference is far greater for the armature current. This now means that the induced torque is greater than the torque of the load, and as a result, the speed increases. Hence the induced voltage increases and the field and armature current decrease. Eventually, when the induced torque equals the torque of the load, the speed remains constant and the motor operates at a higher speed and torque. This method works from no-load to full-load. However, at slow speeds, the flux has a greater effect compared to the armature current and a decrease in flux results in a decrease in torque and therefore speed.

The second most common method of speed control as shown in Wildi (2006), Chapman (2005), and Slemon (2006), is to attach a voltage controller to the armature. An increase of $V_{\mathrm{T}}$ increases $I_{\mathrm{a}}$ and the induced torque, hence the speed and induced voltage increase. An increase of induced voltage creates a back-EMF to the armature 
current, thus decreasing the armature current and the induced torque. This continues until the induced torque equals the load torque and the motor operates at a higher speed.

The third type of control is to place resistors that decrease the armature voltage below the rated voltage. The base speed of the motor is when it is operating with the rated voltage, power, and field current. A method for speed control below the base speed is to decrease the terminal voltage, by increasing the armature resistance. The result is a decrease in armature current and induced torque, which leads to a decrease in speed and induced voltage. This controls the motor at slow speed and is used to start the motor (see Section 2.4.6). Above the base speed, an increase in terminal voltage will increase the current and hence the armature coils heat up, which Chapman (2005) identified as leading to degradation of the insulation and higher maintenance. However, laminating the armature coils decreases the heat build-up, which means a greater amount of voltage is induced and speed is achieved. The torque decreases when the field is weakened and speed is increased so no more power can be achieved after the base speed is reached (Chapman 2005).

\subsubsection{Power Controllers for DC Series Motor}

The motor controllers on the train are either rheostats or choppers and control the speed of the DC motor. Chapman (2005) explains that the traditional control method for a DC motor was to control the value of the resistor connected to the armature of the machine. This is characterised by a camshaft sensing the load current and controlling the rheostat. Schmid (2007) explains how the camshaft will automatically change position and trigger switching relays that control resistors connected in series and 
parallel with the armature (see Figure 12). This rheostat control can reduce the terminal voltage required for operation at slow speeds and is still in use in many urban railways (see Section 2.4.5). For example, in Merseyrail on the C507/8 the camshaft can also control the connection between each motor (Angel Trains 2008). The parallel connection of two motors increases the terminal voltage and hence the speed. At high speed, rheostats connected in parallel with the field windings of the motor, reduce the field current. The rheostat can also be used to reduce the flux in DC series motors.

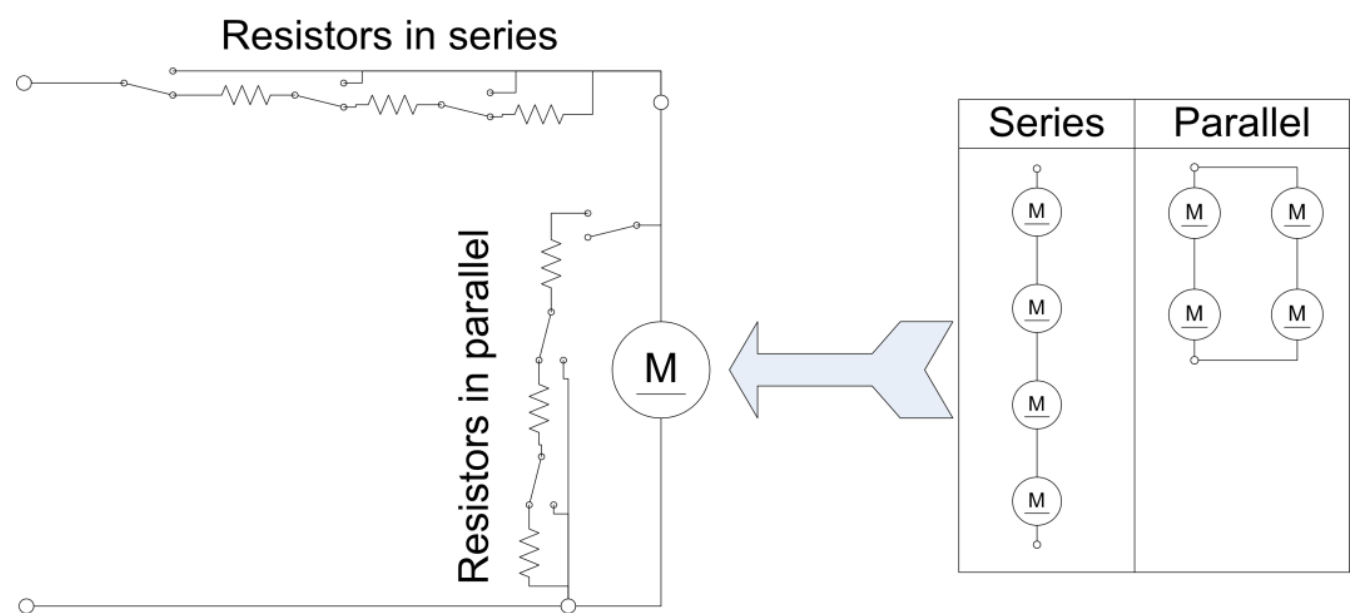

\section{Figure 12: Camshaft controlled $V_{T}$ with series and parallel rheostats loaded with either four series DC motors, or two pairs of DC motors in parallel}

Kemp (1987) demonstrates that modern power electronic controllers for DC railways are chopper controlled circuits. The chopper is a switching circuit that regulates the output power into the machine for speed control.

The DC-DC converter is often a step-up (boost) or step-down (buck) converter. The voltage of a regeneration battery is typically $48 \mathrm{~V} ; 38$ of these connected in series have a potential of $1820 \mathrm{~V}$. The regenerated voltage needs to be stepped-up to reduce losses on the line. For the purposes of regeneration, the boost converter is required. This 
has a switch that is controlled by a control signal. The duty cycle of the switch determines the magnitude of the voltage and the continuity of the output voltage.

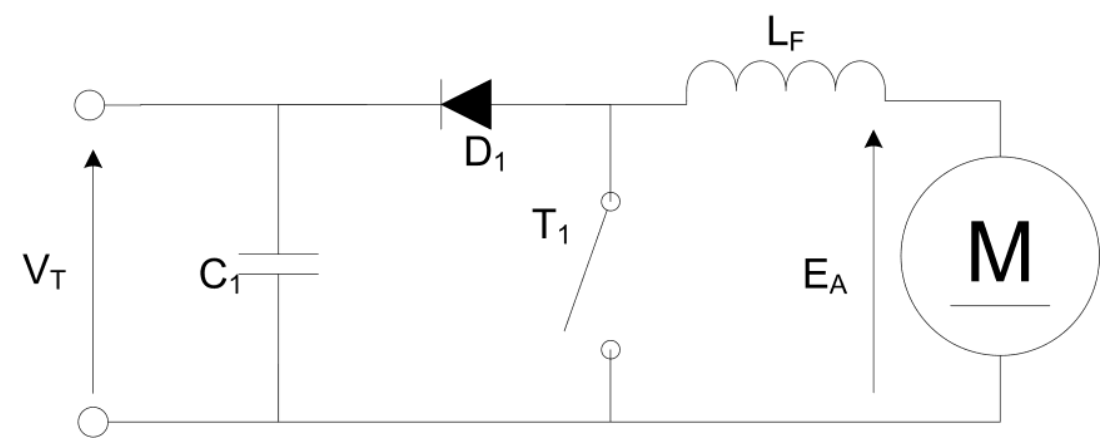

Figure 13: DC-DC converter in the boost configuration with a high-frequency switch $T_{1}$ smoothing inductor $\left(L_{F}\right)$ and capacitor $\left(C_{1}\right)$, and a fly-back diode $\left(D_{1}\right)$

A boost converter is shown in Figure 13. The DC voltage from the machine is connected in series to an inductor. When the switch $\left(\mathrm{T}_{1}\right)$ is on the inductor is charged up, and the fly-back diode $\left(D_{1}\right)$ blocks the source $\left(E_{A}\right)$ from the terminal voltage $\left(V_{T}\right)$, which is now behaving as the load. When the switch is turned off, the inductor and power supply charge the capacitor and supply power to the load. Thus, the voltage is greater. The capacitor has to be large enough to make sure the voltage $V_{T}$ is smooth and constant. The boost converter circuit has the ability to utilise regeneration with the addition of electro-mechanical switches (Schmid 2007, Kemp 1987). 


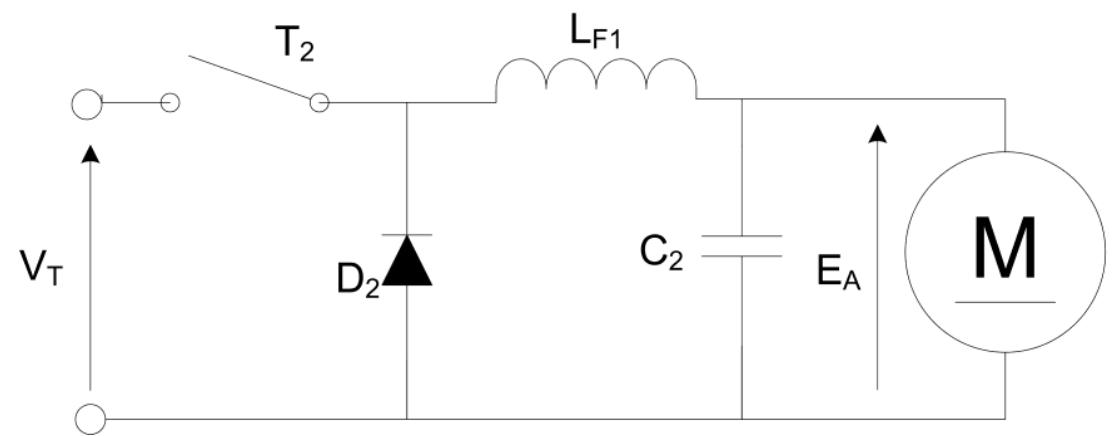

Figure 14: DC converter in a buck configuration with LC filter

The DC chopper can also be used to step-down the voltage using the buck converter configuration (see Figure 14). Mohan (2003) shows that the switching duty cycle determines the frequency of the switch and hence the magnitude of voltage at the machine $\left(E_{A}\right)$. When the switch $\left(T_{2}\right)$ is closed, the inductor $L_{F 1}$ is charged up and it supplies power to the motor. When it is open, the stored energy in $L_{F 1}$ is discharged and current flows around a flywheel diode $\left(D_{2}\right)$, which keeps the motor current positive when the switch is off. The on and off switching duty-cycle needs to be calculated to ensure the changing current of the inductor is stable. This occurs when the sum of the increasing and decreasing inductor current for one period is zero. An LC filter connected to the input of the chopper filters out the harmonic distortions present because of the high switching frequency of $\mathrm{T}_{2}$.

\subsubsection{Rheostat Control for DC Series Motors}

Connected between $V_{T}$ and the armature are a set of series resistors that limit the voltage and hence current to the motor, see Figure 12. This controls the speed but more importantly protects the armature from having an overloading current that causes damage to the windings (Chapman 2005). This is because when the motor is in standby

with a motor resistance of $R_{A}=0.01 \Omega$, supplied with a $V_{T}=750 \mathrm{~V}$ it would give a 
current of $\mathrm{I}_{\mathrm{A}}=75000 \mathrm{~A}$ (see Equation $<2-3>$ ). The series resistors $\left(R_{\mathrm{S}}\right)$ are chosen to step through keeping the armature current at a safe level.

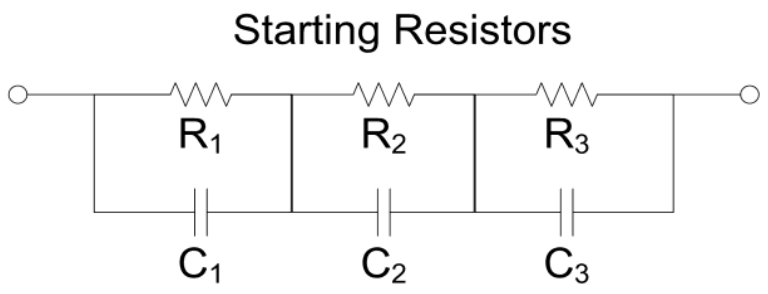

Figure 15: Capacitors switch on starting resistors depending on a time constant

Capacitors $\left(\mathrm{C}_{1}, \mathrm{C}_{2}, \mathrm{C}_{3}\right)$ (see Figure 15) connected in parallel with each starting resistor can control these resistors by switching them in sequence dependant on a time constant (Time constant $=\mathrm{R}_{\mathrm{S}} \mathrm{C}$ ). Initial conditions are with all capacitors charging up, which creates an equivalent short-circuit. Then capacitors $C_{1}$ to $C_{3}$ sequentially become fully charged, which creates an equivalent open circuit. Generally, the first resistor $\left(R_{1}\right)$ limits the armature current to a value that is half of the rated current value of the motor (Chapman 2005). If the current is too high, it causes excessive heat, resulting in the temperature sensors on the armature disconnecting $V_{\mathrm{T}}$ from the armature.

The resistors $\left(R_{1}, R_{2}, R_{3}\right)$ can be controlled with a relay circuit instead of capacitors that trip when a current large enough for the next resistor is sensed (Chapman 2005). Another method for controlling the starting resistors is to measure the current across the armature using trip relays on the resistors. This is a better method, because during start up full load is applied and the motor will need a high current to speed up and increase the torque. This current needs to be reduced again when the load torque equals the induced torque to protect the motor from overheating. If the current becomes too low, an over current sensor connected to the field windings cuts off the 
connection between the terminals and the armature. Fuses attached to the terminals will break when a current is too high, which stops the motor being damaged by voltage fluctuations.

\subsubsection{Energy Loss in DC Series Motors}

Energy loss in the camshaft controlled DC motor is mainly due to the starting rheostat. Heat is dissipated in the starting rheostat, which has a power loss of $P_{\mathrm{S}}=I_{\mathrm{a}}{ }^{2} \mathrm{R}$ a . As the speed increases, the camshaft cuts out the resistors, decreasing this power loss while increasing the current.

Chapman (2005) explains that there are power losses in the brush-commutator contact, armature and field windings, core flux and mechanical losses, stray flux, eddy currents, and saturation. For the C507/8, most of the power loss is from the starting resistors $\left(I_{\mathrm{a}}^{2} \mathrm{R}\right)$. The other losses are typically around $10 \mathrm{~kW}$; accounting for $1.5 \%$ of the rated power.

DC machines have some non-linear properties, which affect the output torque. When the armature voltage is changed, a non-linear effect is shown by the magnetisation curve of field current $\left(I_{\mathrm{f}}\right)$ versus armature voltage $\left(E_{\mathrm{a}}\right)$, where $I_{\mathrm{f}}$ and $E_{\mathrm{a}}$ are equivalent to flux and mmf respectively (see Figure 9). As demonstrated in Chapman (2005), the armature reaction increases the speed and decreases the flux, which in turn decreases the field current and the total mmf. Therefore, motors without inter-poles and compensation windings will have a decreased rate of flux induction from an increase in mmf. 
When a mmf is applied to a ferrite core, hysteresis will occur. Initially, the ferrite core has dormant atoms and electrons with random polarities. When a mmf is applied, the polarities of the electrons start to line up and this process creates a flux, with a resistivity restricting the amount of induced flux (see 'Initial magnetising line' in Figure 16). The maximum induced flux occurs when the polarities of the electrons have lined up. This is just after the saturation point. Hysteresis occurs when the mmf reduces and the flux stays in the material because the polarities of atoms do not all change back to random distributions. Therefore, when there is no mmf applied (see ' 2 ' in Figure 16), an induced flux remains and the ferrite material is now a permanent magnet. To get the material back to the original state, a negative mmf is applied and the flux decreases and follows a negative hysteresis curve until the polarities of the electrons are all lined up in the opposite direction (see '2, 3, to 4' in Figure 16). Now the ferrite core will have a permanent negative magnetisation charge. The increase of $\mathrm{mmf}$ will cause a different mmf versus flux curve, as shown in Figure 16 as between $4,5,6$, to 1 . Manufacturers avoid the hysteresis effect by limiting the maximum flux linkage in the ferrite core. 


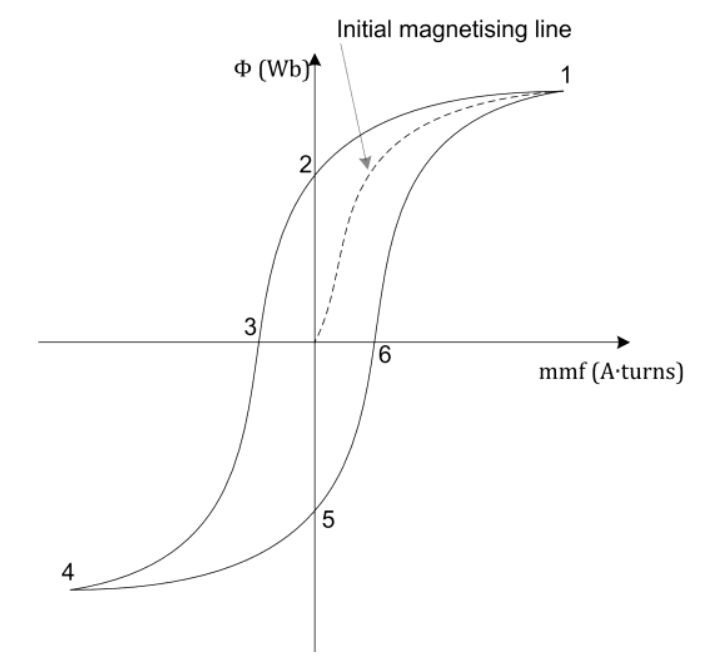

Figure 16: Hysteresis curve of DC motor

Eddy currents circulate on the surface of a ferrite material in a planar fashion. This increases the effective magnetic resistance and can be reduced by laminating the material by making it in thin strips and insulating each layer from each other.

There are many areas of energy loss in the DC motor however, manufacturers have managed to decrease their effect with the use of appropriate technology. The hysteresis effect is avoided by careful operation of the motor in the region before the saturation point. The construction of the motor core needs to be made in thin strips, which gives the motor a smaller resistivity. These energy losses are known in industry and have been minimised with the adoption of technology and operating restraints. However, in the case of the $C 507 / 8$, the main energy loss is with the motor control system. The use of a rheostat is a simple design for a motor control system; however, greater consideration is required for its energy efficiency. A chopper could replace the operation of a rheostat, which regulates the supply voltage instead of dumping it into resistors. There are supplementary benefits of using a chopper control for further developments on the railway network, such as the possibility of implementing regenerative technology, which will be covered in Section 5.2 . 


\subsection{Merseyrail Case Study}

The C507/8 are similar to trains operating on Southern Rail, DLR (apart from these having Automatic Train Operation (ATO), Choppers, etc...), and Glasgow Subway in the way that they use a third rail. Merseyrail has an elevated third rail supplying $750 \mathrm{~V}_{\mathrm{DC}}$ (Network Rail 2007b). The C507/8 trains were built in 1978 and 1979 respectively. They have DC series motors with camshaft driven rheostat control (GEC 2008). However, they are due to be replaced by new rolling stock over the next 5 to 10 years. The new rolling stock should possess technology that has the capability of increasing Merseyrail's energy efficiency to meet the scheduled objectives set by ERRAC and CCC.

The important properties of the C507/8 and Merseyrail's distribution network are shown in Table 1.

\begin{tabular}{ll}
\multicolumn{1}{c}{ Property } & \multicolumn{1}{c}{ Data } \\
\hline Train Output & $8 \times 85 \mathrm{~kW}$ \\
\hline Rated Power & $656 \mathrm{~kW}$ \\
\hline Brakes & Rheostat and Westcode \\
\hline Car Dimensions & {$[19.8,3.58,2.82] \mathrm{m},[\mathrm{L}, \mathrm{W}, \mathrm{H}]$} \\
\hline Unladen Weight & $98,99.49$ tonnes [Class 507,508] \\
\hline Seats & 222 on all except 192 on Class 508/1 \\
\hline Route Miles & 75 \\
\hline Stations & 67 \\
\hline Stations Underground & 4
\end{tabular}

Table 1: Merseyrail trains (Class 507 and 508) and railway properties

\subsubsection{Merseyrail Power Distribution System}

The rail track and conductors in Merseyrail are of the BS113A standard. CORUS made measurements on the conductivity and the cross-sectional area of the rail and conductors with the following results. The rail and conductor resistivity and crosssectional area had a value of; $\rho_{\mathrm{T}}=210 \times 10^{-9} \Omega \mathrm{m}, \rho_{\mathrm{C}}=108 \times 10^{-9} \Omega \mathrm{m}, \mathrm{A}_{\mathrm{T}}=7161 \mathrm{~mm}^{2}$ and 
$A_{C}=9577 \mathrm{~mm}^{2}$ respectively. Using the equation for resistivity (Equation $<2-2>$ ), the resistance is:

$$
\begin{aligned}
\mathrm{R}_{\mathrm{C}} & =11.28 \times 10^{-3} \Omega \mathrm{km}^{-1} \\
\mathrm{R}_{\mathrm{T}} & =29.33 \times 10^{-3} \Omega \mathrm{km}^{-1} \\
\mathrm{R} & =\mathrm{R}_{\mathrm{C}}+\mathrm{R}_{\mathrm{T}}=40.61 \times 10^{-3} \Omega \mathrm{km}^{-1}
\end{aligned}
$$

The amount of available power has to be sufficient for the traction equipment to operate. If the conductor voltage decreases below the rated value of the traction equipment, then the train will decelerate (see Section 2.4). For example, in Merseyrail the line voltage is $750 \mathrm{~V}$ and the motor is rated at $675 \mathrm{~V}$, this allows a voltage fluctuation of $-75 \mathrm{~V}$ or $-11 \%$. This assumes that there is only one train in each direction between substations, which has been established from the timetable (see Section 3.7). A $750 V_{D C}$ third rail network running two parallel C507/8 trains rated at $656 \mathrm{~kW}$, with a $\mathrm{R}=40.61 \times 10^{-3} \Omega \mathrm{km}^{-1}$ will have a maximum substation displacement of:

$$
\mathrm{x}_{\mathrm{T}} \leq \frac{750^{2}}{2 \times 40.61 \times 10^{-3} \times 2 \times 656 \times 10^{3}} \leq 5.28 \mathrm{~km}
$$

The data sheet from Merseyrail, identifies the location of substations. The substations were located in Google Earth. The distance measured between substations was in the range of 2 to $5 \mathrm{~km}$. Figure 17 shows a sample of the Merseyrail data sheet for the route section between Liverpool Central and Brunswick, which are $2.7 \mathrm{~km}$ apart. The calculated maximum substation displacement is $0.28 \mathrm{~km}$ more than the maximum measured substation distributions from Google Earth. This means that these results are in agreement within 5\%, which is in line with the value of the resistance of the conductor and tracks. 
BRUNSWICK
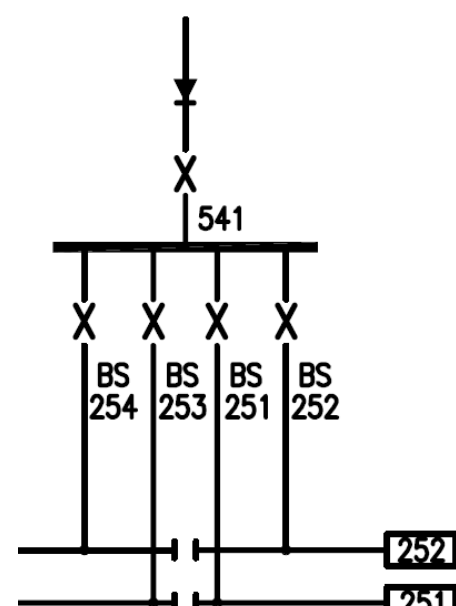

251
LIVERPOOL

CENTRAL

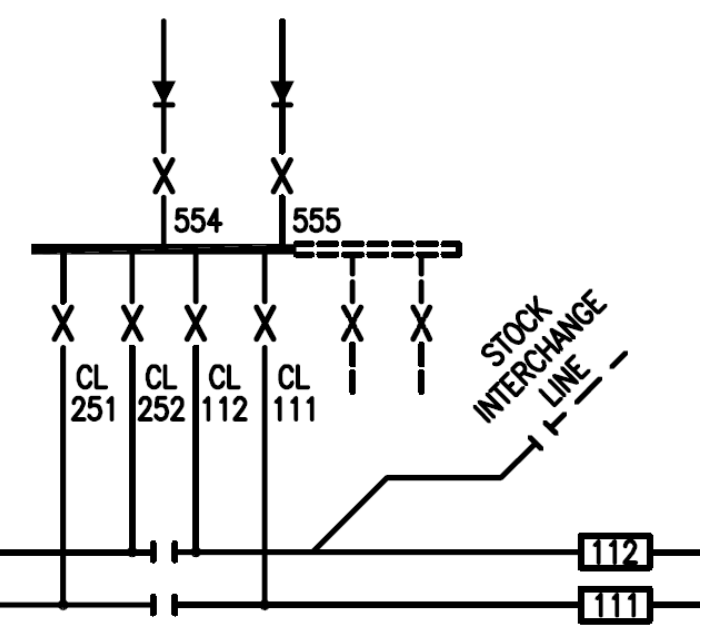

Figure 17: Sample from Merseyrail substation wiring diagram between Liverpool Central and Brunswick

\subsubsection{Merseyrail Rolling Stock}

The differences between the Class 507 and 508 are very small and are limited to the Class 508 weighing 1.49 tonnes more and Class 507 having 30 less seats (Marsden 2007).

The C507/8 has eight DC series motors with inter-poles and compensation windings. The motors are controlled using series or diverter rheostats (see Figure 18) up until the base speed and braked with rheostats and disc brakes. Diverter resistors increase the speed further than the base speed with a configuration of parallel resistors that reduce the field current.

Moving the C507/8 rolling stock are eight series DC traction motors on two pairs of bogies placed on the front and rear coach (Angel Trains 2008). The motors operate in series, parallel and field weakening regions, which depend upon the speed. Angel Trains and Merseyrail supplied technical data sheets and schematics, which identified some of 
the properties of the motor. The data sheets were used to calculate or estimate unknown properties of the DC machine. The useful information encompassed the tractive effort versus current graph, speed versus current graph, notching current graph, series resistances, percentage field weakening and driver controls for C507/8, which are all, apart from the latter, shown in APPENDIX B.

The current versus speed motoring curve is described by Equation $<2-3>$. The train will accelerate from standstill and the camshaft will notch through positions when the armature current falls below the notching current, which is dependent on the mass. Then, as the speed increases, so does the induced voltage, which opposes the voltage at the terminals and therefore the armature current decreases. When the current falls below the notching current, the camshaft will notch up, decreasing the armature resistance.

Notching up into the weak field operating region involves sequentially switching on resistors connected in parallel with the field windings. This diverts current away from the field windings, which weakens the field, hence increasing the speed (as shown in Section 2.4.5). This operational behaviour is illustrated in Figure 18. The voltage drop across one motor in series operation is $168.5 \mathrm{~V}$, when connected in parallel this increases to $337 \mathrm{~V}$. There are four motors on both of the motoring coaches, each of which are supplied by $675 \mathrm{~V}$ from the current collector to the contact on the return rails. 


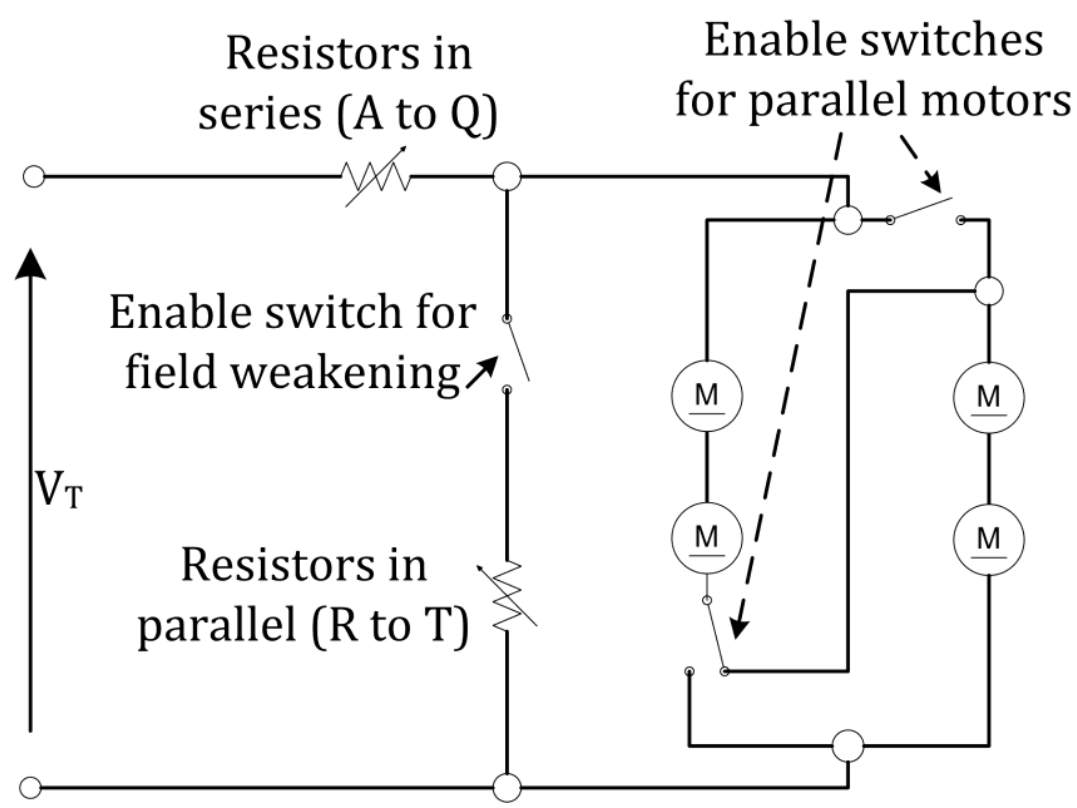

Figure 18: Equivalent circuit diagram for one coach of the $C 507 / 8$ trains showing the rheostat controller and motor configuration

Merseyrail supplied a data sheet that described the properties of the DC motor used on the C507/8 (Angel Trains 2008). However, no information has been obtained on whether the windings are simplex or multiplex, and the number of turns per coil on the type of windings. Without this information, the motor constant cannot be accurately calculated using Equation<2-6>. However, as stated in Section 2.4.2, the physical properties can be approximated. It is likely that the winding type is lap-wound but this could also be frog-leg, resulting in the number of current paths varying between $\mathrm{a}_{\text {lap }}=\mathrm{mP}$ for lap wound, to $\mathrm{a}_{\text {frog }}=2 \mathrm{~m}_{\text {lap }} \mathrm{P}$ for frog-leg. For simplex, lap wound will have $\mathrm{a}_{\text {lap }}=4$ and frog-leg will have $\mathrm{a}_{\text {frog }}=8$.

Considering steady state characteristics, maximum torque and rated speed of the machine, the value of the machine constant is calculated as follows. 
With the rated speed ( $\mathrm{n}$ ) of a motor at $\mathrm{n}=1390 \mathrm{rev} / \mathrm{min}$, the voltage across each motor at $E_{\mathrm{a}}=168.5 \mathrm{~V}$, rated current for each motor is $\mathrm{I}_{\text {rated }}=275 \mathrm{~A}$, the maximum torque is calculated using the equations in Wildi (2006) as:

$$
\mathrm{T}_{\max }=\frac{9.55 \mathrm{P}_{\text {motor }}}{\mathrm{n}}
$$

and the maximum flux as:

$$
\Phi=\frac{2 \pi \mathrm{T}_{\text {max }}}{\mathrm{ZI}_{\text {rated }}}
$$

where $P_{\text {motor }}$ is the power of one motor, $Z$ is the number of conductors and $\omega=\frac{2 \pi}{60} \times n$.

So, substituting in the values gives:

$$
\mathrm{T}_{\max }=\frac{9.55 \times 85 \times 10^{3}}{1390}=584 \mathrm{Nm}
$$

and,

$$
\Phi=\frac{2 \pi \times 584}{368 \times 275}=3.63 \times 10^{-2} \mathrm{~Wb}
$$

Thus from Equation<2-4>:

$$
K=\frac{168.5 \times 60}{0.0363 \times 1390 \times 2 \pi}=31.92
$$

Therefore,

$$
\mathrm{K} \Phi=1.158
$$

From the spreadsheet "Class 507 Motoring Curves" (C507MC) (see 
APPENDIX A), the variation of $\mathrm{K}$ was calculated for lap, frog-leg, simplex, duplex and increasing turns on each conductor. The data sheet from Merseyrail (TMT310) has graphs showing the current versus speed and current versus tractive effort. The current versus speed was plotted in Excel using Equation $<2-3>$ and substituting $\varphi$ from Equation $<2-10>$ for $I_{\mathrm{a}}$ and $R_{\mathrm{a}}=\mathrm{R}_{\mathrm{S}}+\mathrm{R}_{\mathrm{A}}$. The graph was fitted by changing the value of $\mathrm{K}$ in the equation until it agreed with the TMT310 data. The estimated value from the curve fitting exercise was $\mathrm{K} \Phi=0.0105$. The calculated value in $\mathrm{C} 507 \mathrm{MC}$ indicates that the motor is lap wound with a multiplex of 10 giving $\mathrm{K} \Phi=0.0111$, which is $5 \%$ different from the estimated value from the curve fitting exercise.

\subsubsection{Class 507 and 508 Brake Systems}

The forms of braking used by the C507/8 are friction and rheostat. Disc brakes use friction between two composite pads on both sides of a steel disc to slow the train down. This dissipates the power as heat on the discs, which require ventilation holes for safety. Rheostat braking is known as a dynamic brake, which converts kinetic energy into electricity via the DC generator. Rheostat braking is produced by switching in resistors in series with the motor (see Figure 18). The kinetic energy of the train is decreased using the generator to supply current to a camshaft controlled rheostat (see Section 2.4.6), which dissipates the power as heat. The train continues to decelerate until the load torque is equal or less than the machine torque. The rheostat resistance can be increased to further decrease the speed however, it is limited to the value of the resistors. The load torque of the generator has to be greater than the torque of the wheels from the train to continue the dynamic braking. Therefore, at slow speed, disc brakes are used to stop the train. Manufacturers prefer to have a fast and reliable 
braking system, so railway operators combine friction and dynamic braking (Chapman 2005).

The C507/8 and many other trains will have two forms of braking; friction and dynamic. The operator requires the train to have a constant brake rate (Schmid 2008). Using the electric brake gives a power-speed characteristic as shown in Figure 19.

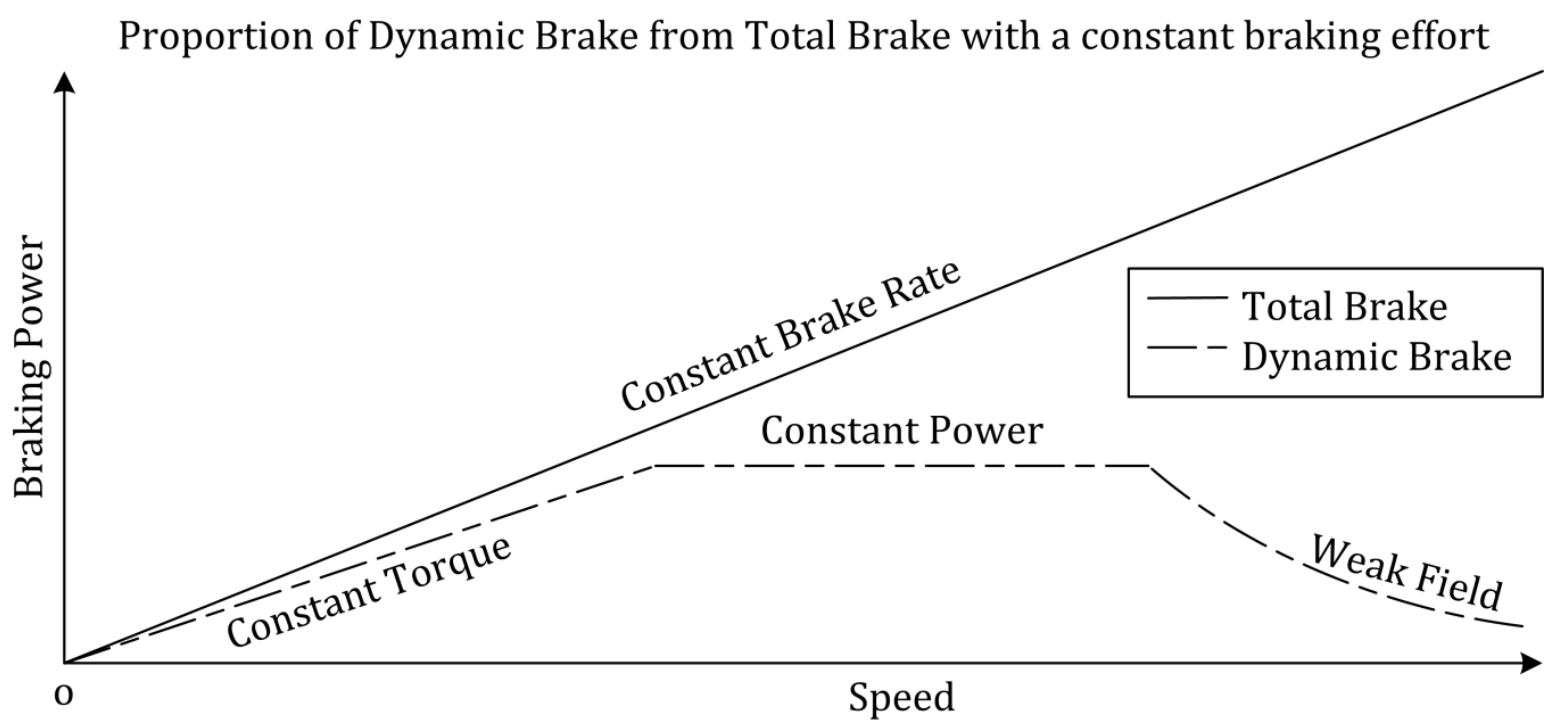

Figure 19: The amount of brake power available from electric motors and the proportion of the total brake rate desired

The C507/8 has two thirds of the axles motored. When braking, the DC machines provide the same power-speed rate as that when motoring. This braking at high speed has a power that increases at a rate proportional to the reciprocal of the speed, and is called weak field operation. At this point the power reaches its rated power and the speed decreases with a constant power. Finally, the speed of the machine will reach the base speed and the power decreases linearly until the train has stopped.

The constant brake rate is achieved when the friction brake supplies the remaining brake power required. This means that during regeneration not all the braking energy is recuperated. As shown by Açikbas (2007), this accounts for a 40\% 
regeneration rate. More on regeneration and retrofitting the traction equipment is covered in Section 5.2.

\subsubsection{Class 507 and 508 Driver Controls}

Drivers have their own style, aptitude, and degree of reliability whilst driving, which affect the energy consumption for each journey. A driver with good performance will operate the train in an energy efficient manner. Railway companies that have good training facilities should have proficient drivers. However, the energy efficient operation of the train is limited by the controls for the driver. The C507/8 has one lever with five speed positions. The driver positions the lever to move the train to different speeds. From stand still in position ' 0 ' the driver changes to position ' 1 ' to increase speed to a slow speed, which is generally used for moving around the depot. In position ' 2 ' the speed further increases with all four motors in series. Position ' 3 ' is the parallel region, which increases the speed until it reaches a base speed. Further speed increase is possible from field weakening (position '4') which accelerates the train to its maximum speed $\left(121 \mathrm{kmh}^{-1}\right)$. The driver has to accelerate the train up to the speed limit and continue at constant speed until the braking point. Since the C507/8 speed control only has 5 speed positions, it is difficult to move the train at constant speed unless the position directly relates to the desired constant speed. For instance, positions 1 to 5 could move the train at a constant speed of $10,15,22,32$, and $121 \mathrm{kmh}^{-1}$ respectively. In this example, the driver will moderate between positions 4 and 5 to move at a constant speed of $60 \mathrm{kmh}^{-1}$ (see APPENDIX B).

The timetable requires the train to travel at the correct speed to complete the journey in time. There is also a time requirement for the passengers to board the train, 
called a dwell time, which is $30 \mathrm{~s}$ for Merseyrail. There is an energy efficient technique, known as coasting, which requires an increase in journey time. It may be plausible to reduce the dwell time to accommodate this energy efficient scheme. More information on this is found in Section 5.3.

An experienced driver should know how to operate a train over a known route with energy efficiency in mind. However, the driver could operate the train in an unconventional way (i.e. break the speed limit) and cause delays, thus increasing the energy losses (Dorrian 2006, Dorrian 2007). The performance of the driver is variable and the effect is studied in Section 5.4.

\subsection{Discussion and Conclusion}

DC railways are used across the globe and have many variations of infrastructure design, motor controllers, and motors. The main advantage of having a third rail current collector systems and rolling stock can be outweighed by the power losses on the conductors and track from higher current losses, leading to increased cost (MorrisonKnudsen 1992) because of closer substation spacing. Modern power electronic controllers have become more reliable and efficient at producing a smoother current (Mohan 2003). Often they are lighter, which further increases efficiency but increases the equipment cost (Chapman 2005). Nevertheless, all motors are capable of utilising the power supplied from the converter/ controller. Compared to induction motors, DC motors have advantages because of their high torque or high speed operation. However, they often require higher maintenance due to degradation of the brush-commutator contact. Several methods can be used to reduce the losses imposed from armature 
reaction, contact losses and maintenance issues (heating, degradation of bearings and winding linkage breakage).

Merseyrail has been chosen because the infrastructure is similar to other DC railways in Britain. Significant improvements can be made from the existing control technology. The findings from the results of the simulator will show the potential energy saving from developing Merseyrail.

The modelling of Merseyrail in the Single Train Simulator (STS) allows the required tractive effort to be calculated. Regenerative braking and driver performance can be included, as simulated developments and comparisons between the original and developed will indicate the potential savings for railways. The STS can be developed to calculate the power of multiple trains and the power flow around the railway power network can be modelled. A model specific to a C507/8 could be combined with the STS and Network Power Flow (NPF) model to make another simulator that is specific to Merseyrail. 


\section{SIMULATION DEVELOPMENT AND DESIGN}

\subsection{Introduction}

The simplest estimate of the energy consumption of a railway is to multiply the power rating of a train by the operating time over a year. Taking Merseyrail as an example, with C507/8 trains rated at $656 \mathrm{~kW}$ operating for 161,200 hours per year (Merseytravel 2005), with those braking and stationary for half of the given time, this equals an estimated energy consumption of 53 million $\mathrm{kWh} /$ year. However, the train will only usually use its maximum power after the base speed and before field weakening, which is for few seconds. Following this, it operates under reduced power. Therefore, this calculation provides an answer well above the actual consumption of the railway. A single train operating over a railway has variable energy consumption with respect to the performance of the driver, the geometry of the track and the traction equipment. These factors are the inputs to the Single Train Simulator (STS), which calculates the energy consumption of a single train travelling across a specified railway route.

\subsection{Mathematical Representation of Train Kinematics}

The traction, braking, and physical properties of a train determine its dynamics. This, in turn, determines the maximum acceleration and deceleration of the train.

The movement of a train over a track is illustrated in Figure 20, which has an acceleration, a resistance to motion, and the effect of gravity. The effect of gravity is determined by the mass of the train, the magnitude, and angle of the track to gravity, see Equation $<3-3>$. 
The DC motor accelerates the train through inter-connecting gears and drive trains, which turn the wheels. The amount of torque produced from the acceleration of the motor decreases directly proportional to the gear ratio and moment of inertia, where the moment of inertia is a constant.

The torque at the wheels and the adhesive friction between the wheel and rail determine the magnitude of the tractive effort. The product of the residual force of the train and distance travelled is the energy consumption of the train.

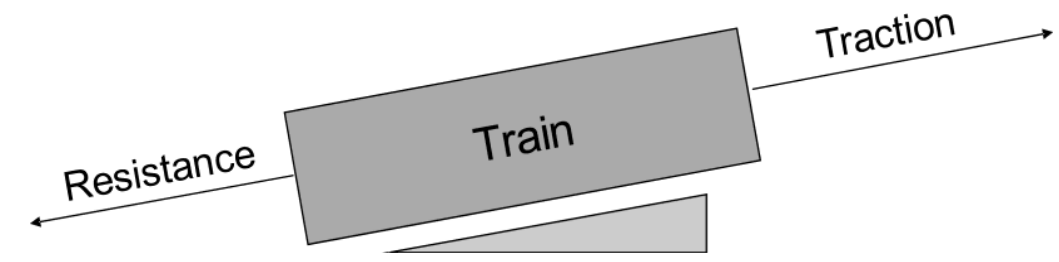

Figure 20: Motion of a train with forward force from traction, resistive force from resistance and effect of the track gradient due to the force from gravity

As shown by Avallone (2006) and Hill (1994a), when a train accelerates, the tractive effort will have a region of constant torque just before the base speed. Afterwards, the amount of available torque will decrease at a rate proportional to the reciprocal of the angular speed $(\omega)$ due to reduced field current (Hill 1994a). Furthermore, Schmid (1994) and Griffith and Plunkett (1978) explain that further speed increase is possible with a reduction in armature current, which further reduces the torque at a rate proportional to $1 / \omega^{2}$. The train stops accelerating when the resistive forces equal the torque, see Figure 21. 


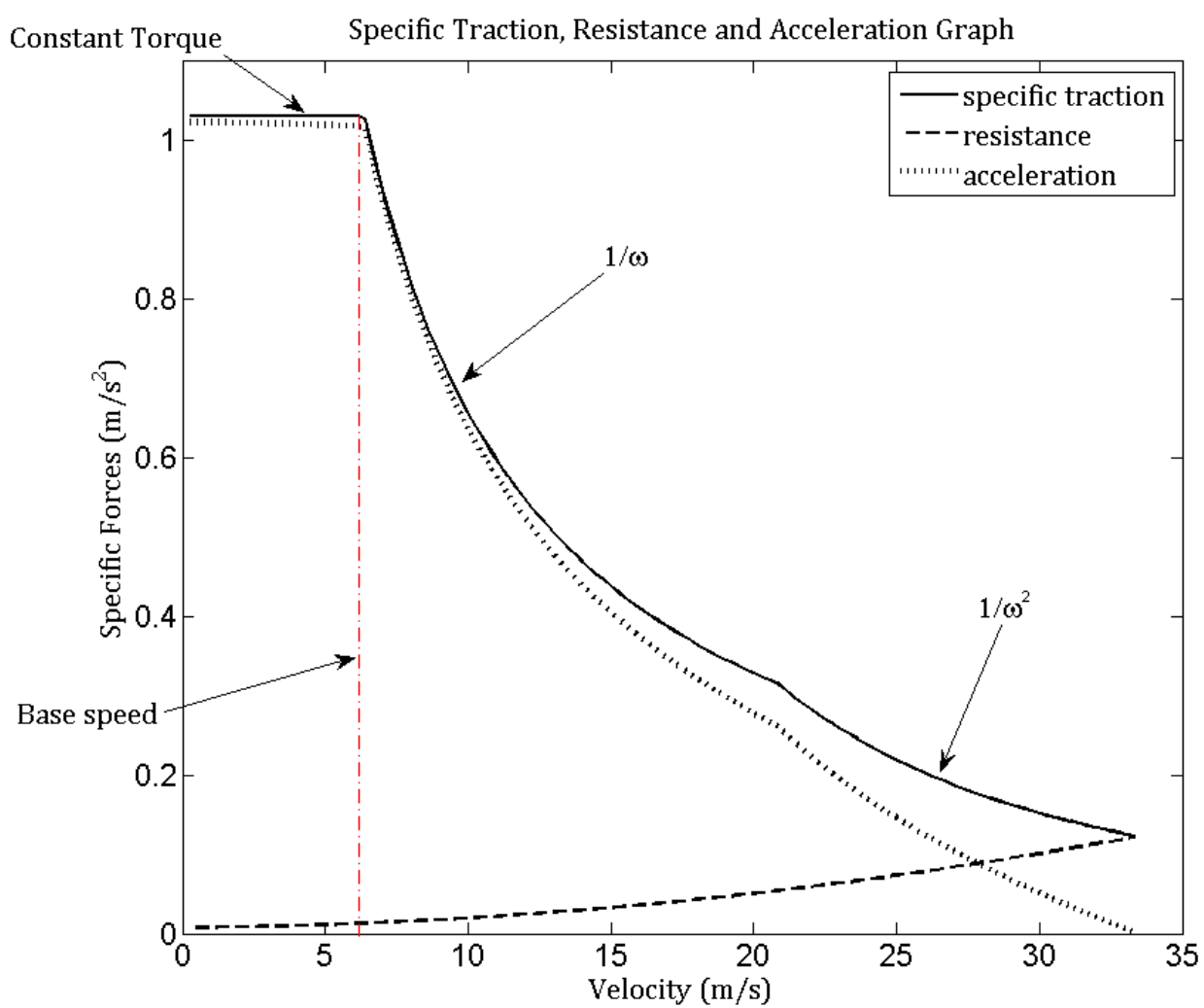

Figure 21: Specific Traction, Resistance and Acceleration curve of an accelerating train

As shown in Section 2.4.5, common methods for speed control are to change the terminal voltage and divert current away from the field windings (Chapman 2005, Griffith 1978). The induced voltage of the DC motor is proportional to the angular speed (see Equation $<2-4>$ ), and the armature current decreases as the angular speed increases (see Equation $<2-3>$ ).

The Davis equation (Hill 1994a, Rochard 2001) is used in the simulator to calculate the resistive force due to moment of inertia (A), wheel-rail and mechanical resistance (B), and aerodynamic drag (C). The moment of inertia restricts the rotation of the wheels due to the mass of the train (Hill 1994a). The Davis equation describes the mechanical resistance, which includes the gears and bearing friction of the traction equipment. It also describes the aerodynamic resistance, which is dependent on the 
shape of the train and the nature of its surface. For instance, if the front of the train is large and flat or the sides are jagged then it has poor aerodynamics. Consideration also has to be given to the gradient of the track, which cannot exceed 2.5\% (Hill 1994a), with the exception of mountain tracks. It includes the value of adhesion between the wheelrail contact, which includes the wheel slip threshold having an allowable amount of wheel slip deviation from maximum adhesion (Mei 2009). The maximum allowance is 5\% for stable wheel slip (Schmid 2007), which operators use to spin the wheels from standstill when the train is highly effected by its moment of inertia.

The Davis equation (Rochard 2001) in Equation<3-1> is different from Hill (1994a) because it does not include a variable for wheel-rail contact.

$$
F_{\mathrm{R}}=\mathrm{A}+\mathrm{B} \frac{d x}{d t}+\mathrm{C}\left(\frac{d x}{d t}\right)^{2}
$$

where $\frac{d x}{d t}$ is the derivative of distance with respect to time and $F_{\mathrm{R}}$ is the resistive force. The wheel-rail contact parameter is not necessary because C507/8 use wheel slip protection, which keeps the level of adhesion below a stable threshold. Therefore, Equation $<3-1>$ is appropriate for the STS. The coefficients of A, B and C can be calculated using either: Armstrong and Swift; French National Railways (SNCF); Sachs; or T. Maeda (Rochard 2001). Rochard and Schmid (2001) compared these methods with measured data. Armstrong and Swift produced results that fit the real data closer than the others. This thesis uses all of the required parameters for calculating the Armstrong and Swift variables, with a similar coefficient of head/tail and bogie drag from Gawthorpe (1978). The results are shown in Equation $<3-2>$. 
From Equation $<3-1>$, parameters $\mathrm{A}, \mathrm{B}$ and $\mathrm{C}$ have inputs of gearing and frictional drag, the total area of the train and wheel-rail contact force. When a train is running in open air, the aerodynamic drag is smaller than it would be in a tunnel, so variable $\mathrm{C}$ will change depending on the situation. Merseyrail has a four stations underground, but this variation is excluded in this work because information concerning the cross-sectional area of the tunnels was unavailable. Inside the tunnel, there is an increase of pressure, which increases the aerodynamic drag. The permitted speed of the train is less than $72 \mathrm{kmh}^{-1}$ in this section, for further information see Section 3.6.

Using the Davis equation and Armstrong and Swift coefficients from Rochard and Schmid (2001), the results of the calculated Armstrong and Swift coefficients are shown below:

$$
\begin{aligned}
\mathrm{A} & =753.2[\mathrm{~N}] \\
\mathrm{B} & =25.47\left[\mathrm{Nsm}^{-1}\right] \\
\mathrm{C} & =4.135\left[\mathrm{Ns}^{2} \mathrm{~m}^{-2}\right] \\
F_{\mathrm{R}} & =753.2+25.47 \frac{d x}{d t}+4.135\left(\frac{d x}{d t}\right)^{2}
\end{aligned}
$$

\subsection{Extraction and Input of Route Information}

The geometry of the track and permitted speed impose constraints on the movement of the train along a railway. The gradient, speed limits, and station spacing affect the way the driver operates the train

Track Maps have information on the reference number of the route of Merseyrail and the distance between stations in miles and chains. The reference number is linked with GEOGIS Speed Data and GRADIX (Network Rail 2007c) data, which have the speed limits at distances in miles and yards and the gradient changes in miles respectively. 
The existing Single Train Simulator (STS) requires the distance in km, station distances, speed limits in $\mathrm{ms}^{-1}$ and gradient as an angle of the slope represented as a percentage. Initial data analysis in MS Excel produced the gradient and speed profiles for all routes. One example is for the route between Moorfields and Southport on the Merseyrail Northern Line (see Figure 22). The Merseyrail network has a total network length of $120.7 \mathrm{~km}$, including 67 stations and speed limit variations from as low as $24 \mathrm{up}$ to $136 \mathrm{kmh}^{-1}$.

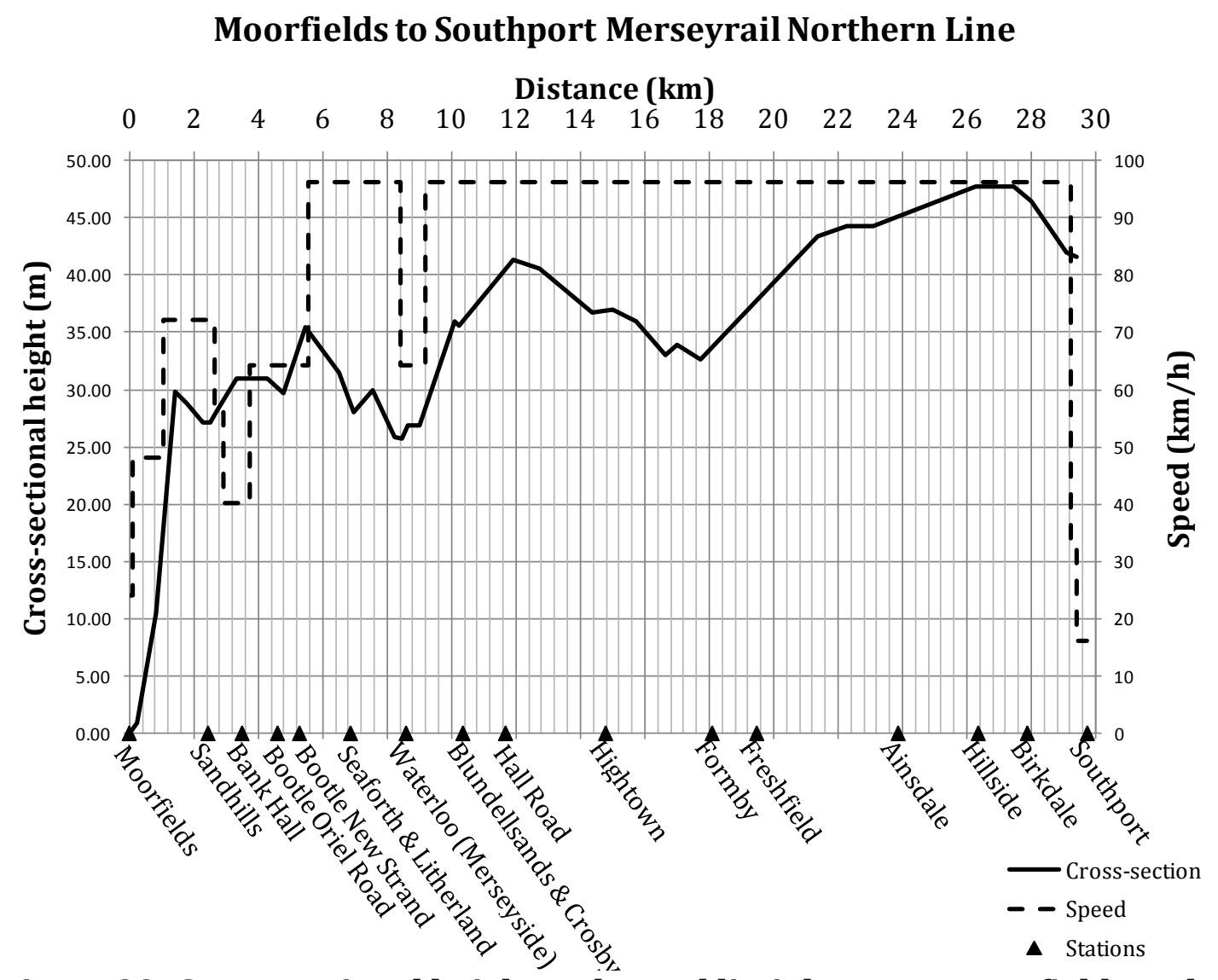

Figure 22: Cross-sectional height and speed limit between Moorfields and Southport on the Merseyrail Northern Line

\subsection{Single Train Simulator}

The STS takes the route information and properties of the train and simulates the movement of the train with three different driving styles. Figure 23 shows a flow 
diagram of how the behavioural characteristic factors of the railway interact in the program. The output is a graph of the power versus time, which after integration gives the energy consumption.

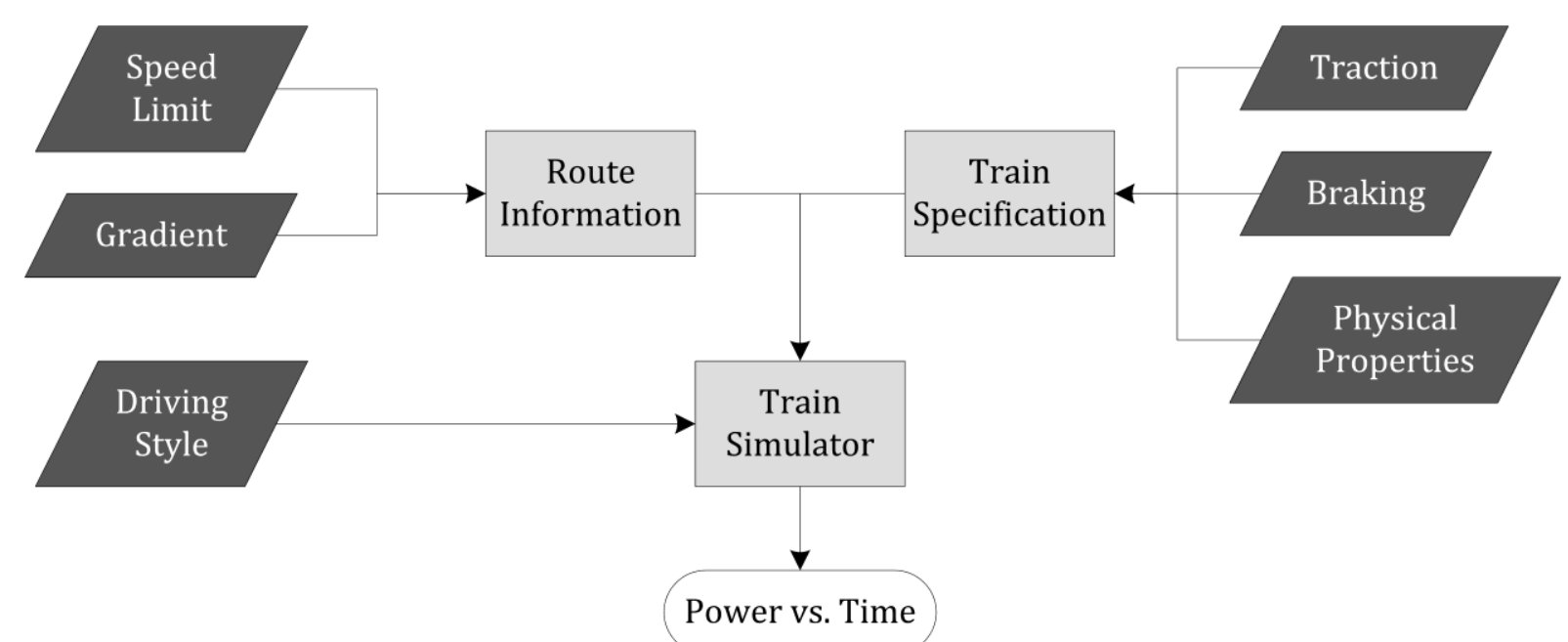

Figure 23 : Flow diagram of processes required to calculate the power versus time of a single train

Railways have speed restrictions that allow trains to travel safely without causing irreparable damage to the track, to meet the requirements of the timetable and ensure safety. The train will accelerate up to the speed limit at a rate governed by its mass $(\mathrm{M})$, tractive effort $\left(\mathrm{T}_{\mathrm{E}}\right)$, the resistive forces $\left(F_{\mathrm{R}}\right)$ and the effect due to gravity as described in Equation $<3-3>$.

$$
\frac{\mathrm{d}^{2} s}{\mathrm{~d} t^{2}}=\frac{1}{\mathrm{M}}\left(\mathrm{T}_{\mathrm{E}}-F_{\mathrm{R}}-\mathrm{Mgsin} \alpha\right)
$$

where $\mathrm{g}$ is gravity $\left(9.81 \mathrm{~ms}^{-2}\right), s$ is the distance, and $\alpha$ is the angle between $\vec{b}$ and track. Hill (1994a) and Wells (2008) show that the signals on track and the stopping distance govern the required distance for a train to stop. The STS calculates the stopping distance from a backward velocity calculation with a braking rate. The traction equipment, as described in Section 2.4, determines the maximum acceleration and deceleration. In the 
STS, a driver is simulated to control the acceleration and deceleration. The performance of the driver has three scenarios; flat-out, proportional, and proportional and notched.

When operating in flat-out, the driver completes the journey in the shortest time. The train travels from stand-still with maximum acceleration until the speed limit, at which time the driver uses constant speed until the braking point where the driver will use the brakes of the train until it reaches the station.

Proportional control imitates a driver who is careful about accelerating up to the speed limit, to make sure the speed of the train is always below the speed limit. In this scenario, as the speed of the train approaches the speed limit the driver will reduce the tractive effort. The simulation is programmed to stop using maximum acceleration when the speed of the train is within a threshold below the speed limit. For instance with a speed limit of $60 \mathrm{kmh}^{-1}$, the driver would operate the train between $55 \mathrm{kmh}^{-1}$ and $60 \mathrm{kmh}^{-1}$.

Proportional and notched control has the same imitation of the driver as proportional, however the driver controls the tractive effort between five stepped positions, as described in Section 2.5.4.

Passenger trains have a varying payload due to dynamic passenger numbers, which are generally greater in areas of high population density. The variation of payload will only have a small affect on the rate of acceleration. Passenger mass is simulated in the STS, however, the dynamics of the payload depend on passenger densities for each station and the operating times. Taking Merseyrail as a case example, a C507/8 weighs 
100 tonnes and has 222 seats, each seating an average passenger weight of $65 \mathrm{~kg}$. This means a fully loaded train has an increase of $7 \%$ in total train mass.

The STS, originally developed by Hillmansen is programmed in MATLAB, which is a mathematical tool that can solve differential equations numerically. The Improved Euler Method is a numerical integration that solves differential equations using a variable step-size between iterations (Birkhoff 1989). A fast simulation time is essential when calculating the energy consumption of a large railway network (Goodman 1998). Euler's improved method depends on a step size in time or distance to approximate the solution of a differential equation. The solution is a set of discrete data points. The size of the step not only determines the stability and accuracy of the solution, but also governs the computational time (Birkhoff 1989). Small step sizes have a higher degree of accuracy, however, this increases the processing time. Even with modern computers, using Euler's improved method to form a highly accurate solution for a large network is particularly time consuming. Therefore, a compromise on the step size between accuracy and time is required, which is assessed depending on the application. At all times the step size must be small enough to maintain stability of the solution. After careful observation of the results, $\Delta \mathrm{t}=0.01 \mathrm{~s}$ was determine as a suitable step-size for Equation $<3-3>$. There is a good resolution and stability of the solution with this stepsize. As stated in (Birkhoff 1989) this method is more accurate than the Euler Method because it increases the stability of the solution and only requires double the amount of calculation time for each step. 


\subsubsection{Results and Analysis}

The results of the STS with different driver styles operating on a test track, shown in Figure 24 to Figure 26 are of the speed-distance (top middle), distance-time (top right), specific traction, resistance and acceleration (bottom left), acceleration-distance (bottom middle) and power-time (bottom right).

Figure 24 is the flat-out case, where maximum tractive effort is used until the speed limit is reached. The train then travels at constant speed until braking is required for a lower speed limit. The acceleration is $1.1 \mathrm{~ms}^{-2}$ initially, which rapidly decreases after the base speed due to torque decrease and resistance to motion. After $1 \mathrm{~km}$, a gradient slope of -0.1 , which equates to an incline of $1 \%$, decreases the acceleration. As shown, operation at a constant speed of $100 \mathrm{kmh}^{-1}$ requires less than half of the tractive effort required for maximum acceleration. While travelling at a constant $60 \mathrm{kmh}^{-1}$ the gradient changes from 0.05 to 0.1 . At this point, the driver brakes proportionally to keep the speed constant. The train must stop at the station at $9 \mathrm{~km}$. Maximum braking effort is used by the driver, which has a rate of deceleration proportional to the speed. 

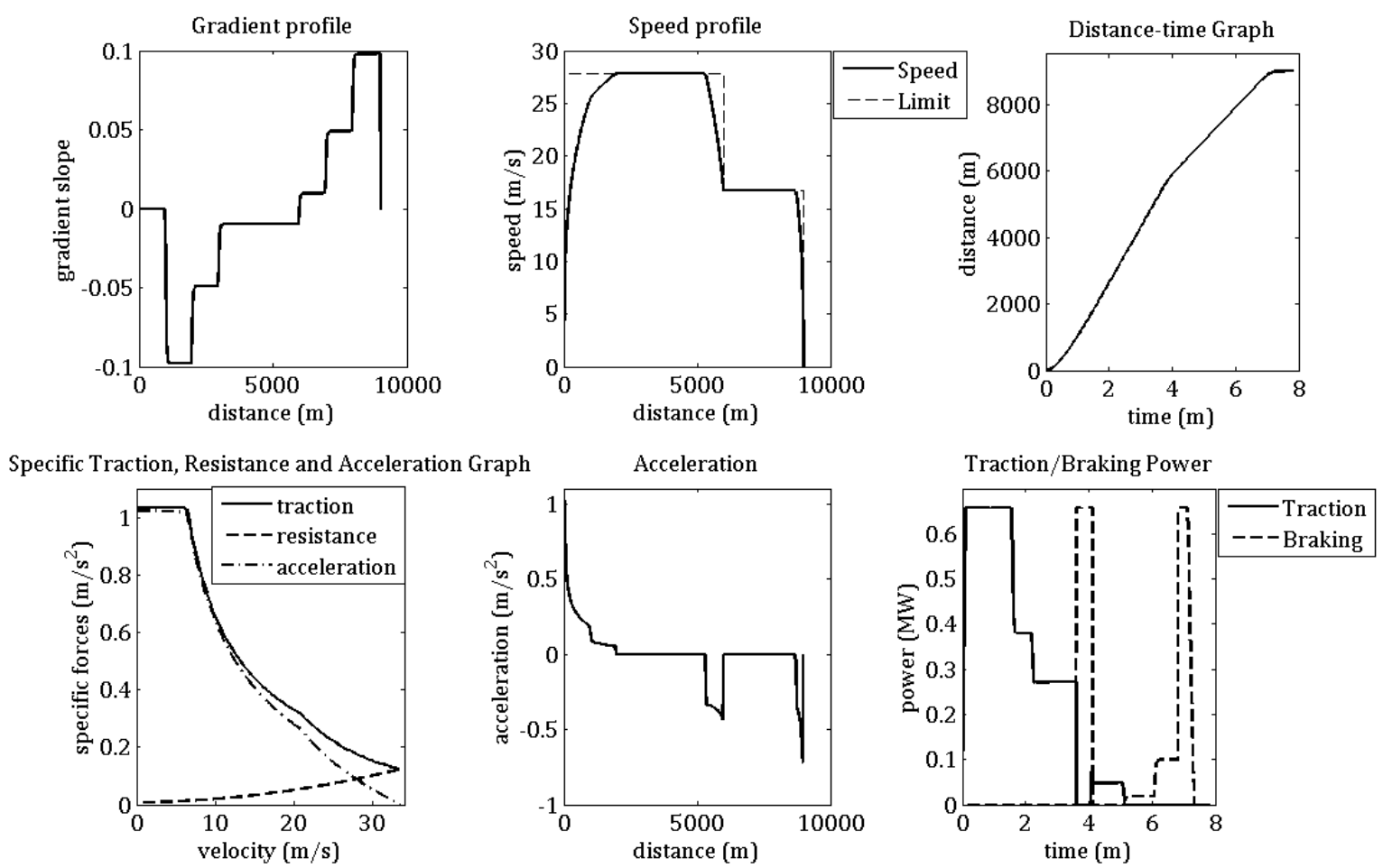

\section{Figure 24: The flat-out case simulation results of a $\mathrm{C507/8}$ on a test track}

Figure 25 is the proportional case where the driver uses maximum tractive effort up until the speed of the train is close to the speed limit. In this case, the maximum speed is not reached until approximately $5 \mathrm{~km}$. The driver reduces the tractive effort just before the speed limit as shown in the traction/ braking power graph and speed profile. The driver then decelerates the train for a lower speed limit and travels at constant speed until the braking point. 

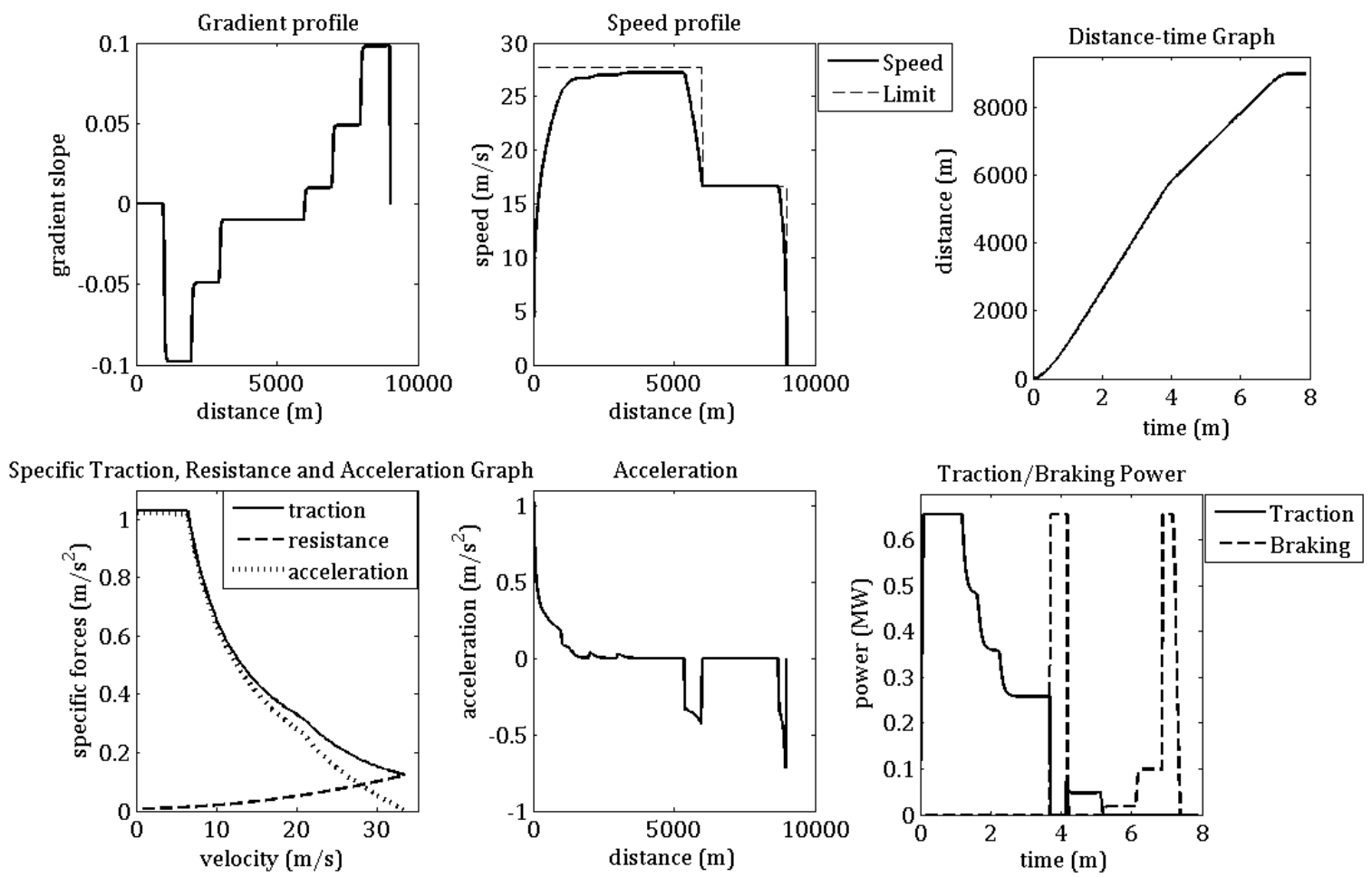

\section{Figure 25: The proportional case simulation results of a C507/8 on a test track}

Figure 26 shows the proportional and notched case simulated on the test track. Here the driver has five notch positions and a small difference between the speed of the train and the speed limit. Just before the speed of the train reaches the limit, the driver notches down, which decreases the tractive power to $525 \mathrm{~kW}$. Following that, the driver varies the tractive effort between the notches to decrease the acceleration and keep the speed lower than the limit. The train is braked using the same method as described for the flatout and proportional driving styles. 

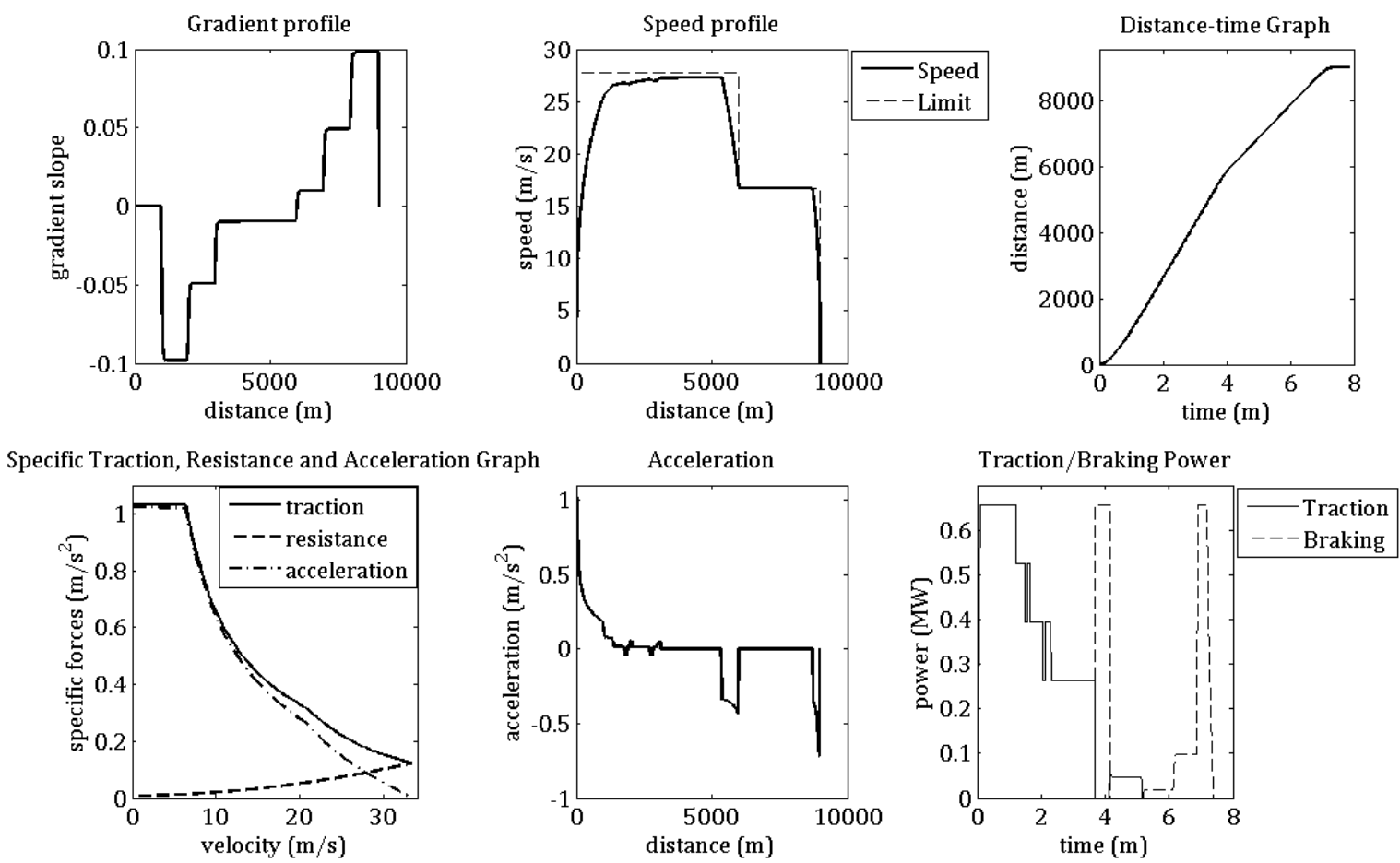

\section{Figure 26: The proportional and notched case simulation results of a $\mathrm{C507/8} \mathrm{on} \mathrm{a}$ test track}

Simulation of the power flow of multiple trains and the behaviour of traction equipment would provide a better approximation of the energy consumption over the entire Merseyrail system. The next section describes an enhancement to the STS to calculate the network power flow and power within the traction equipment.

\subsection{Merseyrail Simulator}

\subsubsection{Introduction}

The Merseyrail simulator (MERS) models the traction equipment of the C507/8 and multiple train operations over the Merseyrail network to estimate the energy consumption. These include geographical, operational, and electrical properties. 
Chymera (2006b) designed a multi-tram simulator using nodal analysis. The equivalent circuit diagram for the power network included parallel trams and a pair of series connected trams in parallel with another pair of series connected trams. The equivalent circuit modelled the network in a modular format, where each module could be connected to form an entire network. The energy consumption estimation was computed with a time step between the movement of the tram and available power on the conductors. The simulator could be used to analyse the power quality of a railway network. Jong (2005) designed a single train simulator that estimates the energy consumption with a model of the traction equipment, auxiliary load, and regenerative braking. Two methods of designing the simulator were used; power based and movement based calculations. Both required a time step to simultaneously calculate the power available for the traction equipment and the rate of acceleration. $\mathrm{Yu}$ (1998) described the simulation process of the Cegelec Projects Limited Multi-train Simulator (CPL MTS). This calculates the energy consumption with detail of the power electronic converter and stray currents. The traction equipment is input as a set of data, which can either be recorded or given. Yu (1998) explained that AC and DC motors can be simulated using this approach.

Goodman (1998) identifies the two methods for simulation of the power network as either at the same time (synchronous) or after the movement calculation (asynchronous). Synchronous simulation is important if the traction equipment demands power greater than that available on the conductors. In this case, the motor would smoothly decelerate (Goodman 1998). Many simulation projects use nodal analysis to calculate the power flow, which Goodman (1998) suggests is easier to use for large inter-connected networks. In comparison, the current mesh analysis method for 
railway simulation design is less common, as used by the MERS. In addition, a model of a camshaft driven rheostat is seldom designed. In this thesis, the power flow around the network is modelled with an equivalent planar circuit diagram of parallel trains operating between substations. The equivalent circuit is solved using current mesh analysis to form bilinear quadratic equations. Current mesh analysis in comparison to nodal voltage analysis benefits from fewer equations and computational demand. In addition, the traction equipment and power electronics of the C507/8 are modelled and integrated with the movement calculation. Such a model was previously unavailable.

\subsubsection{Merseyrail Simulator Design}

Based on the original STS design, the MERS integrates two new models, which are used to calculate the energy consumption in one time frame. The design of the MERS is specific for C507/8 rolling stock operating over the Merseyrail network. The two supplementary programming files are a network power flow (NPF) model and traction equipment (TEm) model. The NPF model calculates the power flow from the current collector, to the power electronics controller, to the DC machine, and finally to the return path via the earth brush. The TEm model required a small step size of either distance or time. However, the simulation time increases when a high degree of accuracy is required using a decreased step in distance. Using modern day computers, the simulation of the entire Merseyrail network using the MERS takes 8 minutes.

The MERS calculates the power demand from the DC machines required to move C507/8s around the Merseyrail network. It then tests whether the train has sufficient power on the distribution network and calculates the power flow. The interaction of the models within the MERS is illustrated in Figure 27. This shows that for a given route 
with inputs of gradient, station location and speed limit, the TEm and movement calculation outputs data of tractive effort and displacement with respect to time. This route is reversed and a second train operates in the opposite direction, storing the data into a single matrix based on distance. The Network Power Flow (NPF) model reads this matrix and tests the magnitude of the demanded power from the tractive effort against the substation distribution. The program will return control to the user if the demanded power exceeds the power on the conductors, producing the error 'Train has stalled'. After establishing that substations provide adequate power for the trains, the mesh currents, voltage and power are calculated and stored in matrices. These processes continue until all routes on the Merseyrail network have been simulated and stored. 


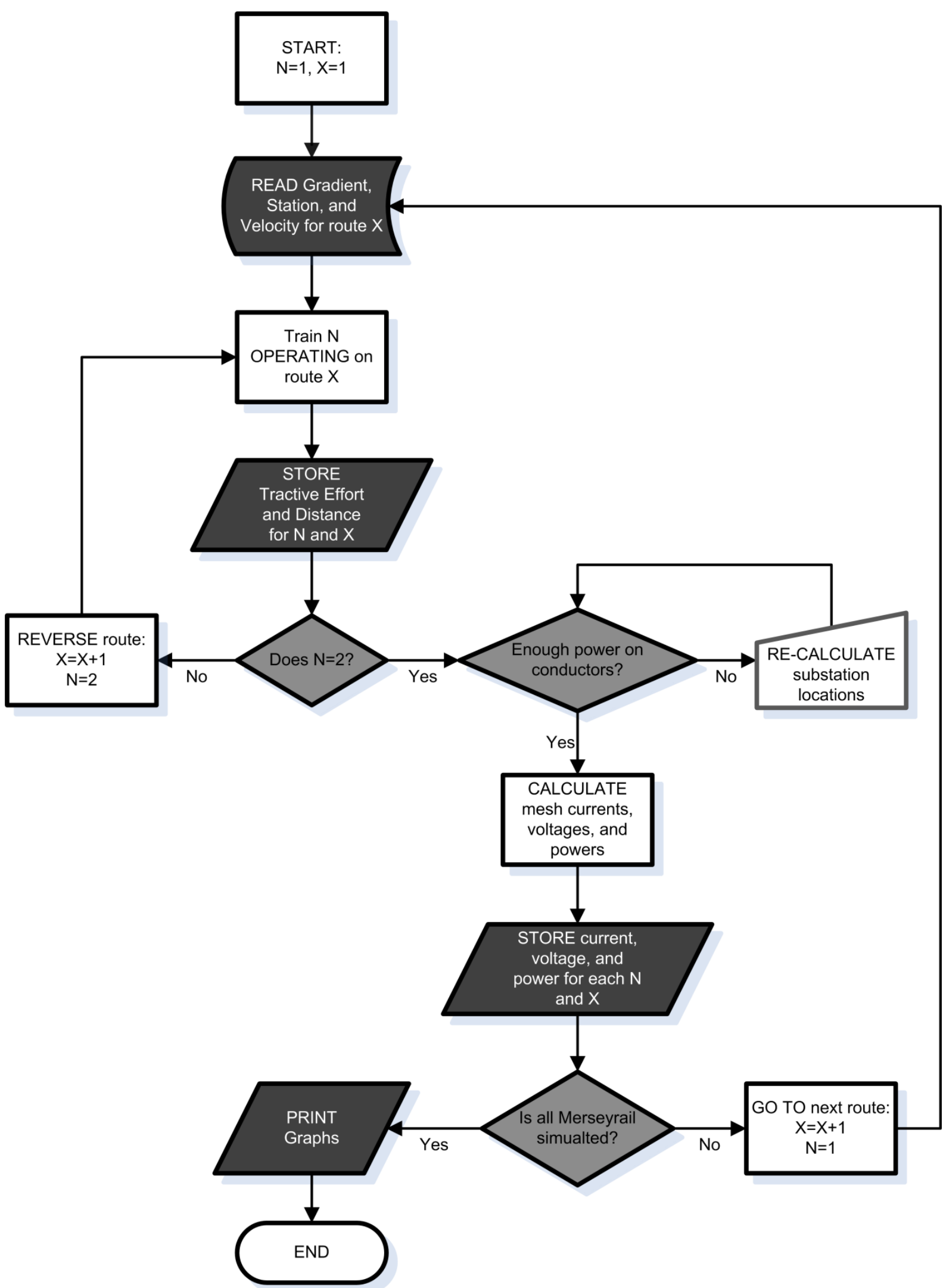

Figure 27: Flow diagram showing operations, conditionals and data storage of the MERS program from start to end 


\subsubsection{Modelling Railway Power Distribution Networks}

A single train is electrically connected to the conductors and rails, which have a resistivity and dissipate power in proportion to the distance of the train from the substations. The dynamic resistance of the conductors and rails was modelled and analysed using a method known as current mesh analysis. When two trains are running in opposite directions, the equivalent circuit has more mesh equations than a single train. Nodal analysis is an alternative method to resolve a situation. Similar to Chymera (2006b), the NPF model represents the network as a set of series connections. Each model connects in a modular format, where the substation locations on the network represent the start and end of a model.

\subsubsection{Single Train Power Flow Model}

As can be seen in Figure 28, the electrical representation of the conductors is as a dynamic resistance that changes in relation to the distance of the train from either substation. The current will flow from both substations into the machine and back to ground. $\mathrm{I}_{1}$ and $\mathrm{I}_{2}$ are current loops, which can be found using current mesh analysis. 


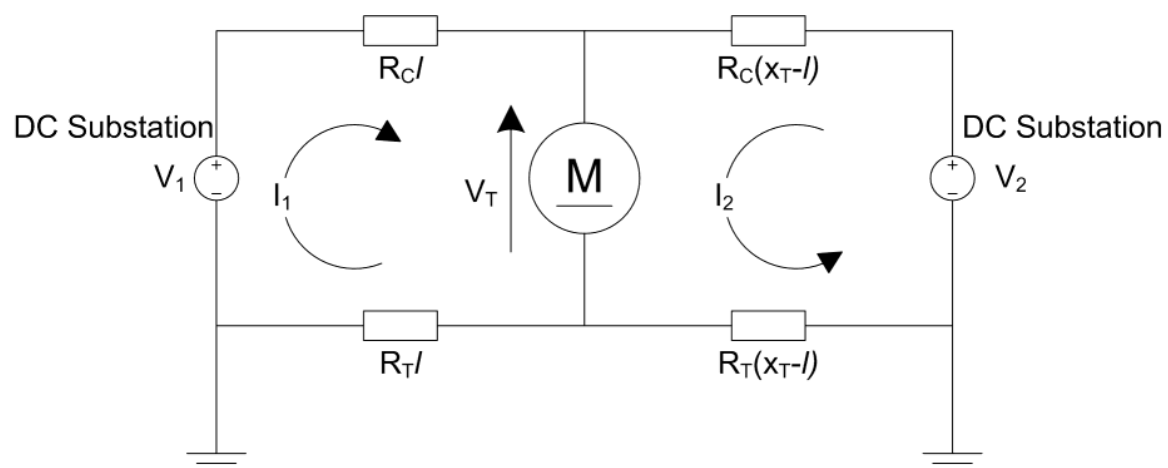

Figure 28: Train $(\underline{\underline{M}})$ between substations $\left(V_{1}\right.$ and $\left.V_{2}\right)$ with $\bar{l}$ osses on conductors and rails ahead $\left(R_{C} l\right.$ and $\left.R_{T} l\right)$ and behind $\left(R_{C}\left(x_{T}-l\right)\right.$ and $R_{T}\left(x_{T}-I\right)$ including current ahead $\left(I_{1}\right)$ and behind $\left(I_{2}\right)$

Kuphaldt (2008) explains that current mesh analysis requires a planar circuit diagram with one earth and all current loops flowing around closed circuits. In Figure 28 when the earth is only connected to the negative of $V_{1}$, it meets the requirements explained by Kuphaldt. Equation $<3-1>$ and Equation $<3-2>$ show the derivation of the current mesh analysis equations. These are simultaneous equations, with a quadratic form.

$$
\begin{aligned}
V_{\mathrm{T}} & =\frac{\Delta P}{\left(I_{1}+I_{2}\right)} \\
\mathrm{R} & =\mathrm{R}_{\mathrm{C}}+\mathrm{R}_{\mathrm{T}} \\
\mathrm{V} & =\mathrm{V}_{1}=\mathrm{V}_{2} \\
\mathrm{~V} & =I_{1} \mathrm{R} I+V_{\mathrm{T}} \\
\mathrm{V} & =I_{1} \mathrm{R} I+\frac{\Delta P}{\left(I_{1}+I_{2}\right)} \\
\mathrm{V}\left(I_{1}+I_{2}\right) & =I_{1}\left(I_{1}+I_{2}\right) \mathrm{R} I+\Delta P \\
0 & =I_{1}^{2} \mathrm{R} I+I_{1} I_{2} \mathrm{R} I-\mathrm{V} I_{1}-\mathrm{VI}_{2}+\Delta P
\end{aligned}
$$

where $\Delta P$ is the power demand of the train, as calculated in the STS.

$$
\begin{aligned}
\mathrm{V} & =I_{2} \mathrm{R}\left(\mathrm{x}_{\mathrm{T}}-I\right)+V_{\mathrm{T}} \\
\mathrm{V}\left(I_{1}+I_{2}\right) & =I_{2}\left(I_{1}+I_{2}\right) \mathrm{R}\left(\mathrm{x}_{\mathrm{T}}-I\right)+\Delta P \\
0 & =I_{2}^{2} \mathrm{R}\left(\mathrm{x}_{\mathrm{T}}-I\right)+I_{1} I_{2} \mathrm{R}\left(\mathrm{x}_{\mathrm{T}}-I\right)-\mathrm{V}_{1}-\mathrm{V}_{2}+\Delta P
\end{aligned}
$$


The result is shown in Equation<3-3>. The equations require an input of the displacement of the train and power demand from the STS. In addition, the maximum substation distance $\mathrm{x}_{\mathrm{T}}$ is programmed as a vector, which changes depending on the displacement of the train. The two currents $I_{1}$ and $I_{2}$ multiplied with the voltage on the track and conductor give the power flow on the network. Therefore, the NPF model processes after the execution of STS. Goodman et al. (1998) refer to this programming method as the modified load flow approach.

$$
\begin{aligned}
& I_{1}=\frac{\mathrm{R}}{2 \mathrm{x}_{\mathrm{T}}} I\left(\mathrm{x}_{\mathrm{T}} \mathrm{V} \pm \sqrt{\mathrm{x}_{\mathrm{T}}^{2} \mathrm{~V}^{2}-4 \mathrm{Rx}_{\mathrm{T}}^{2} I \Delta P+4 \mathrm{Rx}_{\mathrm{T}} I^{2} \Delta P}\right) \\
& I_{2}=\frac{-I \Delta P}{\mathrm{x}_{\mathrm{T}}\left(\frac{\mathrm{x}_{\mathrm{T}}}{2}\left(\mathrm{x}_{\mathrm{T}} \mathrm{V} \pm \sqrt{\mathrm{x}_{\mathrm{T}}^{2} \mathrm{~V}^{2}-4 \mathrm{Rx}_{\mathrm{T}}^{2} l \Delta P+4 \mathrm{Rx}_{\mathrm{T}} I^{2} \Delta P}\right)-\mathrm{V}\right)}
\end{aligned}
$$

\subsubsection{Assumptions and Boundary Conditions}

The equivalent circuit diagram in Figure 28 assumes an ideal substation as a constant voltage source with no earth-current leakage on the return path from the train to the substation. A real substation would have a different power factor, include extra harmonics from the fundamental and sustain losses as described in Section 2.4.8. These are not modelled because the substations have large inductors, which reduce the current ripple and undesired harmonics from the rectifier and hence improve the power factor (Dixon 2005, Hosseini 2005, Mohan 2003). The amount of energy loss in the substation is much less than that lost in the conductors and rails. So, in simulation the calculated energy consumption will not significantly deviate from the actual value.

The effect of earth-current leakage increases the energy loss on the return path from the train to the substation. Hill (1994b) and Chou (2001) show that the direct 
contact of the rails with earth creates a circuit, where current flows through earth and back to the substation. This creates a propagation delay and losses in the earth-current leakage effect. However the majority of the current flows through the rails since it has a smaller resistance. Jordan (2007) states that generally 1 to $3 \%$ of the substation voltage supply is dissipated in the earth. Accordingly, this has only a small effect on the energy consumption.

\subsubsection{Multi-train Power Flow Model}

The circuit diagram in Figure 29 is a planar equivalent circuit diagram of two parallel trains between substations. This is equivalent to the physical configuration shown in Figure 1. Train 1 is travelling between substations 1 and 2 represented on the diagram as voltage sources $V_{1}$ and $V_{2}$. Train 2 is travelling in the opposite direction. As before with the single train shown in Figure 28, current mesh analysis method will be used to extract the equations needed to compute the currents $I_{1}$ to $I_{5}$ (see Equation $<3-4>$ to Equation<3-9>). Kuphaldt (2008) shows that for a planar circuit diagram the current mesh equations will still be valid when the direction of the current and position of the earth changes. 


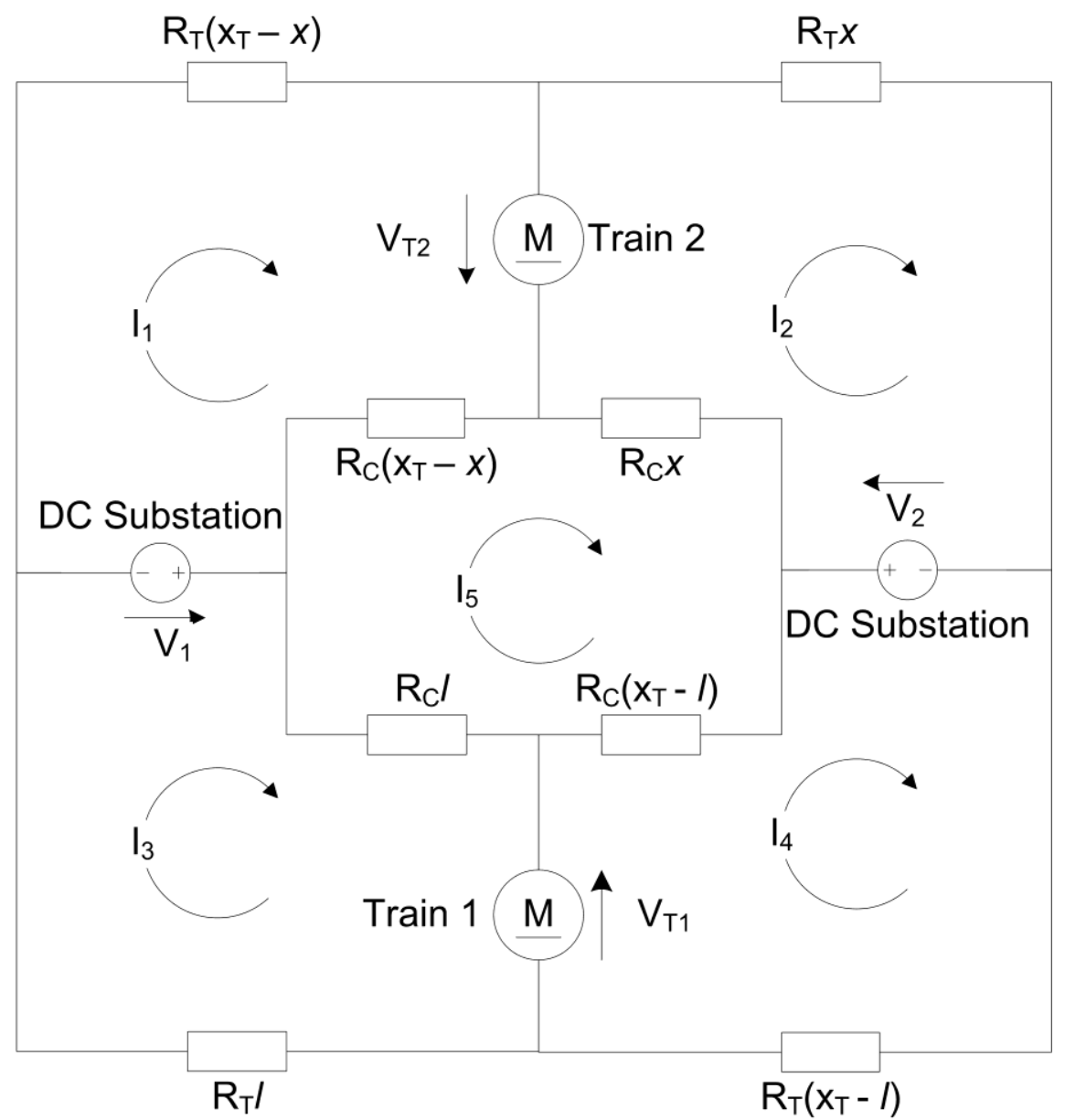

Figure 29: Two trains $(\underline{M})$ in opposite direction between substations $\left(V_{1}\right.$ and $\left.V_{2}\right)$ with losses on conductors and rails ahead Train 1 and Train $2\left(R_{C} l, R_{T} l\right.$ and $R_{C} x$, $\left.R_{T} X\right)$ and behind $\left(R_{C}\left(x_{T}-I\right), R_{T}\left(x_{T}-I\right)\right.$ and $R_{C}\left(x_{T}-x\right), R_{T}\left(x_{T}-x\right)$ ) current ahead $\left(I_{3}\right.$ and $\left.I_{2}\right)$ and behind ( $I_{4}$ and $I_{1}$ ) Train 1 and Train 2

The solution to the interaction of these current meshes can be solved using a technique called current mesh analysis, resulting in four quadratic equations and one linear equation from five meshes. When the trains are next to the substation, the observed currents $I_{1}$ and $I_{4}$ are large and $I_{2}$ and $I_{3}$ are small. This is because there is a small resistance between the trains and sending substations, and a large resistance between the trains and receiving substations.

$$
\begin{gathered}
-\mathrm{V}_{1}=I_{1}\left(\mathrm{R}_{\mathrm{C}}\left(\mathrm{x}_{\mathrm{T}}-x\right)+\mathrm{R}_{\mathrm{T}}\left(\mathrm{x}_{\mathrm{T}}-x\right)\right)-I_{5} \mathrm{R}_{\mathrm{C}}\left(\mathrm{x}_{\mathrm{T}}-x\right)+V_{\mathrm{T} 2} \\
\mathrm{~V}_{2}=I_{2}\left(\mathrm{R}_{\mathrm{C}} X+\mathrm{R}_{\mathrm{T}} \mathrm{x}\right)-I_{5} \mathrm{R}_{\mathrm{C}} x-V_{\mathrm{T} 2}
\end{gathered}
$$




$$
\begin{array}{cc}
\mathrm{V}_{1}=I_{3}\left(\mathrm{R}_{\mathrm{C}} I+\mathrm{R}_{\mathrm{T}} I\right)-I_{5} \mathrm{R}_{\mathrm{C}} I-V_{\mathrm{T} 1} & <3-6> \\
-\mathrm{V}_{2}=I_{4}\left(\mathrm{R}_{\mathrm{C}}\left(\mathrm{x}_{\mathrm{T}}-I\right)+\mathrm{R}_{\mathrm{T}}\left(\mathrm{x}_{\mathrm{T}}-I\right)\right)-I_{5} \mathrm{R}_{\mathrm{C}}\left(\mathrm{x}_{\mathrm{T}}-I\right)+V_{\mathrm{T} 1} & <3-7> \\
\mathrm{V}_{1}-\mathrm{V}_{2}=I_{5}\left(\mathrm{R}_{\mathrm{C}}\left(\mathrm{x}_{\mathrm{T}}-X\right)+\mathrm{R}_{\mathrm{C}} X+\mathrm{R}_{\mathrm{C}} I+\mathrm{R}_{\mathrm{C}}\left(\mathrm{x}_{\mathrm{T}}-I\right)\right)-I_{1} \mathrm{R}_{\mathrm{C}}\left(\mathrm{x}_{\mathrm{T}}-X\right)-I_{2} \mathrm{R}_{\mathrm{C}} X-I_{3} \mathrm{R}_{\mathrm{C}} I-I_{4} \mathrm{R}_{\mathrm{C}}\left(\mathrm{x}_{\mathrm{T}}-I\right)<3-8> \\
V_{\mathrm{T} 1}=\frac{P_{\mathrm{T} 1}}{I_{1}+I_{2}} & <3-9> \\
V_{\mathrm{T} 2}=\frac{P_{\mathrm{T} 2}}{I_{3}+I_{4}} &
\end{array}
$$

The five mesh equations (Equation $<3-4>$ to Equation $<3-8>$ ) are simultaneous where $P_{\mathrm{T} 1}$ and $P_{\mathrm{T} 2}$ from Equation $<3-9>$ and $I$ and $x$ are dynamic parameters. The power $P_{\mathrm{T} 1}$ and $P_{\mathrm{T} 2}$ is dynamic with respect to the operation of the train because this is the power drawn from the motor during acceleration and regenerated by the machine during coasting and braking. The equivalent resistances are dynamic as a product of distance $l l$ and $x$ ). The distance of the train is determined from the product of resistance and distance from both substations.

The assumptions of an ideal substation and no earth current leakage made for the single train model (see Figure 28) still hold for the multiple train model (see Figure 29). In addition to these assumptions, it is assumed that the motor power demand is always met. Goodman et al. (1998) explained that as the voltage on the conductor decreases below the rated value of the motor, it starts to slow down gradually. However, within the programming file of the multi train model, is an equation that identifies whether the power has fallen below the rated value. If it has, an error message is displayed stating that the train has stalled. 
The voltage of the simulated substation is ideal. This assumes a constant DC voltage. In reality, the voltage will drop in the substation depending on how many trains there are in the section between substations. As Hill (1994b) explained, there is a regulation of $6 \%$ in the substation voltage, which occurs because of losses in the AC-DC conversion process. The parallel trains model, see Figure 29, represents the two substations sharing the load from two trains. This model is connected in a modular format across the Merseyrail network.

\subsubsection{Modelling Traction Equipment}

Merseyrail and Angel Trains supplied data sheets as described in Section 2.5 the information is analysed and modelled as a Traction Equipment (TEm) model. Figure 67 in APPENDIX B, which is the graph of current versus speed and notching current, was analysed and modelled in the TEm model. This involved a curve-fitting technique using the motor constant $(\mathrm{K})$ as a variable. The result is shown in Figure 30. The solid lines represent the series region, where resistors connected in series with the armature are sequentially switched off to increase the terminal voltage, illustrated in Figure 18. After all resistors are switched off, further speed increases are possible when two pairs of motors are connected in parallel, which doubles the terminal voltage for each motor. In the parallel region (see dashed lines in Figure 30) a similar operation occurs compared to the series region, where series resistors are sequentially turned off. The last stage is the field weakening region (see dotted lines in Figure 30). 


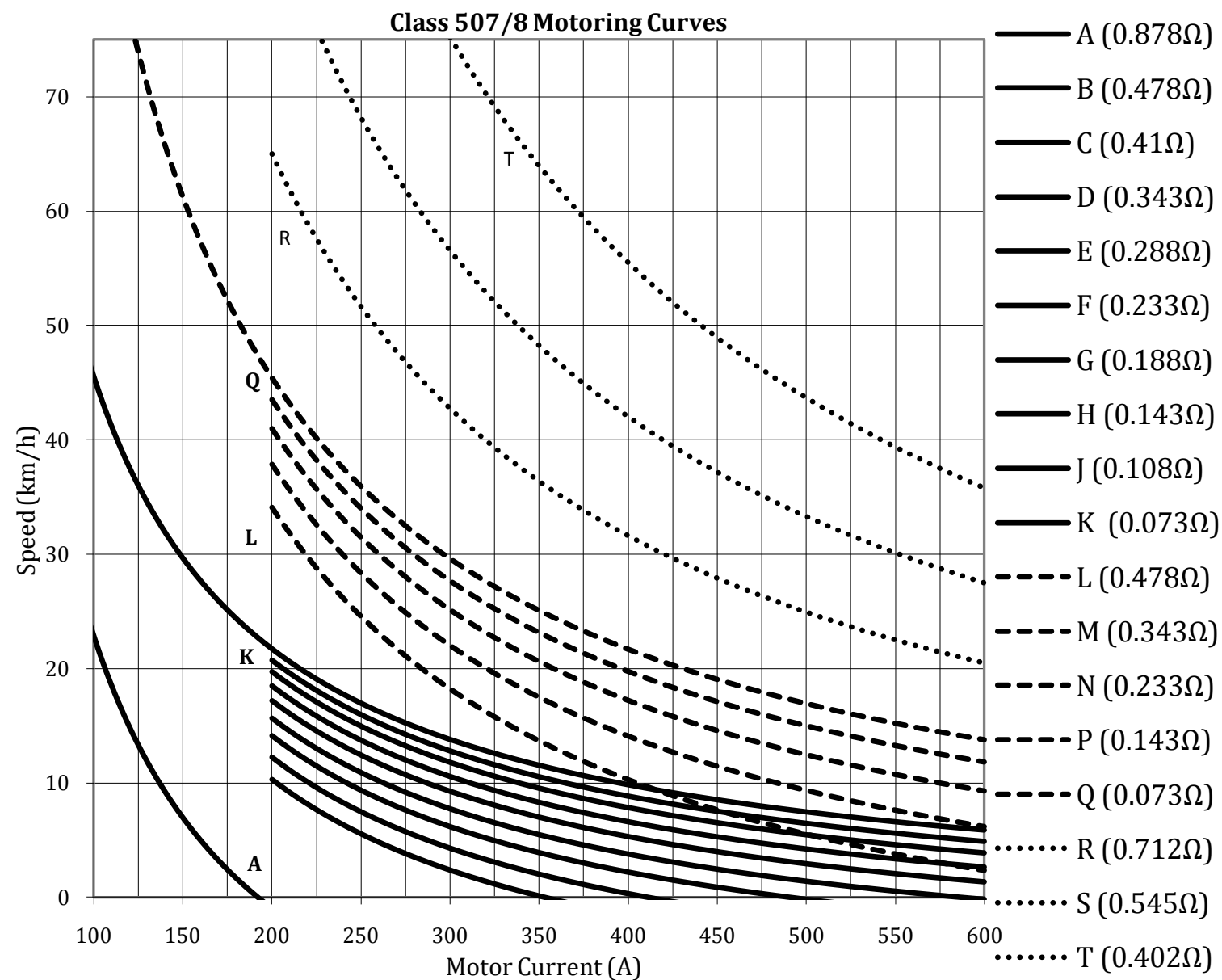

Figure 30: Motoring Curves for $\mathrm{C507/8}$ with operating ranges of series (solid, $\mathrm{A}$ sequentially to $\mathrm{K}$ ), parallel (dashed, $\mathrm{L}$ sequentially to $Q$ ) and field weakening (dotted, $R$ sequentially to $T$ )

The tractive effort versus current graph was digitised and a group of $2^{\text {nd }}$ order polynomial trend lines were fitted to extract the tractive effort equations as a function of current. This depends on the angular speed $\omega$, which is $\gamma / \mathrm{r}$ times greater than the linear speed, where $\gamma$ is the gear ratio and $r$ is the radius of the wheels. The initial model developed used a constant torque supplied to the acceleration equation (see Equation $<3-3>$ ); later improvements to this model included a derivation of torque for all regions of field weakening. The camshaft moves between positions $\mathrm{Q}$ to $\mathrm{T}$ for $100 \%$ field force (FF), 75\% FF, 58\% FF and 46\% FF respectively. One method to model the tractive effort versus current curve from the Merseyrail data sheet was to digitise it. The plot was 
analysed and a $2^{\text {nd }}$ order polynomial trend line was fitted to extract equations for the tractive effort, see Figure 31. The initial C507/8 MATLAB model used differential equations with respect to speed, which excluded a time or distance variable. However, later improvements in the MATLAB model included time and distance based simulations.

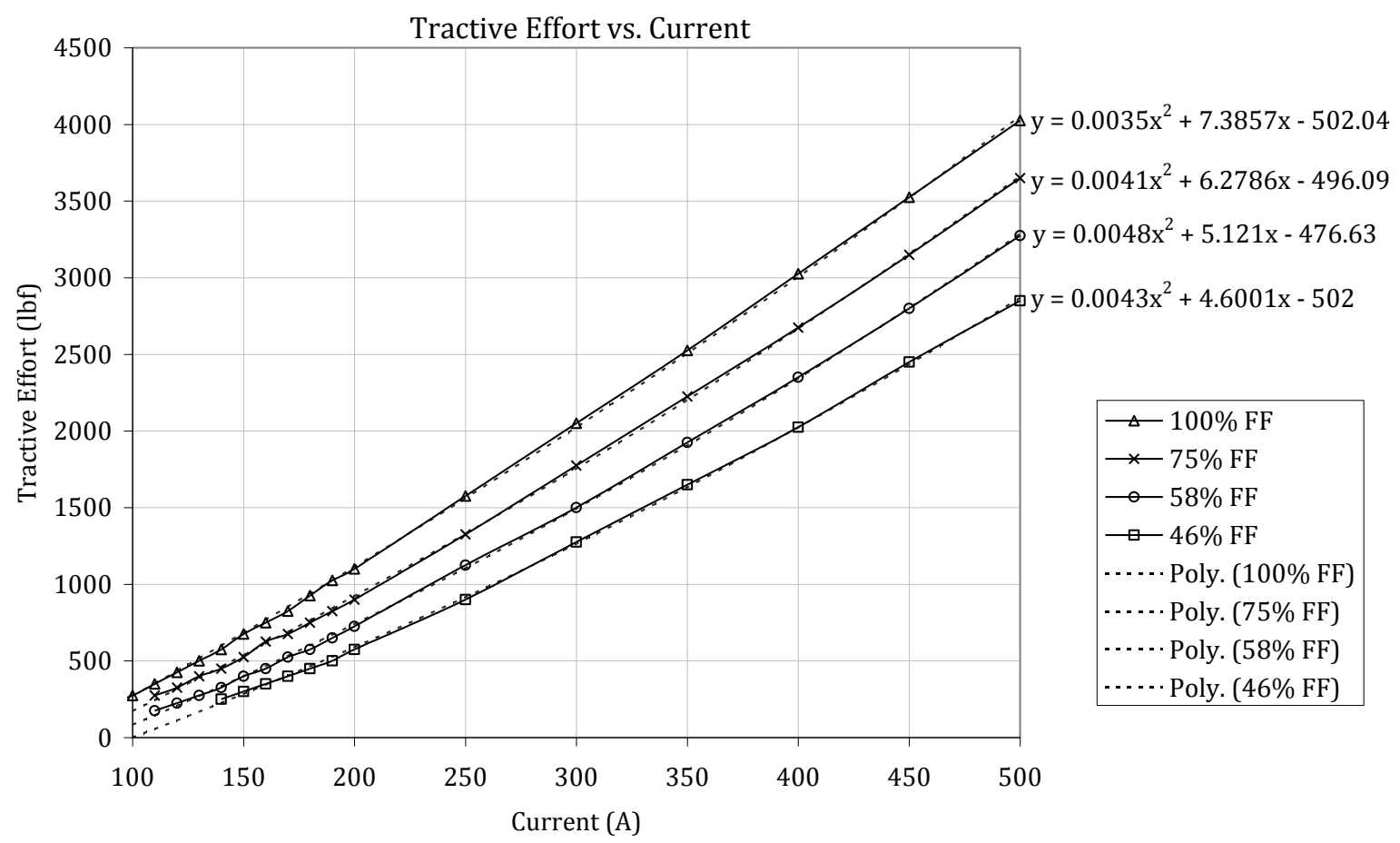

Figure 31: Digitised tractive effort versus current curve indicating field weakening percentages, trend-line, and equation of trend-line

The traction equipment of the C507/8 has been modelled with the use of well known equations, an approximated motor constant from a curve-fitting exercise and equations of trend lines that were fitted to a digitised plot. The differential equations were solved using an improved Euler's Method, with a time step size chosen to give a stable solution. The model was able to approximate a C507/8 running over the Merseyrail network, with results for its motion and power, as described in Section. 3.7. 


\subsection{Assumptions and Limitations of the Merseyrail Simulator}

The railway subsystem models of the MERS have assumed ideal operational behaviour, which has differences compared to a real railway network. It will be critically analysed as to how they affect the energy consumption and why it may not be necessary to model them.

The DC motor model used steady-state equations (see Section 2.4), which did not consider armature reaction (saturation and voltage build-up due to the inductance of the armature coil windings), hysteresis, eddy-current losses and other minor losses (i.e. brush contact). The reason for not modelling this is justified, as industrial DC motors have inter-poles and compensation windings, which minimise the effect of armature reaction (see Section 2.4.4). Operators can avoid the effect of hysteresis by limiting the operation of the motor before the saturation point (see Section 2.4.8). Eddy-current losses are minimised by laminating the magnetic material of the DC motor (see Section 2.4.8).

Ideal substations supply a fixed DC voltage to the conductors. Non-ideal substations have harmonics and voltage fluctuations; however, the power quality is improved in practice with LC filters or active filters on the outputs of the substations (Hosseini 2005).

The wheel-rail contact is modelled with maximum adhesion because the C507/8 has a system to detect and protect against unstable wheel slip (Angel Trains 2008). Controlled wheel slip allows the wheels to spin from standstill and improves the rate of acceleration (Hill 1994a). The allowance is limited to 5\%, so the wheels will only spin 
when the train is too heavy and for a short time. Thus, there is a small difference between the energy consumption of a train with wheel slip and one without.

The model of the train aerodynamics is only valid in open air. When underground there is an increase in the pressure and aerodynamic drag (Kirkland 1995). However, there is a small section underground of the total network of Merseyrail, so the total energy consumption will be slightly greater.

The high-speed operation of a motor increases its temperature, especially when used over long periods (Chapman 2005). However, this was not modelled because the radiators in the train keep the motor at an operating temperature to meet specified power demands and speed requirements. In warm weather, the ambient temperature will have an effect that increases the temperature of the motor. Ever since temperature recordings had begun, Britain's weather has never exceeded $40^{\circ} \mathrm{C}$, where the hottest day was $10^{\text {th }}$ August 2003 (BBC News 2003). Weather is unpredictable and has a variable effect on the energy consumption; this has not been modelled and could be considered as further work.

The auxiliary load is the supply of power from the current collector system to the passenger facilities. This requires a DC-AC inverter and typically consumes less than $10 \%$ of the rated power of the motors for supplying lighting and heating. The auxiliary load includes the lights inside the train, which are on during operation and can be calculated as a constant energy consumption. The auxiliary load also includes the energy consumption of the radiators. This depends on the ambient temperature, amount of passengers, and the duration that the doors stay open, which draws a dynamic power from the supply. In addition, the rheostat can be used as a radiator, which dissipates the 
braking energy as heat. This is an effective method of decreasing energy consumption. However, the rheostat has a decrease in braking performance when its temperature exceeds its rated operating temperature. The auxiliary load depends on many variables, some of which are unavailable to model. This has not been modelled, which means that the simulated energy consumption will be less than the energy consumption of the real network.

It has been assumed that friction in the bearings is minimised by regular maintenance and the application of grease and lubrication (GEC 2008).

\subsection{Results and Analysis}

The results of the MERS are comparable with the Merseyrail data sheets. As can be seen from Figure 32 and Figure 33, there is a maximum speed of $121 \mathrm{kmh}^{-1}$ at a maximum acceleration of $1 \mathrm{~ms}^{-2}$. This speed is the same as the rated maximum speed as shown in (Marsden 2007) and the rate of acceleration is the same as that described in the data sheet TMT310 supplied by Merseyrail. As shown in the speed-time graph, the train takes $1.1 \mathrm{~km}$ to reach $96 \mathrm{kmh}^{-1}$ and takes $900 \mathrm{~m}$ to stop while braking from that speed. For a mode distance between stations of $2 \mathrm{~km}$ and speed limit of $96 \mathrm{kmh}^{-1}$, it is expected that the train will be accelerating for half of the journey time and then braking until the station. 


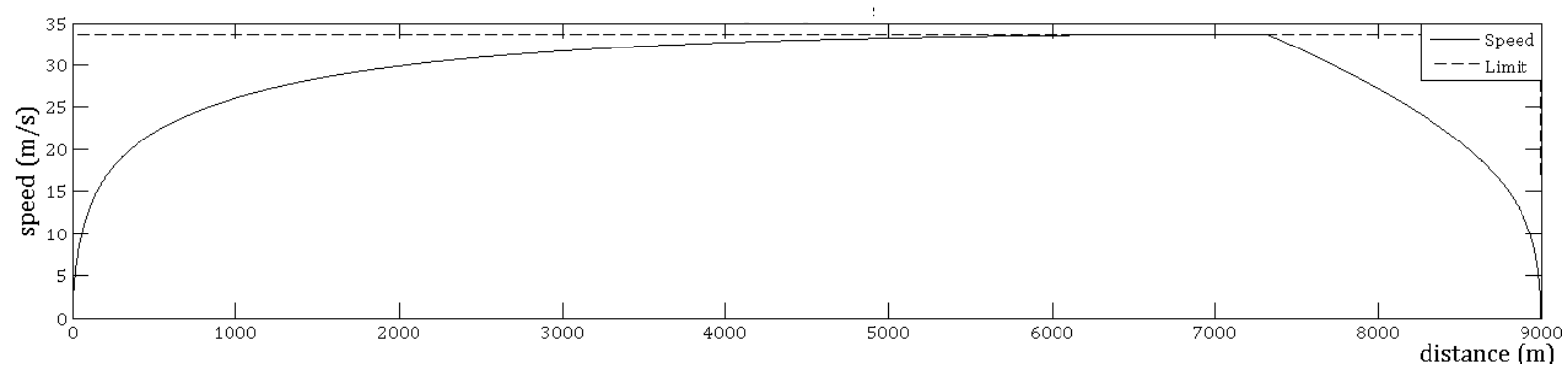

Figure 32: Simulated speed-distance graph for C507/8

Of particular note in the acceleration curve is a high frequency of deviation between 0.6 and $1 \mathrm{~ms}^{-2}$ between 0 and $130 \mathrm{~m}$. This is not a smooth journey and it is expected that the passengers would feel the train jerk as it notches through the camshaft positions. During the field weakening region the acceleration decreases at a rate proportional to the angular speed, as described in Section 3.2.

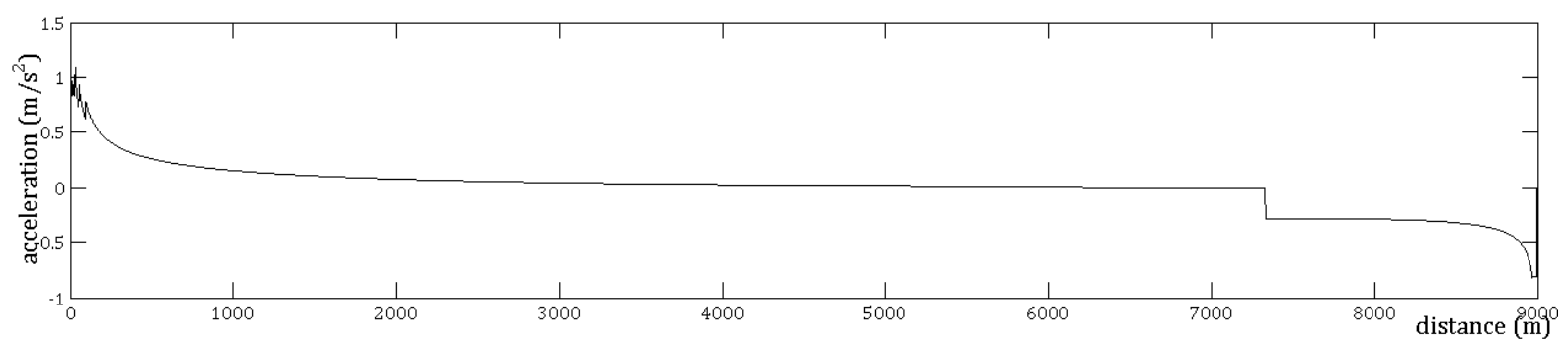

Figure 33: Simulated acceleration versus distance graph for C507/8

The simulator models trains operating in different directions over every route in the network. As previously discussed in Section 2.4, as the speed increases, the armature current will decrease. As shown in Figure 34, when this falls below the notching current, it will trigger a notch-up or down on the camshaft. There are 18 camshaft positions, that limit the current to falling below $358 \mathrm{~A}$ when the train is unloaded and $408 \mathrm{~A}$ when fully loaded. A to $B$ is the series region, $B$ to $C$ is the parallel region and $C$ and above is the field weakening region. The change of region between series and parallel has an increase of terminal voltage and thus the current increases significantly. Further from parallel operation into the field weakening region diverter resistors decrease the current flow 
around the field windings, which weakens the field. A series DC motor has similar behaviour and is controlled with series resistors and diverter resistors as described by Chapman (2005) and Wildi (2006) and in Section 2.4.

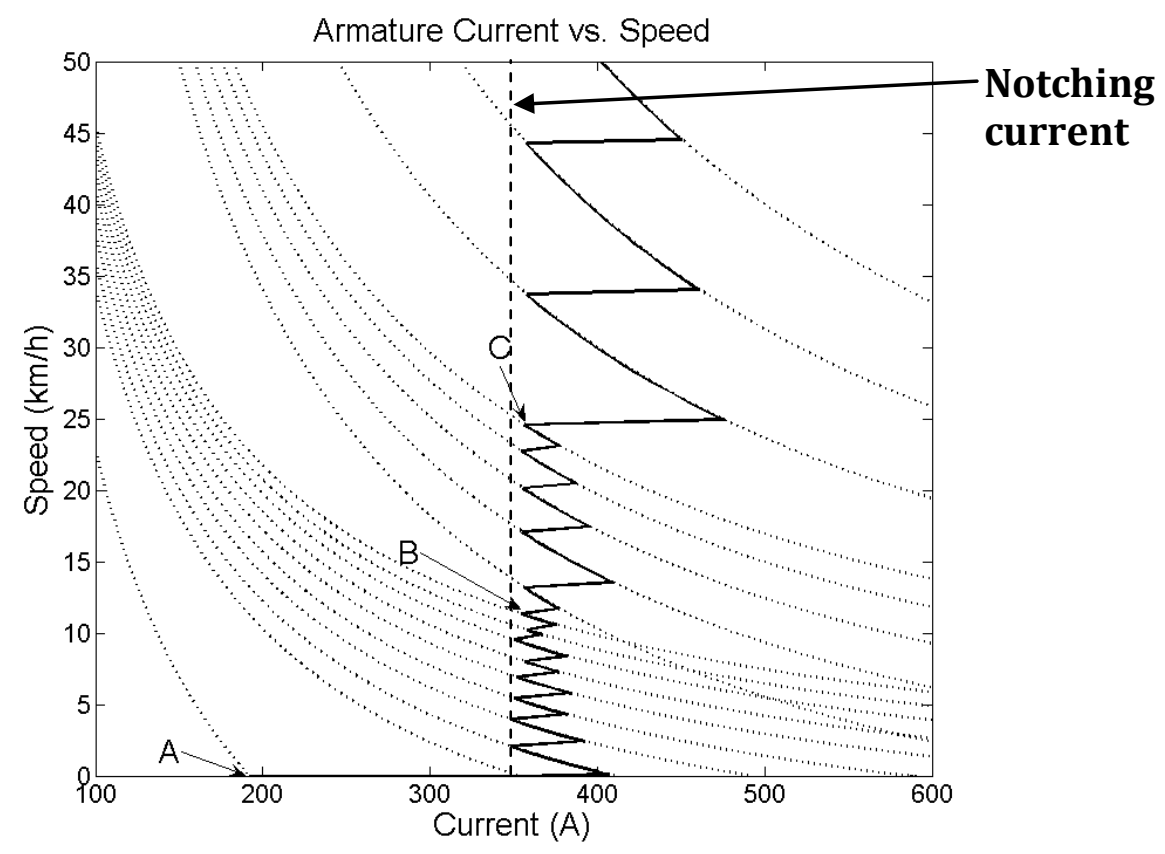

Figure 34: Simulated speed versus current graph for $\mathrm{C507/8}$ with operating regions series $A$ to $B$, parallel $B$ to $C$ and field weakening $C$ and above

There is a slight difference between the simulated and data sheet results, which is likely to be due to the losses in the gears (see APPENDIX B) and saturation of the air gap and pole faces as described in Section 2.4.4. Fam et al. (1988) and Robles et al. (2007) show how the Frölich equation can model the effect of saturation on the modelling of magnetic field strength versus magnetic field intensity curve for electric motors. This could be implemented as further work. 


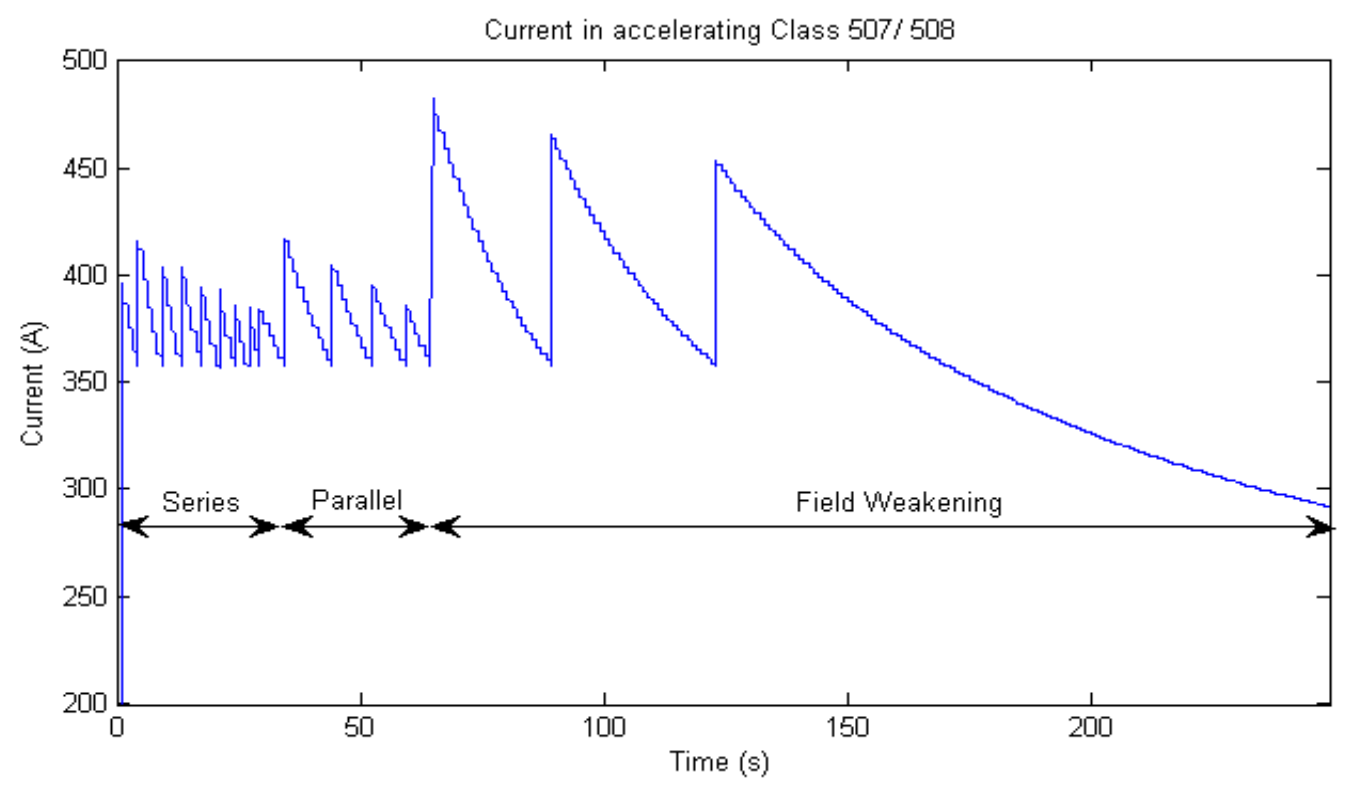

Figure 35: Simulated current for $\mathrm{C507/8}$ with series, parallel and field weakening operating regions

The operating C507/8 will have a current with a saw-tooth waveform, as shown in Figure 35. The maximum deviation in current is $175 \mathrm{~A}$, which is when the $\mathrm{C} 507 / 8$ changes from parallel to field weakening at 75\% Field Force (FF). Using the rate of change between each conductor segment as calculated in Section 2.4 .4 of $235 \mu$ s, the rate of change in current would be $0.7 \times 10^{6} \mathrm{As}^{-1}$. As a general guide, the Siemens catalogue of DC motors (2004) listed the inductance of the armature for similar DC motors as within the $\mathrm{C} 507 / 8$. The average inductance from 9 motors is $3.8 \mathrm{mH}$, which would give a voltage build-up of $2.7 \mathrm{kV}$ on the brush-commutator contact. However, inter-poles on the $\mathrm{C507/8}$ reduce the sparking here because, as described in Section 2.4.4, they have an equal and opposite flux to the conductor directly over the brush, which reduces the induced voltage to zero. 


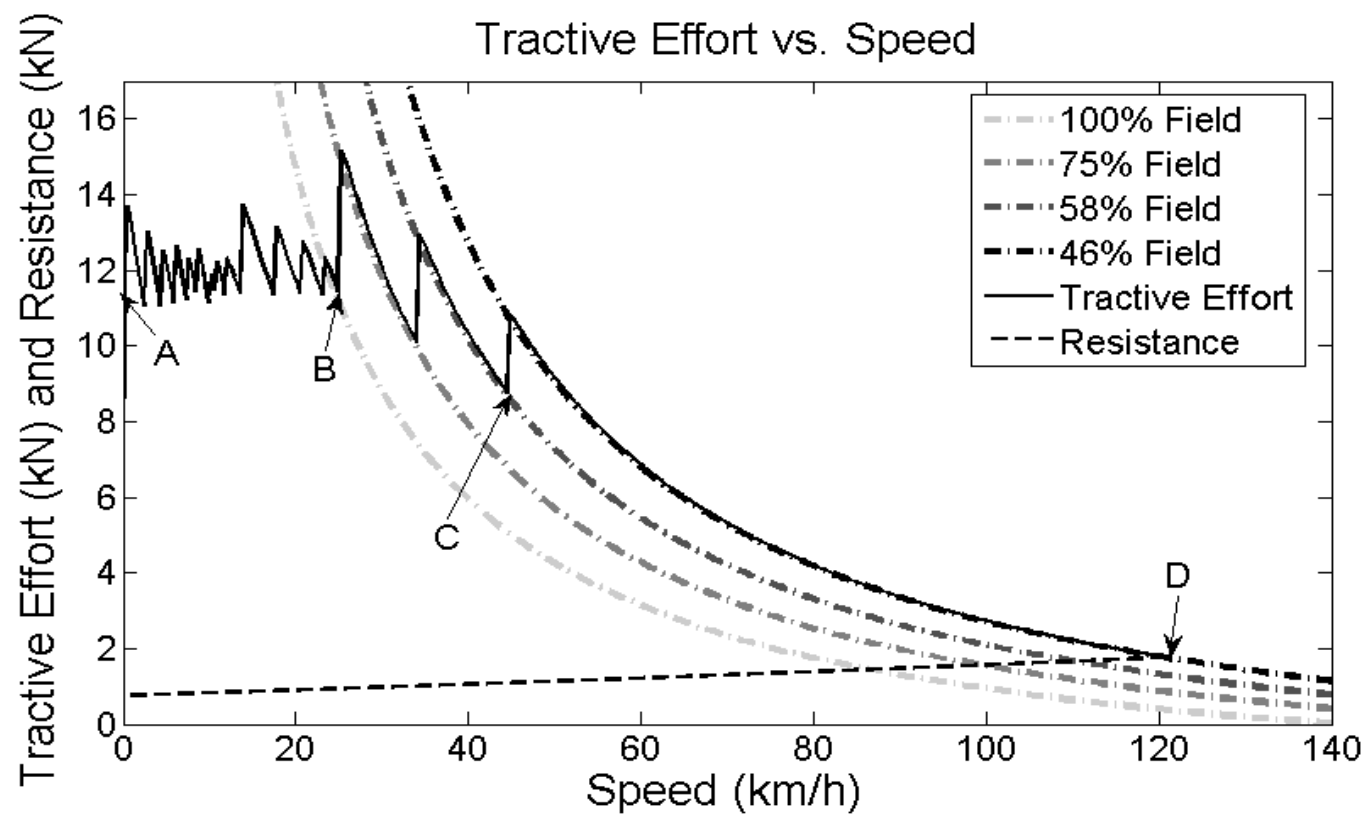

Figure 36: Simulated tractive effort and resistance versus speed. Indications of operating regions series ( $A$ to $B$ ), parallel ( $B$ to $C$ ) and field weakening ( $C$ to $D$ )

The same characteristics of torque versus speed curves can be seen in Figure 36 as regards the previous examples from Griffith (1978), Hill (1994a), and Schmid (2007). Four curves represent the tractive effort of one motoring car. The gear ratio is 69:14, so the train will have a total tractive effort that is multiplied by the gear ratio and number of motoring cars. The simulated tractive effort shows the curve for different field force strengths , expressed as a percentage. After the field is weakened, the armature current increases (see Equation<2-3>) and hence the torque increases because the increase of $I_{\mathrm{a}}$ is far greater than the decrease of $\varphi($ see Equation $<2-5>)$. These characteristics are the same as identified in Section 2.4 and shown in Slemon (1992), Chapman (2005), and Wildi (2006). The ripple in the torque is similar to the current ripple because the torque is dependent on the current. However, the constant tractive effort or constant torque region can still be identified as between $A$ and $B$. There is a decrease in tractive effort after the base speed at a rate of $1 / \omega$ between $B$ and $C$. Then, as the speed increases, there is further tractive effort reduction at $1 / \omega^{2}$ between $C$ and $D$. When the resistance 
equals the tractive effort, the acceleration becomes zero, hence at point $\mathrm{D}$ the train has reached maximum speed $\left(121 \mathrm{kmh}^{-1}\right)$.

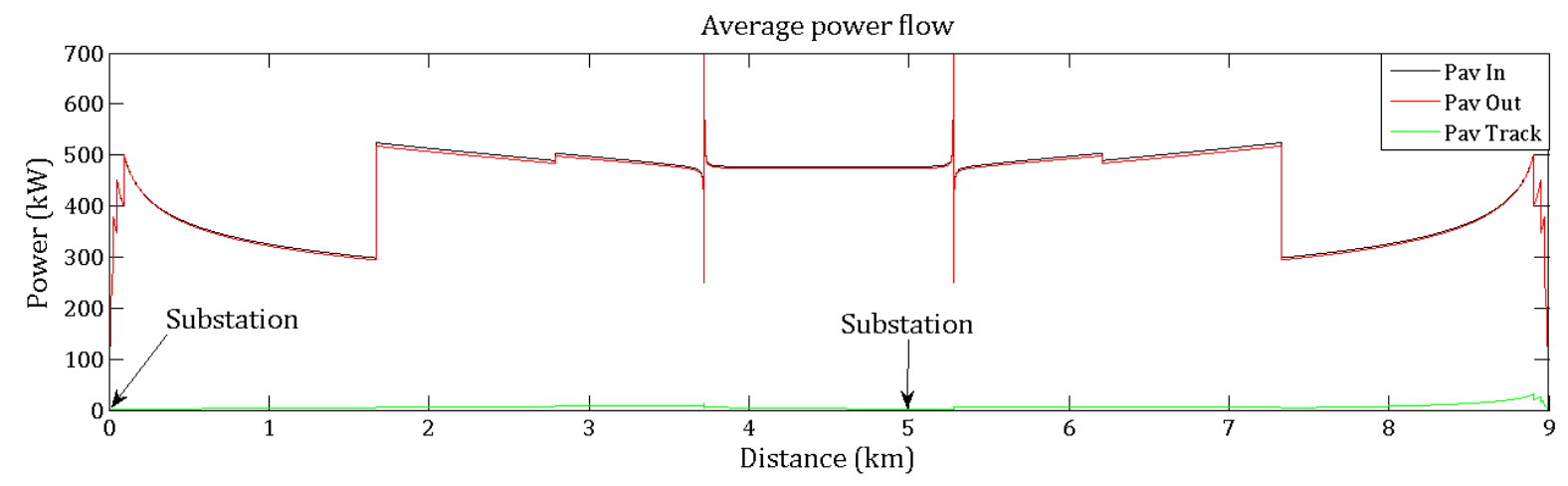

Figure 37: Simulated average power flow of two trains in opposite direction between two substations, where average power in Pav In, average power out Pav Out and average power on the track Pav Track

As identified in the timetables, station spacing and location of substations, Merseyrail only schedules a maximum of two trains travelling in opposite directions between substations. For example, a train travelling on the Northern Line arrives in Birkdale at 12:02 pm and at the same time the train behind arrives in Hightown. These two stations are $13 \mathrm{~km}$ apart which, according to the maximum substation displacement of $5.3 \mathrm{~km}$ as shown in Section 3.5.3 suggests that there are only two opposing trains between substations in Merseyrail.

As shown in Figure 37, the peak of the average power between two substations is less than the rated power of a C507/8. It also shows two power spikes at 3.8 and $5.2 \mathrm{~km}$, which each last for $20 \mathrm{~ms}$. Industries use snubber circuits to minimise the effect of these, which sense a spike and limit the current flow. This is characterised in the programming as an over-current sensor.

The track losses do not exceed $10 \mathrm{~kW}$. The maximum is at the point where the train travelling from $9 \mathrm{~km}$ to $0 \mathrm{~km}$ is using full tractive effort for maximum acceleration 
up to the speed limit between 8.9 and $8.8 \mathrm{~km}$. Afterwards the track losses decrease and then increase in the middle of the section between substations as the train moves further away from the substation. The minimum track losses are when the train is at the substations because the resistance of the track is proportional to the displacement of the train from the substation, as described in Section 2.3.

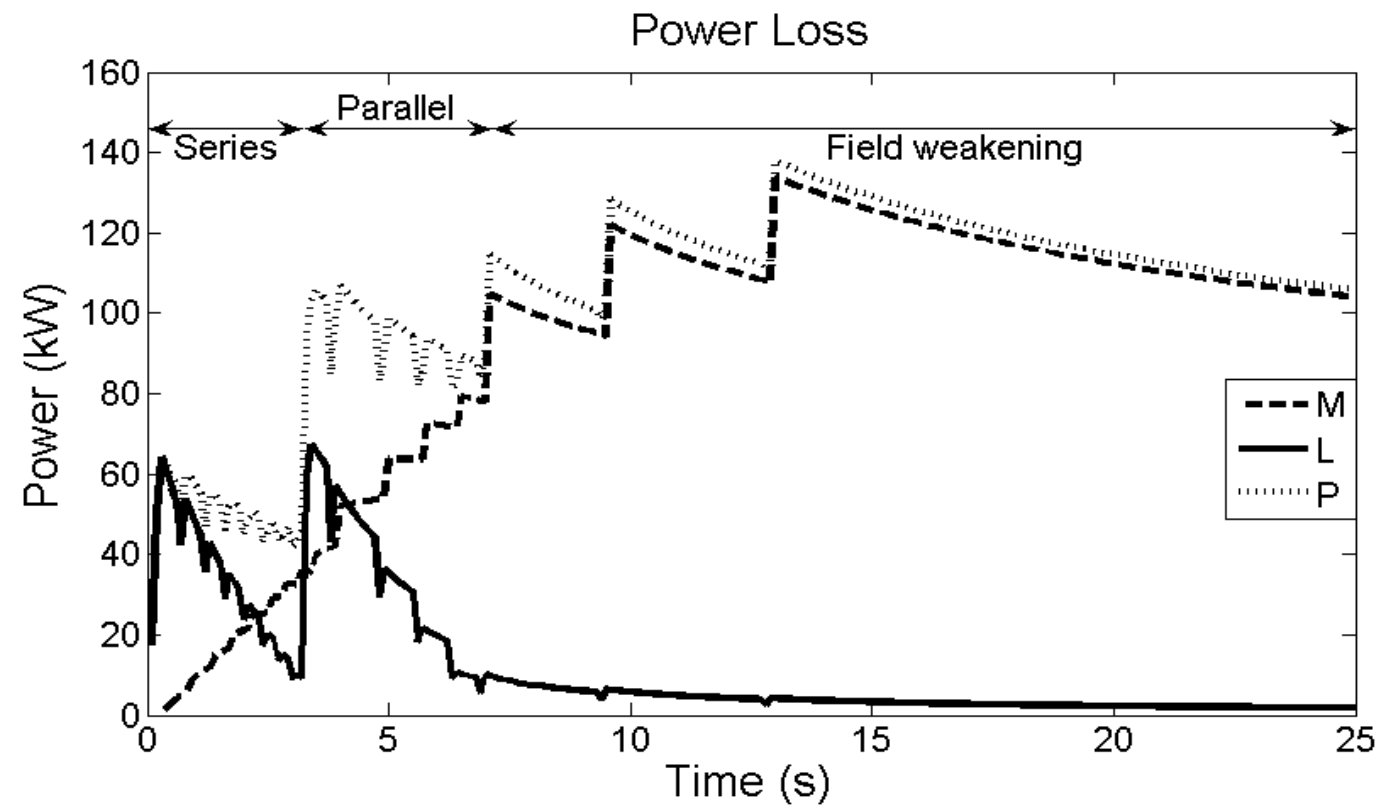

Figure 38: Simulated power loss versus time for $\mathrm{C507/8}$ with operating regions indicated, torque loss $M$, power controller loss $L$ and total power loss $P$

Losses in the train are within the traction equipment, as explained in Section 2.4.8 and illustrated in Figure 38, where $\mathrm{M}$ is the mechanical power, $\mathrm{L}$ is the starting power loss, and $\mathrm{P}$ is the power consumed. It is shown that $\mathrm{L}=\mathrm{P}-\mathrm{M}$. The mechanical power $(\tau \omega)$ increases logarithmically, because after the base speed the torque decreases at a rate proportional to $1 / \omega$ until the acceleration reaches zero, as described in Section 2.4. Starting resistors dissipate the power as heat as a product of $I_{\mathrm{a}}^{2} R$. This linearly decreases while approaching parallel and field-weakening regions because the resistors are sequentially turned off, at which point the energy efficiency is greater. This suggests that for this particular rolling stock using maximum tractive effort up to the speed limit 
would have greater energy efficiency because less energy is dissipated as heat. In addition, the speed limit is reached in a shorter time, thus the train would travel at constant speed earlier. In most cases between stations when the ratio of acceleration to constant speed is greater for constant speed, less energy is consumed.
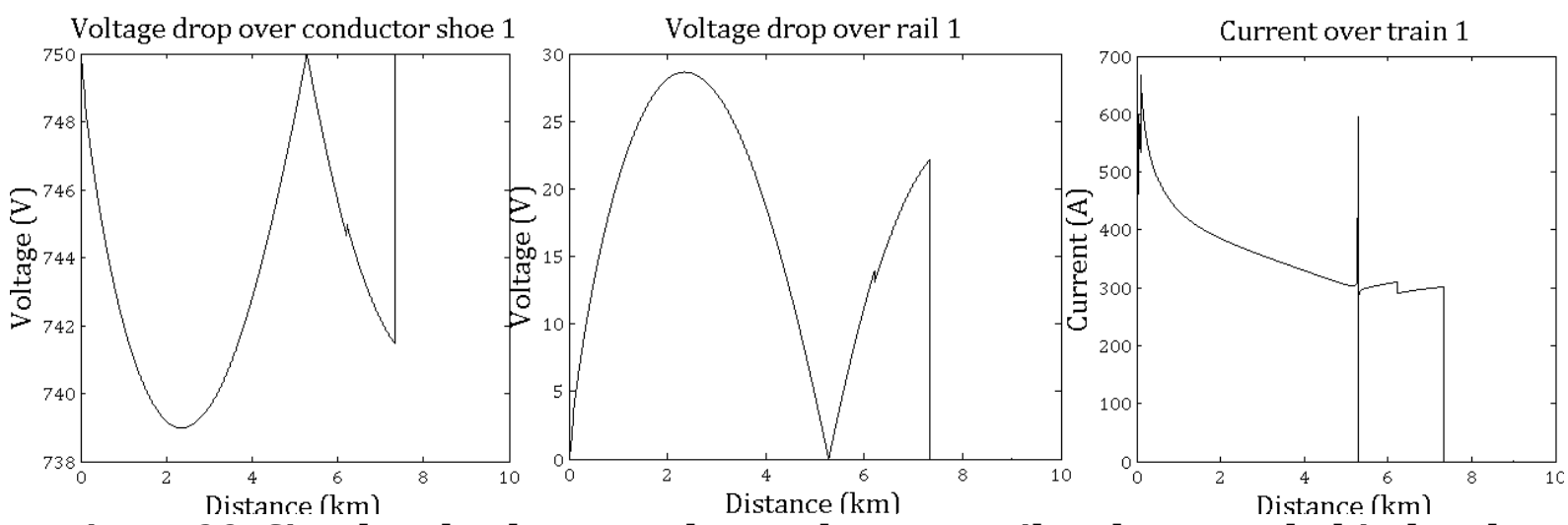

Figure 39: Simulated voltage on shoe, voltage on rail and current behind and before Train 1

In Figure 39 and Figure 40 a graphical output from the MERS of voltage and current on the conductors and rails between two substations is shown. This shows the voltage drop on the conductors and voltage rise on the rails. These are clearly below the $11 \%$ threshold, which is 575 to $900 \mathrm{~V}$ on the shoe. A decrease in the resistivity of the rails has the potential of decreasing the energy consumption of a railway network. Equation $<2-2>$ shows that an increased cross-sectional area, or the choice of a rail alloy with higher conductivity would decrease the resistance of the rails. 

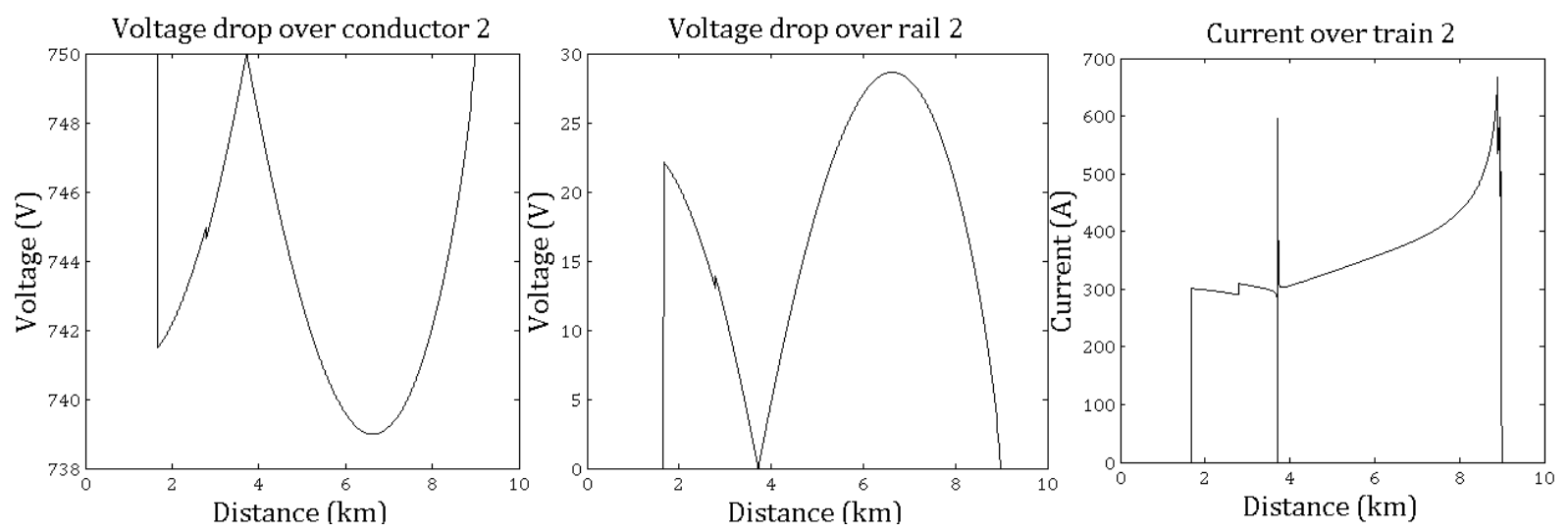

Figure 40: Simulated voltage on shoe, voltage on rail and current behind and before Train 2

The current mesh equations for the equivalent circuit shown in Figure 29 are bilinear quadratics. This means that the waveform will be an elliptical form as shown in Figure 39 and Figure 40. The currents of both trains have a spike when the train passes a substation. This is because the resistance of the conductors and rails equal zero, which gives an infinite current, but is limited by the program when an overloading current is sensed.

The total network energy consumption in a year is calculated and compared with the annual network consumption of Merseyrail in Section 5.5. In that section, there is a comparison of the simulated energy consumption of the flat-out case with the energy consumption when energy efficient schemes are implemented.

\subsection{Conclusion}

The STS is capable of calculating the energy consumption of single trains with different driver performances. Data extraction of line speed and geometry from Track Maps and Network Rail data and properties of the train from Marsden (2007) are necessary for the simulation of the Merseyrail route and C507/8. The route information for Merseyrail has been extracted from GEOGIS, GRADIX, and Track Maps. However, some parameters 
such as signalling and payload dynamics were unknown, which needed to be generalised or averaged. The effects of the generalisations on energy consumption were given explanations and reasons. For instance, it was assumed that operators would use standard procedures that minimised the effect on energy consumption. Some unknown parameters were not necessary to implement because of the assumption that Merseyrail's operating procedures would minimise the effect of those parameters. For example, trains are required to keep safe distances between each other. In addition, the timetable design allows continuous movement of all trains between stations. Therefore, when these two operating procedures are in effect, there will be a safe stopping distance for all trains in the event of an emergency.

The simulation specific to Merseyrail included a NPF model and a TEm model. The simulation program STS was used as a base for developing the MERS. The final program is a time-based simulation of $\mathrm{C507/8}$ operating over the entire Merseyrail network, with an asynchronous power flow calculation.

The equivalent circuit diagram for multiple trains travelling between substations had five current mesh equations. The movement of the train was characterised with dynamic resistances on the conductors and rail track. A section is the part of the network between two substations that are placed a maximum of $5.3 \mathrm{~km}$ apart. The simulation of the train travelling across the network required a vector that represented the distance of the substations, and the program calculates the power flow for each section. Since the mesh equations resulted in bilinear quadratics, it was shown that the power dissipation of the conductor and rails is elliptical, where the minimum is at the substation locations. 
The traction equipment includes eight series DC motors, which are controlled with a camshaft and rheostats. The data sheet from Merseyrail provided information on the values for the rheostats as well as graphs describing the tractive effort and speed. This information was extracted and used in equations, where the graphs were fitted using curve-fitting techniques to find equations and unknown parameters. The simulated results were in agreement with the original information, as well as other previously cited properties of the rolling stock, such as the maximum speed. Exclusions from the model include the effect of armature reaction, hysteresis, and eddy currents. However, the effect of these on the energy consumption is limited due to manufacturers using techniques to avoid them occurring, such as using inter-poles and compensation windings.

The speed control of the C507/8 DC motor is inefficient in the series and parallel regions of operation. This is because rheostats decrease the speed of the motor below the base speed by reducing the terminal voltage. The rheostats dissipate the energy as heat. It is more efficient to operate the motor just before and at the end of the parallel region, and in the field-weakening region. Retrofitting the traction equipment with a chopper speed control would further increase the efficiency of speed control. 


\section{VERIFICATION AND RELIABILITY OF THE MERSEYRAIL}

\section{SIMULATOR}

\subsection{Introduction}

Only a verified simulator should be used for development testing, otherwise the results cannot be considered to be reliable. Simulators are verified using a verification procedure with measurement data or other simulators. A verification procedure entails a comparison of results from two or more sources, which both represent the same phenomenon (McPherson 1990, Barlow 1996). A simulator estimates the results for a real world environment. Therefore, for verification purposes it is necessary to compare the results of the simulator with those from the measurement data. However, measurement data is not available for Merseyrail. Another simulator, Overhead Electrical System Loading (OSLO) is commonly used in industry and verified with measurement data. Therefore, a comparison of the MERS with OSLO is a suitable means of verification. As stated in the ATKINS report (ATKINS 2009), OSLO has been compared with measurement data and is within a limit of 10 to $15 \%$ of the results. The comparison of the MERS with OSLO and the Multi-train Simulator (MTS) will be judged according to the factors of power, operational time, voltage, and other programming characteristics. The Docklands Light Railway (DLR) route between Canning Town and Becton and B2K rolling stock is simulated for the verification test. In this chapter, the results from OSLO and the MTS are compared as a base case to determine how good the comparison is between the MERS and OSLO. In addition, the different programming methods are described and their similarities identified. 


\subsection{Docklands Light Railway Rolling Stock and Distribution Network}

The route between Canning Town and Beckton has eight stops and a variable speed limit between 30 and $80 \mathrm{kmh}^{-1}$, see Figure 41 . There are three substations near Canning Town, Custom House, and Gallions Reach and two parallel connections near Royal Albert and Beckton.

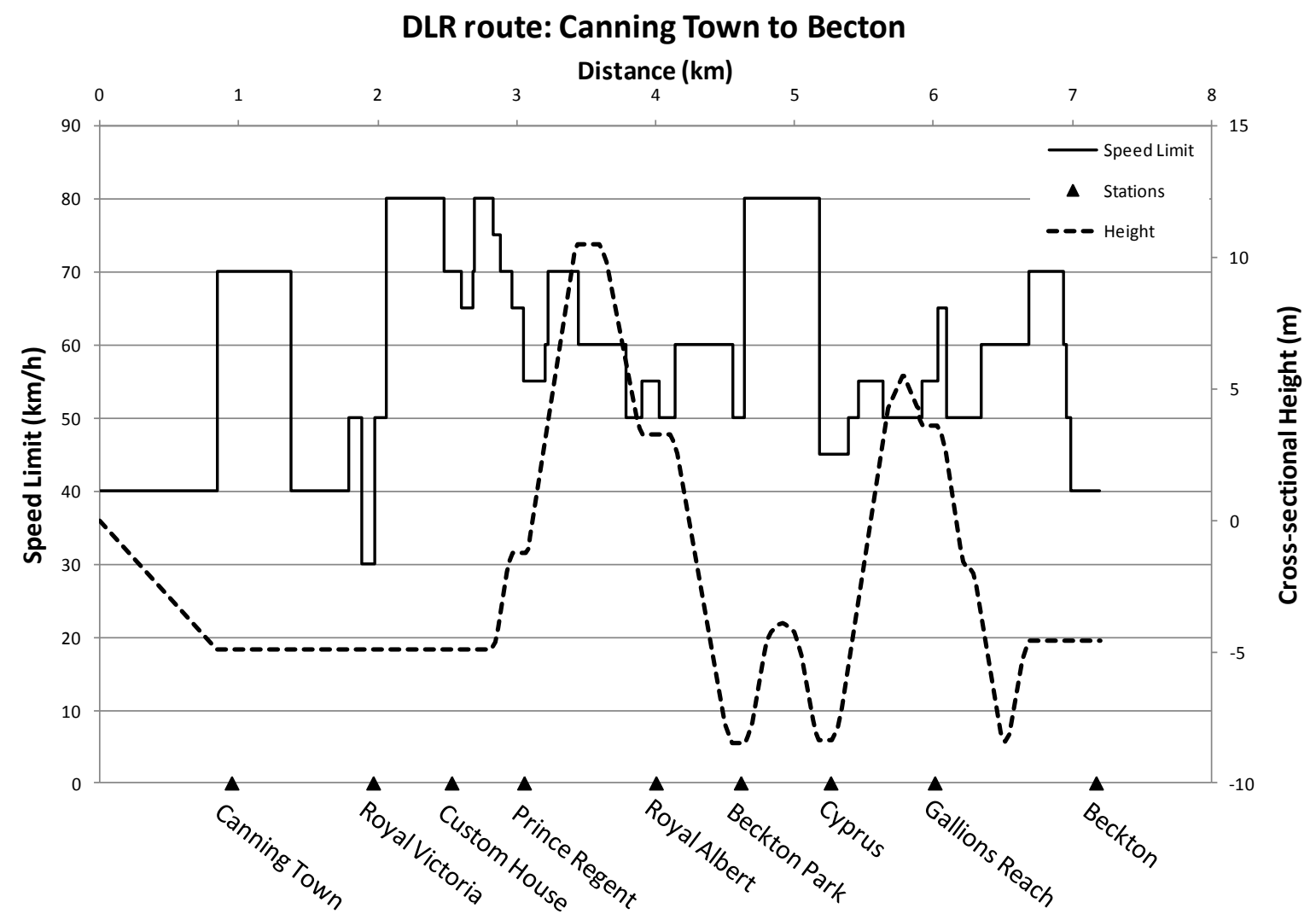

Figure 41: DLR route between Canning Town and Beckton showing the speed limit and cross-sectional height

The rolling stock of the Dockland Light Railway are either Class B90, B92 or B2K. The terminal voltage, power rating, conductor, and rail resistance including the properties of the rolling stock are detailed in Table 2 . 


\begin{tabular}{|c|c|}
\hline Parameter & Value \\
\hline Power Rating per car & $4 \times 280 \mathrm{~kW}$ \\
\hline Weight & $76 \mathrm{~T}$ \\
\hline Dimensions & $2 \times 28,2.65$ [height, width] $\mathrm{m}$ \\
\hline Capacity & $2 \times 284,2 \times 70$ seated \\
\hline Acceleration/ Deceleration & $1.3 / 1.3 \mathrm{~ms}^{-2}$ \\
\hline Conductor Resistance & $0.04 \Omega / \mathrm{km}$ \\
\hline Rail Resistance & $0.02 \Omega / \mathrm{km}$ \\
\hline $\mathrm{X}_{\mathrm{T}}$ & $2.4 \mathrm{~km}$ \\
\hline Supply Voltage & $750 \mathrm{~V}_{\mathrm{DC}}$ \\
\hline Maximum Speed & $80 \mathrm{~km} / \mathrm{h}$ \\
\hline Davis $(\mathrm{A}, \mathrm{B}, \mathrm{C})$ & $1.376,2 \times 10^{-2}, 6 \times 10^{-2}\left(\mathrm{~N}, \mathrm{Ns} / \mathrm{m}, \mathrm{Ns}^{2} / \mathrm{m}^{2}\right)$ \\
\hline
\end{tabular}

Table 2: Properties of distribution network and rolling stock of DLR

The motor is a DC brush-contact type motor that is controlled using a chopper, as described in Section 2.4.6. The operation of the train is automatic, which maintains a smooth constant speed and brakes precisely at the right distance. This automatic train operation (ATO) is a program that operates the train between stations, within a given timetable (Kemp 1987).

The ATKINS report specified that four cars are connected together and simulated over the route. This is similar to how the trains are operated on the real DLR network. This means that the total power rating will be $4 \times 280 \mathrm{~kW}$. The terminal voltage of each power substation was increased to $785 \mathrm{~V}$ to cope with the power demand. The weight of four cars including the payload increased the weight to 100 tonnes. MTS and OSLO had the same operational characteristics as described above.

\subsection{Simulators for the Docklands Light Railway Route}

The MERS, the Multi-train Simulator (MTS) and Overhead Electrical System Loading (OSLO) are three simulators that can simulate the DLR route between Canning Town and Beckton. The MTS has been developed by The University of Birmingham and OSLO has been used by ATKINS. All simulators are capable of estimating the operational time, 
power flow, and speed of trains over a large network. They were all programmed to simulate the DLR route and rolling stock, which were described in Section 4.2.

The given information to simulate the route includes track geometry, substation locations, power distribution network (length of conductor segments and resistance), and a voltage/ current look-up table. The verification test of a single train operating on the DLR route between Canning Town and Beckton required the extraction of data from the ATKINS (2009) report. This detailed information on track geometry, speed limits, substation locations, and rolling stock.

The MTS simulated operation of the train with a proportional controller and ATO, which would control the tractive effort to meet speed restrictions. This method of speed control means the ATO will keep the train at a constant speed by frequently accelerating and decelerating, depending on the speed of the train and the present speed limit.

OSLO also simulated a proportional controller and ATO to operate the train. However, OSLO programmed the train to slow down just before the speed limit, thus the train would travel at the speed limit until braking point. This method gives a smooth continuous tractive effort control and constant speed operation.

The MERS simulated the operation of the DLR train with five notch positions, which control the amount of torque that is used from the motor. While the train is accelerating up to the speed limit, the maximum tractive effort is used. Just before the speed limit is reached, the ATO frequently mediates between 20 different notch positions to keep the train below the speed limit. This is similar to MTS train operation, 
except the ATO of the MERS has a lower frequency of mediations between notch positions and always keeps the train below the limit.

The tractive effort for the rolling stock was calculated in the MTS and OSLO from a current and voltage look-up table. However, the MERS is unable to utilise the look-up table for modelling purposes. The DLR rolling stock utilises a chopper and ATO for speed control, which produces a smoother current output compared to the camshaftcontrolled rheostat. Therefore a simplified TEm model was used which had a notched speed controller and a highly accurate driver to mimic the characteristics of the ATO.

The MERS verification procedure had two unknown parameters. These were approximated with suitable values with a rail resistance of $0.02 \Omega \mathrm{km}^{-1}$ and a braking rate of $0.7 \mathrm{kN}$.

\subsection{Results}

The results of a verification test (ATKINS 2009) between the MERS and OSLO and the MTS and OSLO are summarised in Table 3. This test shows the difference for this particular DLR route, which verifies that the simulators agree with a small percentage difference on the train voltage, energy and running time. 


\begin{tabular}{|c|c|c|c|c|c|}
\hline Output & MTS & MERS & OSLO & $\begin{array}{c}\text { OSLO/MTS } \\
\text { Error (\%) }\end{array}$ & $\begin{array}{c}\text { OSLO/MERS } \\
\text { Error (\%) }\end{array}$ \\
\hline Average train voltage (V) & 769 & 771 & 769 & 0.0 & 0.3 \\
\hline Total train energy (kWh) & 98.1 & 96.6 & 96.7 & 1.3 & 0.3 \\
\hline Minimum train voltage (V) & 728 & 726 & 728 & 0.0 & -0.3 \\
\hline Run time to: & & & & & 1.1 \\
\hline Royal Victoria (s) & 91 & 92 & 91 & 0.0 & -2.0 \\
\hline Custom House (s) & 52 & 50 & 51 & 1.9 & 2.2 \\
\hline Prince Regent (s) & 45 & 46 & 45 & 0.0 & 0.0 \\
\hline Royal Albert (s) & 74 & 75 & 75 & -1.4 & -1.9 \\
\hline Beckon Park (s) & 54 & 53 & 54 & 0.0 & 1.9 \\
\hline Cyprus (s) & 52 & 53 & 52 & 0.0 & 0.0 \\
\hline Gallions Reach (s) & 68 & 66 & 66 & 2.9 & 1.1 \\
\hline Beckton (s) & 90 & 91 & 90 & 0.0 & 0.0 \\
\hline
\end{tabular}

Table 3: The results of the validation test for the train voltage, energy, and run time between MTS and OSLO, and MERS and OSLO

As shown in Table 3, the differences in percentage error between the results from the MTS and OSLO for the validation test over the DLR route are within a range of $+2.9 \%$ to $-1.4 \%$. For the same test variables, the differences between the MERS and OSLO are within a range of $+2.2 \%$ to $-2.0 \%$. Between Cyprus and Gallions Reach, the MTS simulation does not reach the speed limit as fast as in OSLO, which results in a $2 \mathrm{~s}$ increase in run time. In addition, between Prince Regent and Royal Albert the MTS simulates the operation of the train to exceed the speed limit, thus resulting in a $1 \mathrm{~s}$ decrease in time.

For the MERS there is a faster run time between Royal Victoria to Custom House, and Royal Albert to Beckton Park. There is a $1 \mathrm{~s}$ decrease in running time compared to the results from OSLO. The results from the MERS have a $1 \mathrm{~s}$ increase in running time between Custom House and Prince Regent, and $1 \mathrm{~s}$ between Beckton Park and Cyprus. 


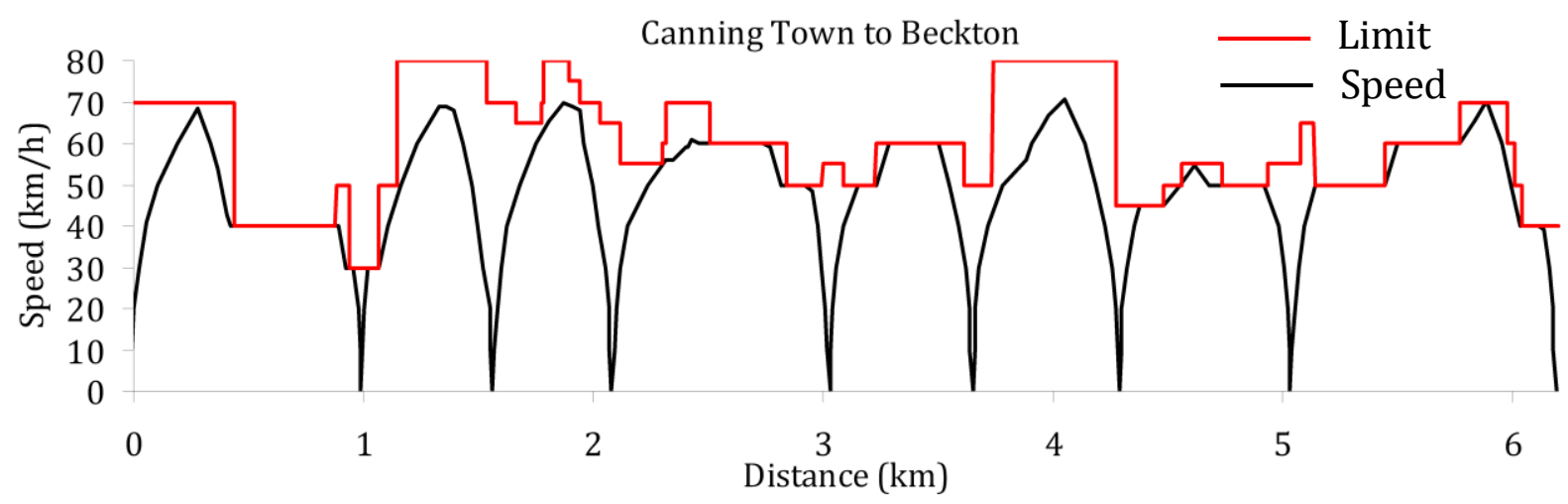

Figure 42: Speed-distance graph for OSLO between Canning Town and Beckton

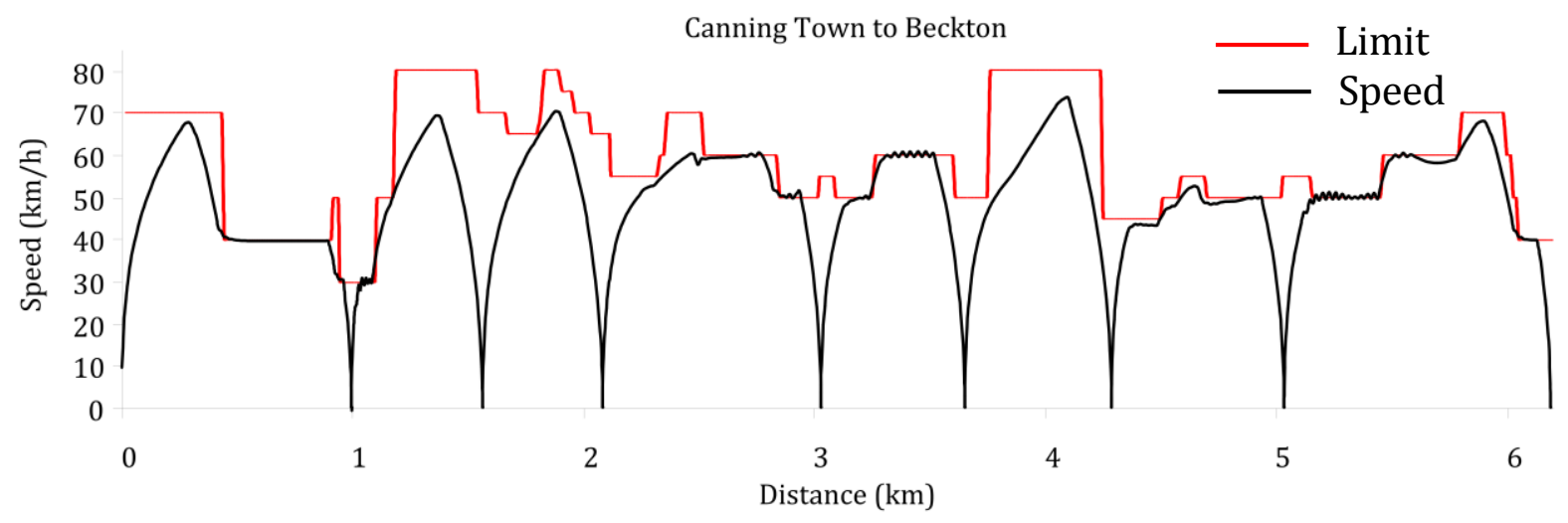

Figure 43: Speed-distance graph for MTS between Canning Town and Beckton

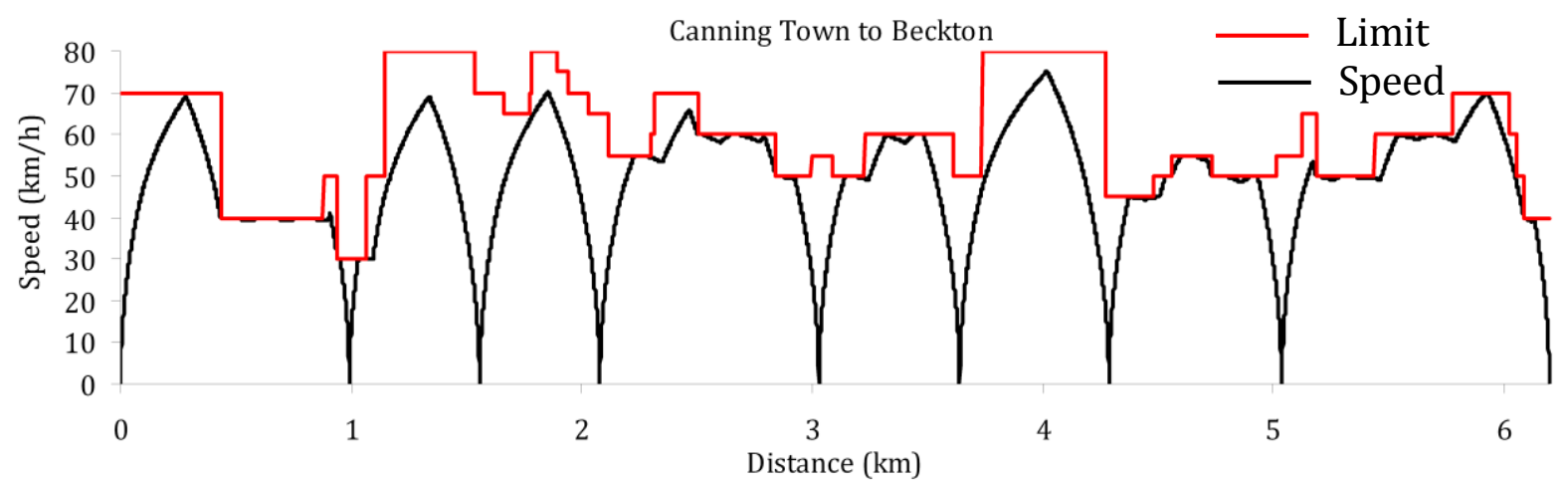

Figure 44: Speed-distance graph for MERS between Canning Town and Beckton

OSLO, the MTS, and the MERS output the speed-distance graph of their simulated DLR train, shown in Figure 42, Figure 43, and Figure 44 respectively. All simulators simulate the operation of the train with maximum acceleration from standstill and brake in time for the stations. The effect of a gradient change is similar for all simulations, where there is a relative change in acceleration for an incline or decline. There are, however, differences in the results when the train travels at constant speed. OSLO simulates the 
train to have a constant speed when it reaches the speed limit. In the MTS, when the speed limit is reached, the simulated ATO frequently mediates between the tractive effort positions to keep the speed of the train around the speed limit. However, as can be seen, this makes the train exceed the speed limit several times, but only for a short duration. In the MERS, the operation of the train is simulated to keep the speed of the train below or equal to the speed limit. This is shown when the speed of the train decreases after it reaches the speed limit. This difference occurs because the current and voltage look-up table was not integrated into the MERS. This results in the acceleration of the train decreasing more at higher speeds compared to OSLO and the MTS.

The MERS, the MTS, and OSLO have differences between each method of train operation. The constant speed operation is smooth for OSLO, unlike the speed profile from the MTS, which increases and decreases frequently around the speed limit, while that of the MERS is similar to the MTS, although the speed limit is never exceeded. This results in some journeys from the MERS being slower than the MTS and OSLO because it has a speed that is less than the speed limit. 


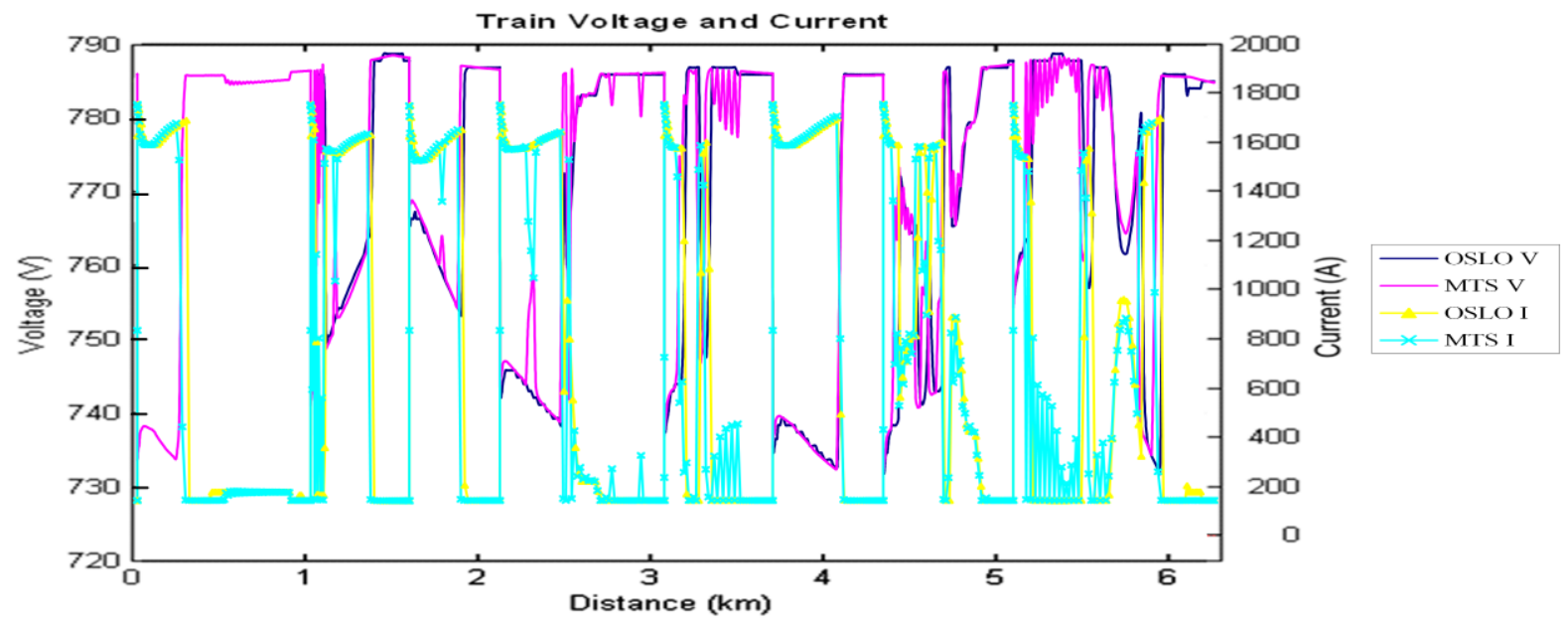

Figure 45: Train Voltage and Current for MTS and OSLO between Canning Town and Beckton

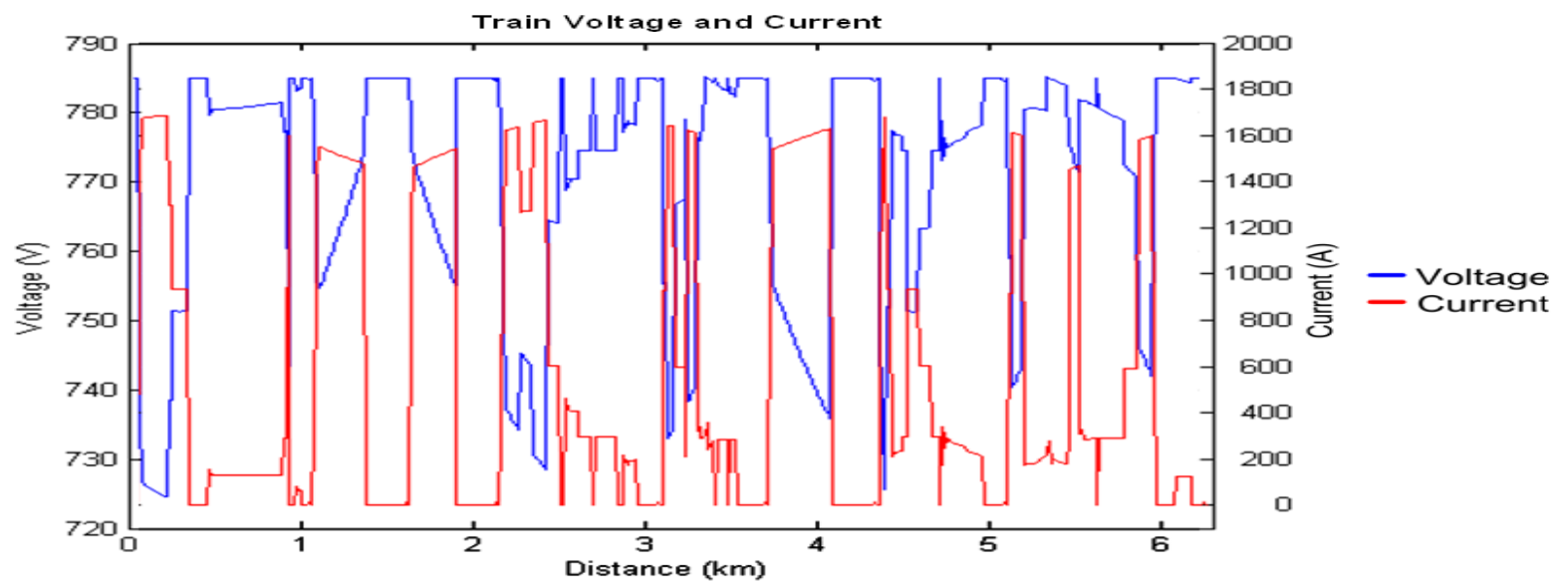

Figure 46: Train Voltage and Current for MERS between Canning Town and Beckton

During acceleration, the traction equipment will drop a voltage and have a current flowing in the DC motor, as shown in Figure 45 and Figure 46 . When the traction equipment is idle (during braking) $150 \mathrm{~A}$ flows through the train. The MTS and OSLO were supplied with a current and voltage look-up table, which specifies the voltage and current magnitudes for a demanded tractive effort. Hence the waveforms are almost equal, with the exception at $2.2 \mathrm{~km}$, where the MTS brakes for the $60 \mathrm{kmh}^{-1}$ speed limit but OSLO travels at constant speed, see Figure 42 and Figure 43 . The train voltage and current from the MERS varies from 725 to $785 \mathrm{~V}$ and from 0 to $1700 \mathrm{~A}$. The range of current is different compared to OSLO because the MERS does not use the current and 
voltage look-up table and did not simulate the auxiliary load. After biasing the current waveform in Figure 46 by $150 \mathrm{~A}$, the comparison between OSLO and the MERS has similarities in magnitude and frequency.

\subsection{Discussion}

OSLO had been used in industry by ATKINS, and ATKINS reported it to show agreement with their measured data within $\pm 15 \%$. This percentage difference is the maximum percent difference for all test variables, such as run time and energy consumption.

The verification of the MERS is best when done with real measurement data. However, this is somewhat difficult to achieve, since measurement data is unavailable. If the MERS is compared with a simulator that has been verified using measurement data, then the MERS shares that verification.

The comparison of the MERS and measurement data from the Merseyrail network would enable a verification test. Since this is unavailable, it is considered as possible further work. This would allow more parameters to be compared, such as the energy loss in the traction equipment.

\subsection{Conclusion}

The comparison between the MERS and OSLO are closer to the validation test between OSLO and the MTS. The results of run times, energy consumption, and train voltage were compared with identification of the maximum percentage difference between the results, and a breakdown of the differences and how they related to the graphs from the simulation test. 
The percentage difference was less between the MERS and OSLO and it had the same total run time. Considering running times, energy consumption and train voltage the MERS has greater agreement with OSLO compared to the MTS, however the rail resistance and braking rate were unknown variables and were approximated with suitable values. However, there is greater difference in the current and voltage graphs. 


\section{SIMULATION AND RESULTS OF ENERGY EFFICIENCY}

\section{SCHEMES}

\subsection{Introduction}

The purpose of the MERS is to provide a test bed for evaluating the effectiveness of energy efficiency initiatives on the Merseyrail power network. ERRAC and CCC have set energy efficiency improvement targets and environmentally friendly guidelines. ERRAC requires a 50\% improvement in energy efficiency between 2001 and 2020 from European railways and $\mathrm{CCC}$ set an objective of a $42 \%$ reduction in $\mathrm{CO}_{2}$ and other pollutant gases between 1990 and 2020 for UK railways. An operating commuter railway requires enough energy to transport passengers safely between stations within the constraints of the timetable. Some operators have traction equipment capable of regenerating electric energy, which reduces the energy consumption of their networks. The energy efficiency $(\eta)$ of a railway power network in general is given by Equation $<5-1>$ :

$$
\eta=\frac{W_{\mathrm{a}}+W_{\mathrm{P}}-W_{\mathrm{R}}}{\mathrm{W}_{\mathrm{S}}} \times 100 \%
$$

where $W_{\mathrm{a}}$ is the energy to accelerate the train, $W_{\mathrm{p}}$ is the energy of the passenger facilities, $W_{\mathrm{R}}$ is the energy of regeneration, and $W_{\mathrm{S}}$ is the energy from the substations.

There are several sources of energy loss in the system. Such sources include the resistance of the conductors, geometric track layout and driving technique. These 
energy losses result in both major energy expenditure and $\mathrm{CO}_{2}$ emissions for the railway industry.

Regeneration, coasting points and improving the performance of drivers are three energy efficiency schemes. The MERS evaluates their potential contribution in reducing the energy consumption of Merseyrail. However, the optimal solution is likely to be a combination of these three schemes.

\subsection{Retrofit Traction Equipment}

Traditionally, DC electric trains are braked using friction disc brakes or regenerative braking. Both methods commonly dissipate the braking energy as heat (see Section 2.5.3). However, regenerative braking energy can be reused if the train has a DCDC converter (see Section 2.4.6). For the C507/8 a buck converter would be suitable to replace the series rheostat for speed control, thus the entire series and parallel regions of speed operation would have an energy efficiency improvement.

The terminals of the chopper can connect to an on-board storage device, such as a battery (Hillmansen 2006), as shown in Section 2.4.6. A battery can power the train while at slow speed for a short duration because it can store high power but has limited energy (Wen 2007). It could reduce the energy consumption by using it to power the train during initial acceleration. Once the power from the battery has been expended, the DC motors can be switched on to power the train. However, the extra weight of the battery decreases the rate of acceleration. This slightly decreases the potential to improve energy efficiency because the weight of the battery increases the energy consumption by about $2 \%$. The battery can, however, store about $40 \%$ of the energy 
during braking and improve energy efficiency by eliminating the use of the rheostat speed controller during start-up.

Alternatively, the DC-DC converter could be used to transmit the regenerated electricity down the conductors and back into the power grid via inverting substations or wayside energy storage systems (ESS) (Fletcher 1991). An ESS receives, temporarily stores and re-transmits the energy from one train to another. The ESS could have the storage capabilities of a battery, ultra capacitor, or a flywheel (Sandia National Laboratories 2003). Compared to onboard storage the ESS has the advantage of a greater storage capacity. This system is beneficial because there is no extra weight as is evident in the case of using onboard batteries. However, some of the regenerated energy is dissipated in the conductors. This dissipation can be reduced by positioning the ESS in positions where the trains are most likely to brake and to accelerate, such as at stations.

To resupply into the power grid as shown in Riberiro (2001), the substations have to be retrofitted with a rectifier/inverter and as explained in Davis (2005), with bidirectional circuit breakers. The power conditioning of the electricity re-supplied into the power grid is essential. The DC chopper adds harmonics because of high-frequency switching that distorts the power quality and will affect other utilities directly connected to the power grid, see Section 2.4.6. Using LC or active filters at the substation reduces the total harmonic distortions and improves the power factor.

As Liu (2007) shows, the energy dissipated on the conductors can be minimised when the voltage is increased. These are a few design restraints that are mandatory for implementing off-board regeneration. To implement off-board regeneration many factors are still needed to be addressed in terms of practicality and cost. Implementing 
an ESS has less requirement for power quality, however, resupplying into the power grid has the advantage of having an increased quantity of recuperation.

Using regenerative braking is more useful for journeys with regular stops, such as on a commuter railway. For onboard storage this is because the duty-ratio between each recharge is small and for off-board because the receptivity is high. Açikbas (2007) and many other research projects identify that the recuperation rate of regeneration is $40 \%$. In this scenario a C507/8 that is rated at $656 \mathrm{~kW}$, and is travelling at $70 \mathrm{kmh}^{-1}$ taking $50 \mathrm{~s}$ to stop, using a constant deceleration will get $3.64 \mathrm{kWh}$ (see Equation $<5-2>$ ). This can be stored with 36 Maxwell (BMOD0063-P125-B21) Ultracapacitors, each having $102 \mathrm{Wh}$ of available energy, and would require 36 modules in total weighing 2 tonnes, taking up $4.7 \mathrm{~m}^{3}$ of space.

$$
656 \times 10^{3} \times 40 \% \times\left(\frac{50}{3600}\right)=3.64 \mathrm{kWh}
$$

\subsection{Coasting Points}

When a train is coasting, there is no tractive effort (pulling force) from the motor or brake. There will be acceleration when travelling on a negative gradient and deceleration on a positive gradient. There would also be deceleration from the friction of the drive train and resistance to motion (Wong 2004). When the train is operating flatout, it takes the minimum amount of time to travel between stations. Upon arriving at the station, there is an operator defined dwell time that allows passengers to board and disembark. The operating timetable is designed to be suitable for passengers, the timetable limits the available time a train has to travel between stations. Rus (2007) identified that passengers prefer a fast journey. This indicates that a suitable time 
allowance should be determined when considering coasting points. For instance, between Liverpool Central and Liverpool Lime Street there is a scheduled run time of $1 \mathrm{~min} 30 \mathrm{~s}$ and a $30 \mathrm{~s}$ dwell time. A coasting allowance of $10 \%$ of the total time is $12 \mathrm{~s}$, which could be accounted for by decreasing the dwell time to $18 \mathrm{~s}$.

The inclusion of a coasting allowance in the timetable defines the range of available positions for allocating a coasting point. The coasting allowance is limited by the required time for a journey between stations. The greater the coasting allowance, the smaller will be the energy consumption (Bocharnikov 2007). Several coasting algorithms can determine the coasting point with a trade-off between time and energy. The algorithm finds the solution after iterations within the solution space, where the first solution is midway between stations (Wong 2004).

The four regions for operating a train are acceleration, constant speed, coasting, and braking. The first and last region cannot be changed because of passenger comfort requirements and the force required to overcome the moment of inertia (Wong 2004). The calculation of a coasting point is within the second and third regions because these are not necessary for the train to complete its journey (Bocharnikov 2007).

Coasting algorithms have two categories, single and multi-dimensional. A singledimensional finds one coasting point, which is useful for short routes. A multidimensional finds multiple coasting points, which is feasible for longer routes because after the first coasting point, more energy may be required to accelerate back up to the line speed. The most used searching algorithms are Fibonacci, Genetic Algorithms, Golden, Gradient, and Nelder \& Mead. Wong (2004) compared these for short and long 
routes, which found Gradient as having the least amount of iterations to find a single coasting point, but required further information on the gradient of the track.

Other research projects have identified methods for finding the ideal coasting point in terms of energy-time and number of iterations. However, they did not assess the effect of coasting on the recuperation of braking energy. This thesis shows how the use of coasting points affects the proficiency of regeneration.

\subsection{Driver Performance}

A driver will accelerate the train until it has reached the maximum permissible speed set by the operator. The traction equipment and the driver limit the rate of acceleration. Generally, using maximum acceleration will consume less energy than using a slower rate (Schmid 2007). An experienced driver should know the route well enough to determine gradient changes. The appropriate use of tractive effort to counter the gradient changes could further improve energy efficiency. For instance, a train accelerating up to the speed limit with a gradient change to negative will have an increase of acceleration due to gravity. The driver should decrease the tractive effort to avoid exceeding the speed limit, which improves energy efficiency. The adverse scenario is that the driver could behave inappropriately (i.e. breaking the speed limit) and prompt traffic congestion, hence increasing the energy consumption (Dorrian 2006, Dorrian 2007). Dorrian (2007) identified that fatigued drivers consume more energy because they do not use full traction at departure, break the speed limit, will not regularly use dynamic brakes, and use the disc brake excessively. Dorrian (2006) found that a driver who is highly fatigued will increase the energy consumption by $9 \%$. 
Training programmes and driver advisory equipment could make further improvements to the performance of the driver. These should be able to identify gradient changes and the appropriate tractive effort.

The train driver has varying levels of performance depending on cognitive ability, agility and quality of training. There has been a lack of research into how much the performance of the driver affects the proficiency of using a coasting point and regenerative braking. This thesis simulates the performance of the driver with a variation of the driver's efficient operation, while testing energy efficient schemes. It is hypothesised that the three schemes can be implemented on the Merseyrail network to improve energy efficiency by $50 \%$ or greater.

\subsection{Simulation Results and Analysis}

The energy efficient schemes are tested individually and in collaboration as regards their proficiency in improving the energy efficiency of Merseyrail. The results of the simulator were compared between the total network energy consumption and the operational time throughout the Merseyrail network.

There are 67 stations in total on the Merseyrail network and seven routes where trains travel in opposite directions, see Figure 47. All routes are simulated according to the timetable. For instance, the route Chester-Liverpool Central has 18 stations and goes underground between James St. and Hamilton Square. 


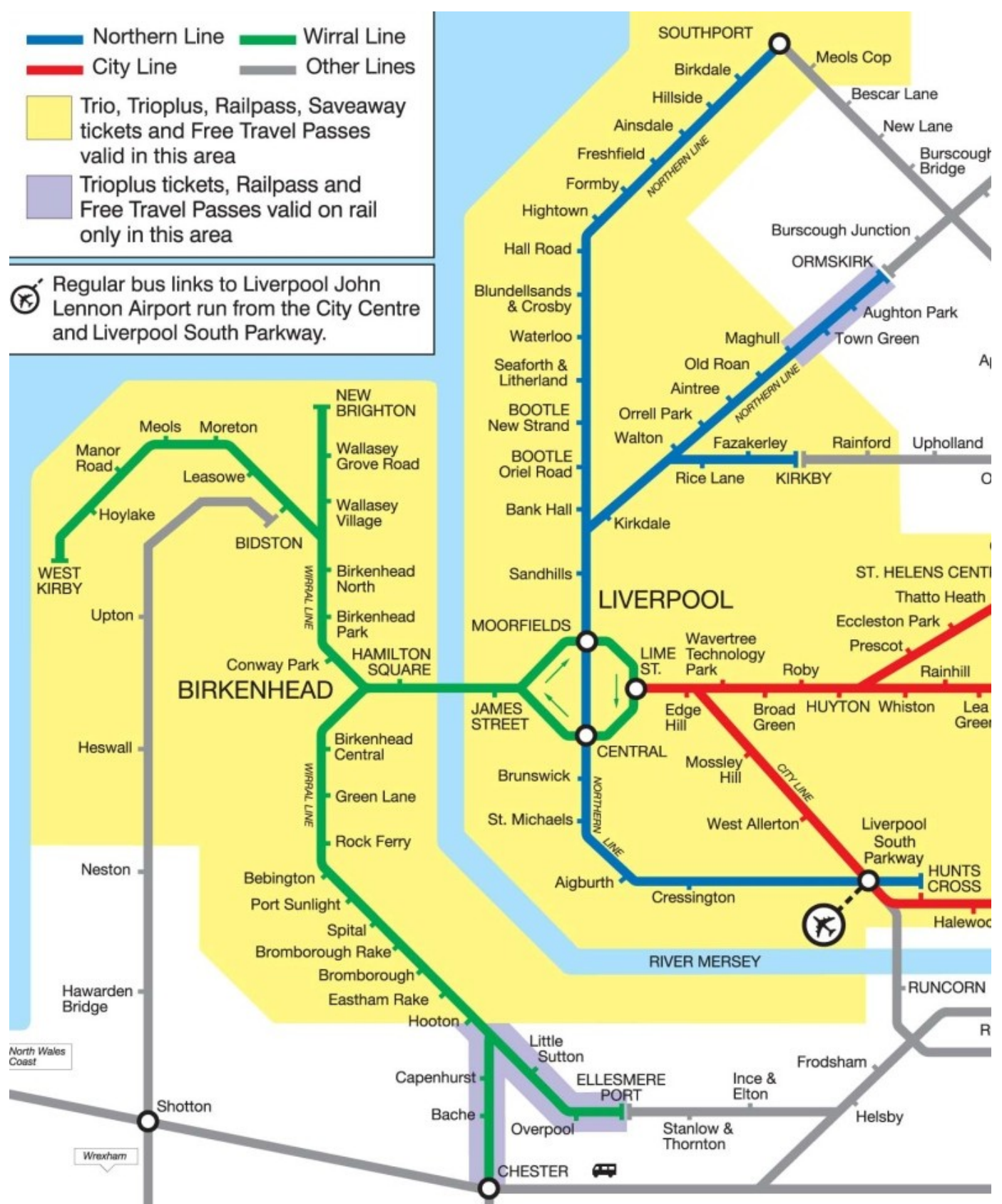

Figure 47: Merseyrail route map showing the Wirral and Northern lines including other routes not operated by Merseyrail (Merseytravel 2005)

Figure 48 shows the simulated route from Chester to Liverpool Central, where Chester is at the start and Central is at the end. The other routes are simulated for each branch of the network, which the results are shown in APPENDIX C. For the Chester to Liverpool Central route, the $\mathrm{C} 507 / 8$ took 44 minutes to complete the journey, the same duration is that shown in the Merseytravel timetable. The acceleration is the same rate as described 
in the data sheet TMT310, which decreases when in the weak field region. The braking power is a constant power, resulting in a deceleration that increases proportionally to speed. At maximum acceleration, the train uses a maximum of $656 \mathrm{~kW}$, which is the rated power of the DC motor. When the train is travelling at constant speed on a flat section of track, the traction equipment uses a constant power of $110 \mathrm{~kW}$ to travel at $96 \mathrm{kmh}^{-1}$. This differs when the gradient changes, as can be seen between $2.5-2.9 \mathrm{~km}$ and $34-37 \mathrm{~s}$. Here the power used decreases to $14 \mathrm{~kW}$, where the train travels at $72 \mathrm{~km}^{-1}$.
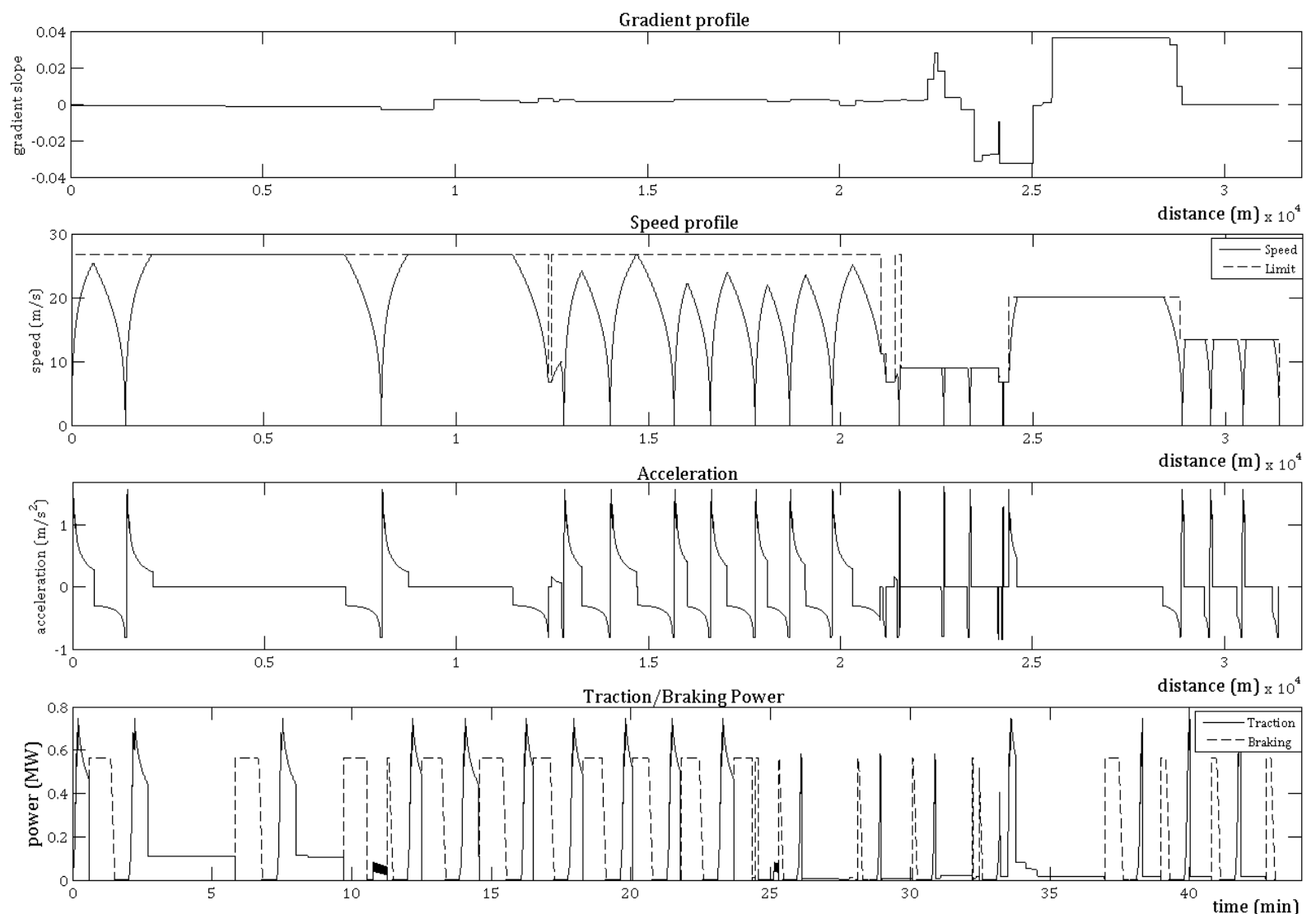

Figure 48: The MERS simulating one train from Chester to Liverpool Central

The total network energy consumption in a year is calculated with inputs of the average power and average operating time of two trains travelling in opposite directions. The product of these two inputs gives the output of the energy consumption of each train. 
The Merseytravel timetable shows the operating time between stations for each route, and the total operating time for each route is shown in Table 4.

\begin{tabular}{l|c}
\multicolumn{1}{c|}{ Route Totals for All Directions } & Weekly Operating Time (hrs) \\
\hline Chester to Liverpool Central & 411 \\
\hline Southport to Hunts Cross & 961 \\
\hline New Brighton to Liverpool Central & 320 \\
\hline Kirkby to Liverpool Central & 237 \\
\hline West Kirby to Liverpool Central & 351 \\
\hline Omskirk to Liverpool Central & 407 \\
\hline Ellesmere to Liverpool Central & 411
\end{tabular}

Table 4: The routes from the Merseytravel Timetable and the calculated operational time for all directions

The MERS outputs the power and time for the routes listed in Table 4 . This is the calculation of the energy consumption by simulating all the routes with two trains travelling in opposite directions. The power used by each train at a particular distance is input into the NPF model, which calculates the energy consumption between each substation over the Merseyrail power network. The energy consumption of two trains for each route is shown in Table 5.

\begin{tabular}{l|c}
\multicolumn{1}{c|}{ Route Totals for All Directions } & Energy Consumption (kWh) \\
\hline Chester to Liverpool Central & 192 \\
\hline Southport to Hunts Cross & 320 \\
\hline New Brighton to Liverpool Central & 68.1 \\
\hline Kirkby to Liverpool Central & 86.2 \\
\hline West Kirby to Liverpool Central & 177 \\
\hline Omskirk to Liverpool Central & 156 \\
\hline Ellesmere to Liverpool Central & 176
\end{tabular}

Table 5: The MERS calculated energy consumption for all routes on the Merseyrail network

The product of the weekly operating time and the energy consumption gives the weekly energy consumption for that route, see Table 6. The sum of the weekly energy 
consumption for all routes, multiplied by 52 weeks in a year gives the yearly energy consumption.

\begin{tabular}{l|c}
\multicolumn{1}{c|}{ Route Totals for All Directions } & Energy Consumption (MWh) \\
\hline Chester to Liverpool Central & 79 \\
\hline Southport to Hunts Cross & 307 \\
\hline New Brighton to Liverpool Central & 22 \\
\hline Kirkby to Liverpool Central & 20 \\
\hline West Kirby to Liverpool Central & 62 \\
\hline Omskirk to Liverpool Central & 63 \\
\hline Ellesmere to Liverpool Central & 72 \\
\hline Total Weekly Energy Consumption & 626
\end{tabular}

Table 6: The MERS calculated weekly energy consumption for all routes on the Merseyrail network

During 2006-2007, Network Rail reported that Merseyrail consumed 53 million $\mathrm{kWh} /$ year for all their facilities from the lighting and heating of stations to the power used by the traction equipment. The MERS should calculate the total energy consumption less than 53 million kWh/year. The MERS calculated 33 million kWh/year, with no passengers. There is a difference of $39 \%$ between the two results, which may relate to the fact that the MERS does not consider the auxiliary load and dynamics such as weather conditions, amount of passengers $(0-8 \%)$, delays, losses in the substation and earth current leakage $(0-3 \%)$. The substation locations in the simulator are distributed at the maximum displacement (see Section 3.5.3).

The actual substation distribution is not constant and may have shorter separations. This would increase the annual energy consumption because the substations would be supplying more power to the trains, however, there would be a decrease in energy consumption because less energy is lost on the conductors and rails. With a substation distribution at half of the maximum $(2.64 \mathrm{~km})$, the flat-out annual energy consumption decreased by $1 \%$. 
The simulated energy consumption used drivers that operate the trains flat-out, which is different compared to how Merseyrail drivers would operate the trains. The flat-out driving style is the operation of the train with maximum tractive effort until a speed limit, where the train travels at constant speed until the speed limit changes or the train is required to brake for the next station. On Merseyrail, the driver might consume more power by exceeding the speed limit or by using a slower rate of acceleration. Alternatively, the driver might decrease energy consumption by keeping the speed of the train below the speed limit, similar to the proportional, and proportional and notched driving styles of the MERS.

Over a year, the weather conditions and payload dynamics affect the average power of the train. The simulator assumes no effect from these variables and the energy deviation can be seen from the comparison of annual consumption data and simulation results. Therefore, to exclude the deviation, the efficiency improvement and difference in time, the schemes are compared with the simulated flat-out case. 


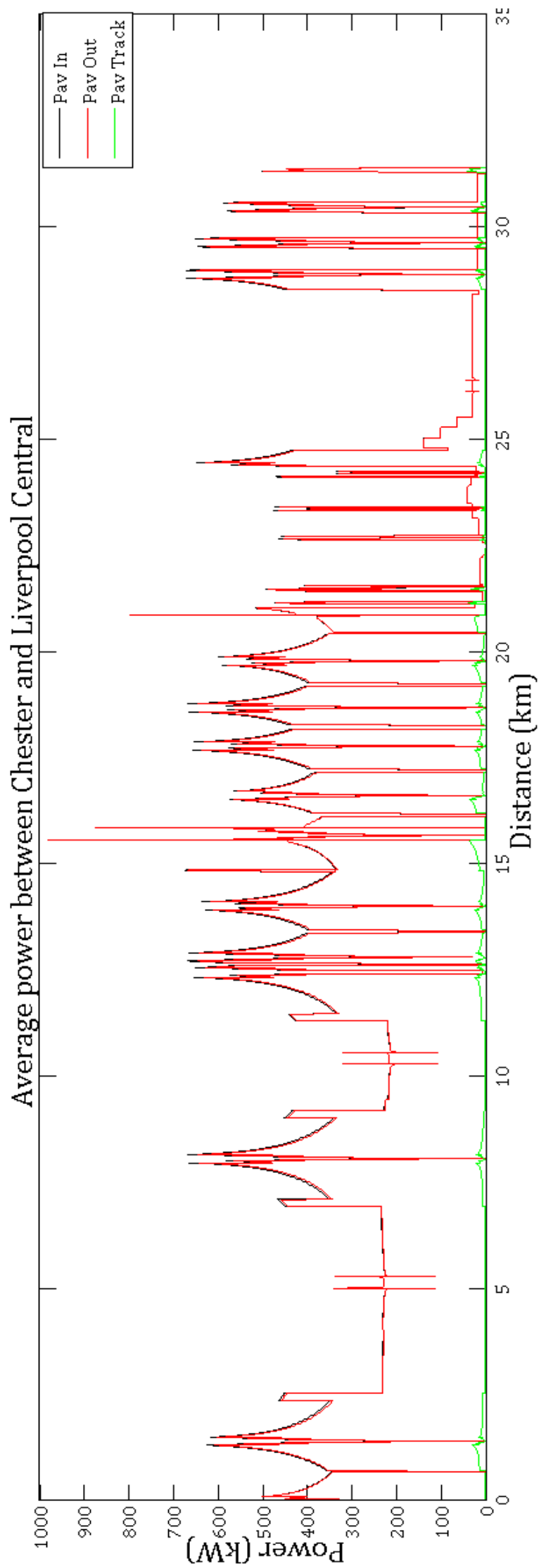

Figure 49: The average power of $\mathrm{C507/8}$ trains with a driving style of flat-out travelling between Chester and Liverpool Central 
The flat-out case simulates the shortest possible time for the train to complete its journey. Merseyrail drivers attempt to drive flat-out, however for each driver there will be a different level of performance. This may affect energy consumption because the train could be operated with a decreased acceleration rate or the speed limit could be exceeded. The simulated flat-out case is the C507/8 with a camshaft and rheostat controlling the DC motors, where all trains have an unladen weight and trains travel in all directions that have been specified according to the timetable. As shown in Table 7, the flat-out case has a difference of $39 \%$ compared to the recorded energy consumption by Network Rail between 2004 and 2005 . The energy consumption and running time of the flat-out case will be used to compare with the other simulation results because these are comparable.

Flat-out

\begin{tabular}{lr}
\hline Total running time for one run over all routes (hours) & 15.67 \\
\hline Total Energy $\left(\times 10^{6} \mathrm{kWh} /\right.$ year $)$ & 32.57 \\
\hline Energy consumption of Merseyrail $(2004-2005)\left(\times 10^{6} \mathrm{kWh} /\right.$ year $)$ & 53.00 \\
\hline Difference $(\%)$ & 38.54
\end{tabular}

Table 7: Flat-out case scenario for a $\mathrm{C507/8}$ operating over the Merseyrail network

When the train is fully loaded, the energy consumption will increase. The C507/8 has a notching current that changes depending on the load. It increases to $408 \mathrm{~A}$ when it is fully loaded. The MERS has simulated the increase in weight of 14.43 tonnes with a notching current of $408 \mathrm{~A}$, which is displayed in Table 8. When all the trains are fully loaded on the Merseyrail network there is a $10 \%$ increase in energy consumption and the average time of all trains travelling between stations increases by $2 \mathrm{~s}$. In reality, the trains would rarely be fully loaded or unladen. Most likely, the train would be loaded with about half of the fully laden weight. This could be represented in detail with 
information on the amount of ticket sales per hour to determine the passenger densities each hour.

\section{Full Load C507/8}

\begin{tabular}{lr}
\hline Average time increase per interstation $(\mathrm{s})$ & 2.07 \\
\hline Total Energy $\left(\times 10^{6} \mathrm{kWh} /\right.$ year $)$ & 35.79 \\
\hline Energy Efficiency Increase (\%) & -9.87
\end{tabular}

Table 8: Results of MERS for fully loaded C507/8

Figure 50 shows the average power when the $C 507 / 8$ is operated in the proportional driving style. This is between Chester and Liverpool, which is one of the seven routes simulated in the MERS. The train driver operates the train with a slight variation when compared to the flat-out case. For instance, between 3 and $6 \mathrm{~km}$ the driver operates the train at a constant speed. The driver gradually decreases the amount of tractive effort, which is shown from $2.5 \mathrm{~km}$ with the power decreasing from $400 \mathrm{~kW}$ to $150 \mathrm{~kW}$. In the case scenario Driver (prop), the driver has absolute control over the tractive effort. As the train approaches the speed limit, the driver reduces the tractive effort and keeps underneath the speed limit. This results in a $5 \mathrm{~s}$ increase to the operational time of a train travelling between stations, however this method of driving is beneficial because it saves 1.6 million kWh of energy per year when compared to the flat-out case, see Table 9. 


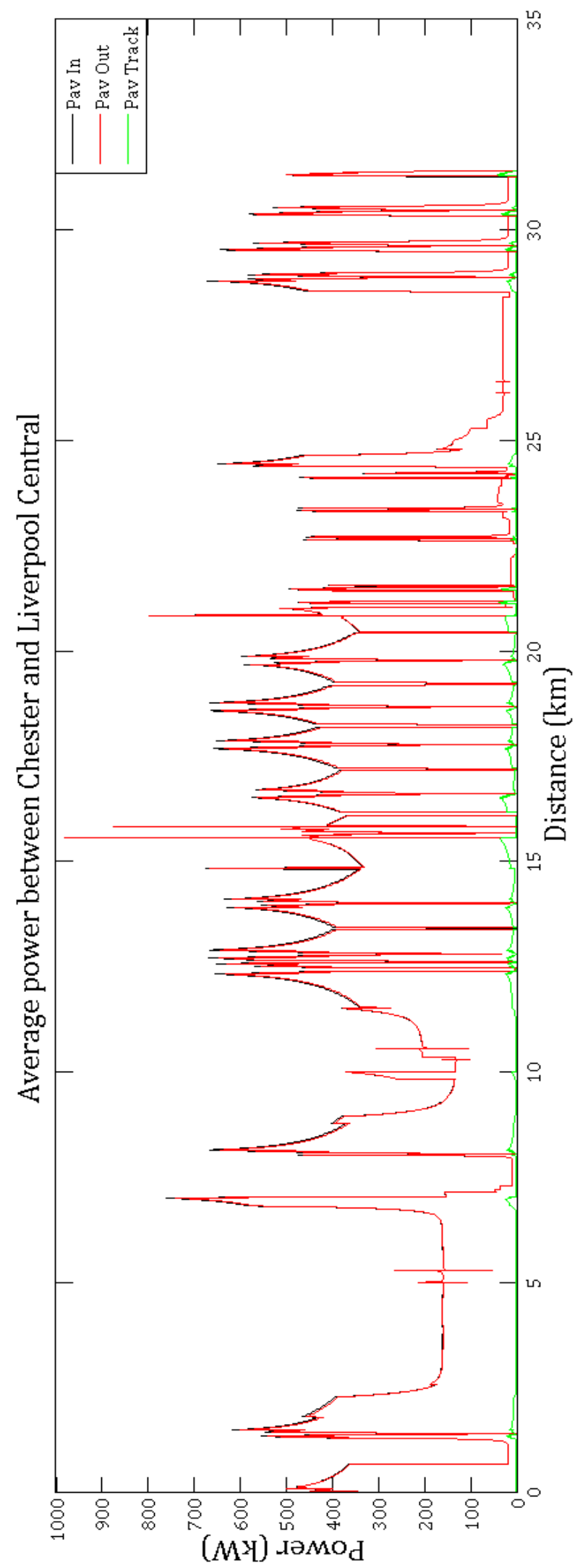

Figure 50: The MERS result between Chester and Liverpool Central of the average power from C507/8 trains operated in the proportional driving style "Driver (prop)" 
Driver (prop) C507/8

\begin{tabular}{lr}
\hline Average time increase per interstation (s) & 4.61 \\
\hline Total Energy $\left(\times 10^{6} \mathrm{kWh} /\right.$ year $)$ & 30.94 \\
\hline Energy Efficiency Increase (\%) & 5.02
\end{tabular}

Table 9: Proportional driving style case scenario for $\mathrm{C507/8}$

The case scenario Driver (prop notched), simulates the operation of the train by the driver with five tractive effort positions, which are evenly distributed between the minimum and maximum tractive effort. C507/8 trains have five tractive effort positions; these are the same as described in information from Merseyrail (see Section 2.5.4). This decreases the linearity of speed control compared to the Driver (prop) case. The result is a $6 \mathrm{~s}$ increase and a 1.11 million $\mathrm{kWh} /$ year energy consumption decrease compared to the flat-out case, see Table 10. This takes more time and consumes more energy compared to Driver (prop).

Figure 51 shows the average power of a proportional and notched C507/8 travelling between Chester and Liverpool Central. When the train has reached the speed limit, a power between 120 and $200 \mathrm{~kW}$ is used to operate the train at constant speed. One instance of this occurrence is shown to be from 3 to $6 \mathrm{~km}$. 


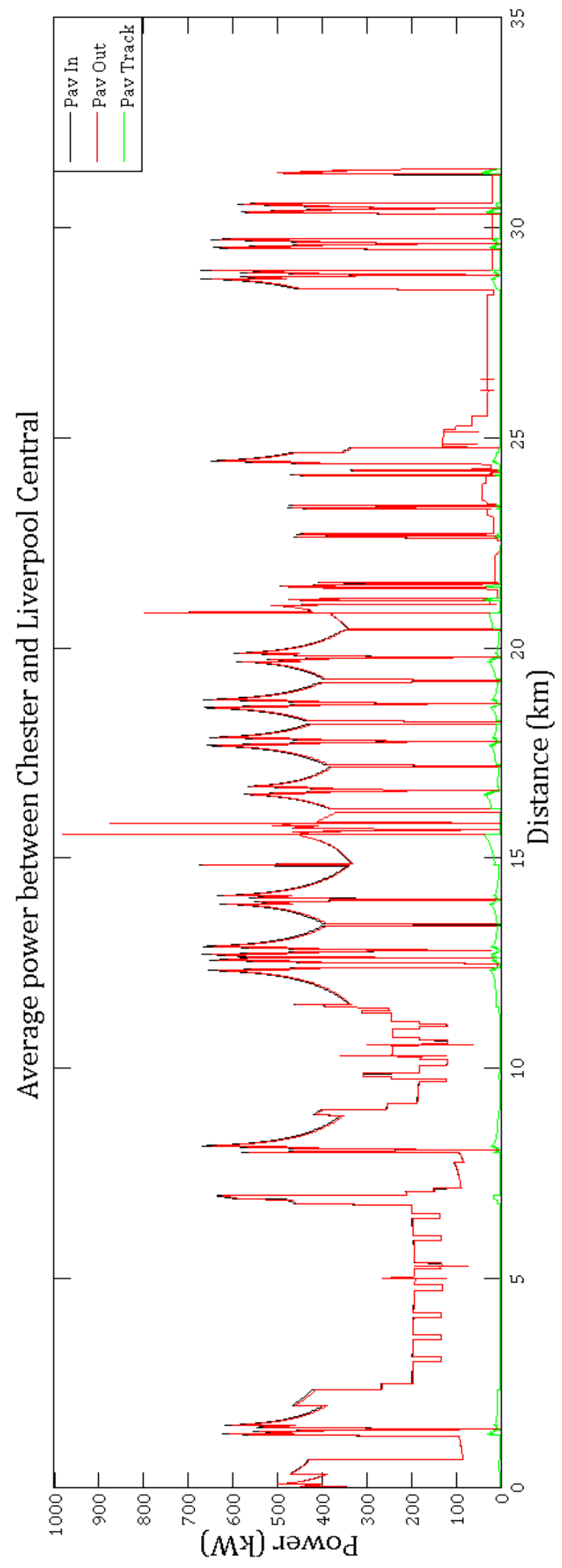

Figure 51: The MERS results of the average power of a proportional and notched controlled C507/8 between Chester and Liverpool Central 
Driver (prop notched) C507/8

\begin{tabular}{lr}
\hline Average time increase per interstation (s) & 5.52 \\
\hline Total Energy $\left(\times 10^{6} \mathrm{kWh} /\right.$ year $)$ & 31.46 \\
\hline Energy Efficiency Increase (\%) & 3.42
\end{tabular}

Table 10: Proportional and notched case scenario for $\mathrm{C507/8}$

The controls and performance of the simulated driver in a C507/8 increase the operational time. The energy consumption decreases for this case because the driver operates the train at a slower speed. The improvement of the C507/8 driver controls has a potential of saving up to $1.7 \%$ of the annual energy consumption and decreases the operational time by $1 \mathrm{~s}$ per interstation. The driver should be trained and the controls of the $\mathrm{C507/8}$ should be improved to give a greater accuracy in traction control and a control system that allows a better resolution of traction power. This case is the same as the flat-out case, which is used in the coasting and regeneration development tests because it does not increase the running time.

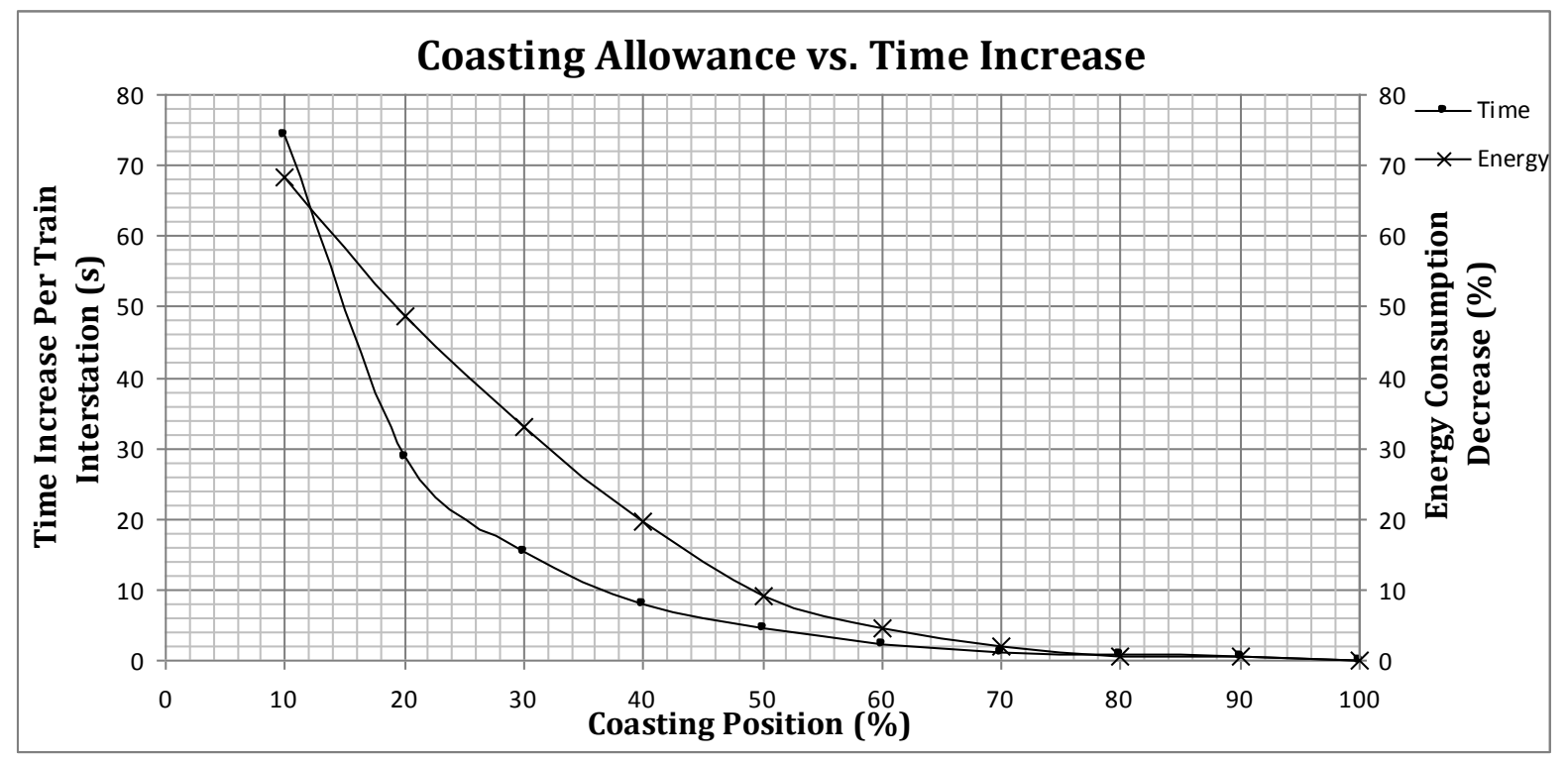

Figure 52: Simulation results of $\mathrm{C507/8}$ with coasting points showing the decrease in energy consumption and increase of time

The simulation of a coasting point in this thesis is at a predefined location outside the initial acceleration boundary between every station. The percentage of a coasting 
allowance is from 10 to $100 \%$, where $10 \%$ is coasting just after the train departs from a station and $100 \%$ is when the train has arrived at the next station, i.e. no coasting points. Figure 52 shows the effect of a coasting allowance on the duration of the C507/8 trains between stations and the amount of energy that is saved over the Merseyrail network. This shows that for a 10\% energy efficiency increase, coasting points should be placed at 49\% between stations. Figure 53 shows that a $10 \%$ energy saving results in a $5 \mathrm{~s}$ increase in time between stations.

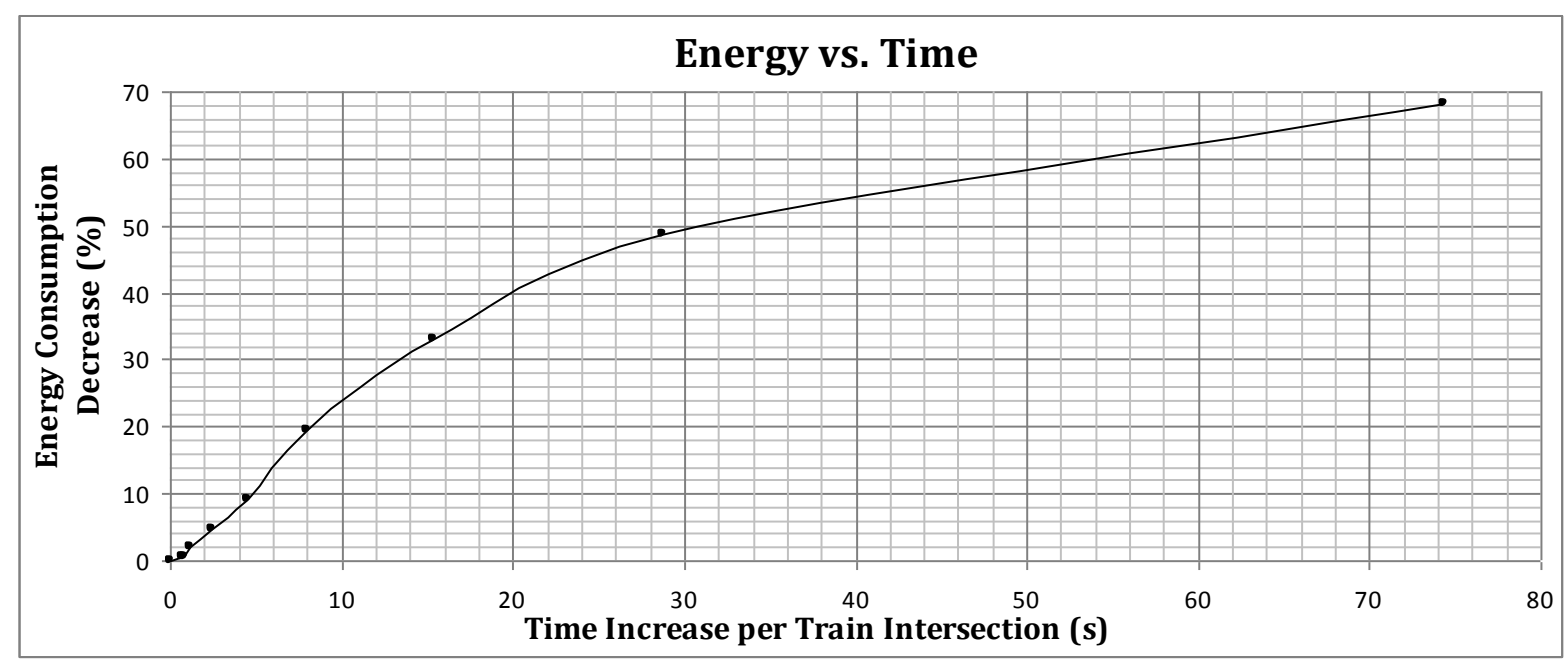

Figure 53: Energy against time graph showing percentage of energy saved for an increase of running time because of coasting points

The Merseytravel timetable has a dwell time of 30 s, however, the DLR has a dwell time of $20 \mathrm{~s}$. It could, therefore, be feasible to decrease the dwell time of Merseyrail to $20 \mathrm{~s}$, which would give $10 \mathrm{~s}$ for a coasting allowance. This would give an energy efficiency increase of $22 \%$ and would require coasting points at $37 \%$ between stations. Figure 54 , Figure 55, and Figure 56 show the MERS results of speed and average power between Chester and Liverpool Central with coasting points at 37\% between stations. The speed decreases each time the train has passed the coasting point because the driver has selected zero tractive effort, hence zero power is used. 


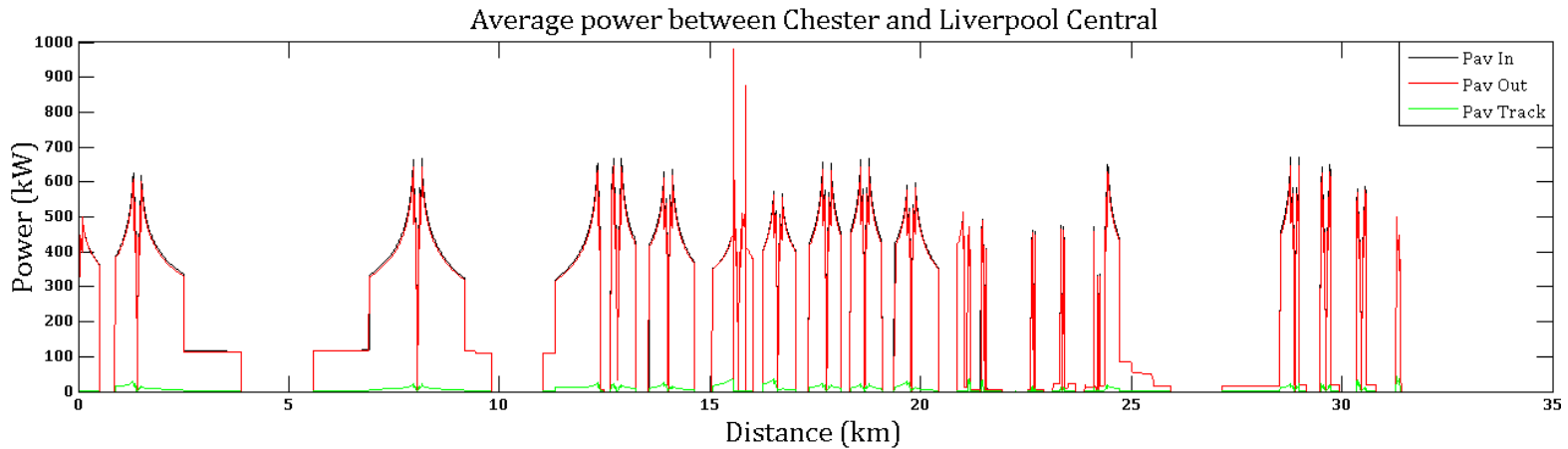

Figure 54: The MERS results of the average power of trains travelling between Chester and Liverpool Central with coasting points placed at $37 \%$ between stations

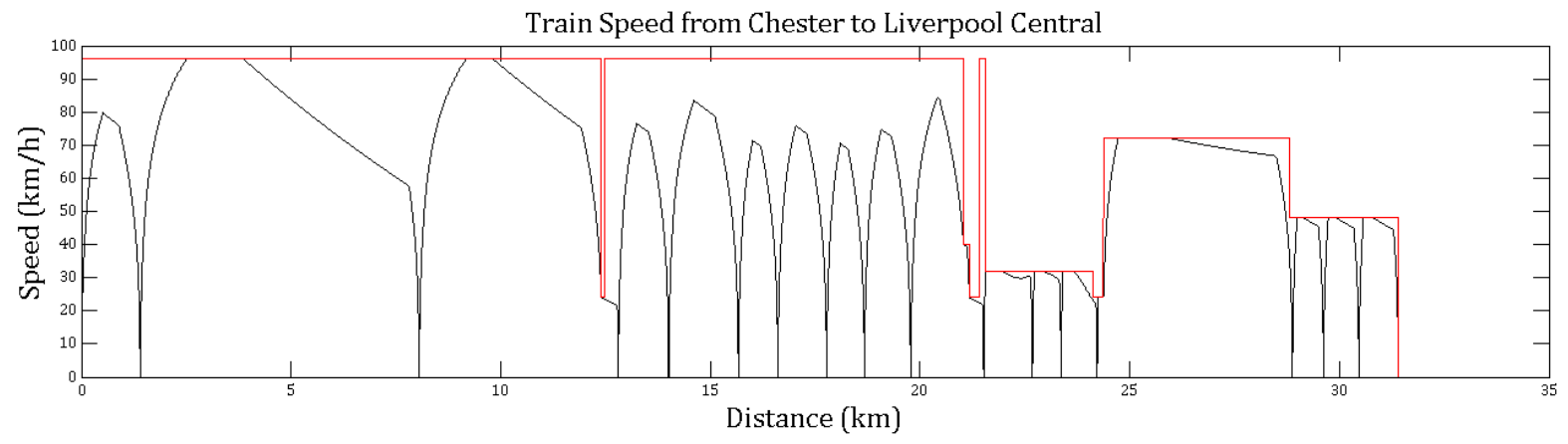

Figure 55: The MERS simulated speed-distance of a train travelling from Chester to Liverpool Central

Train Speed from Liverpool Central to Chester

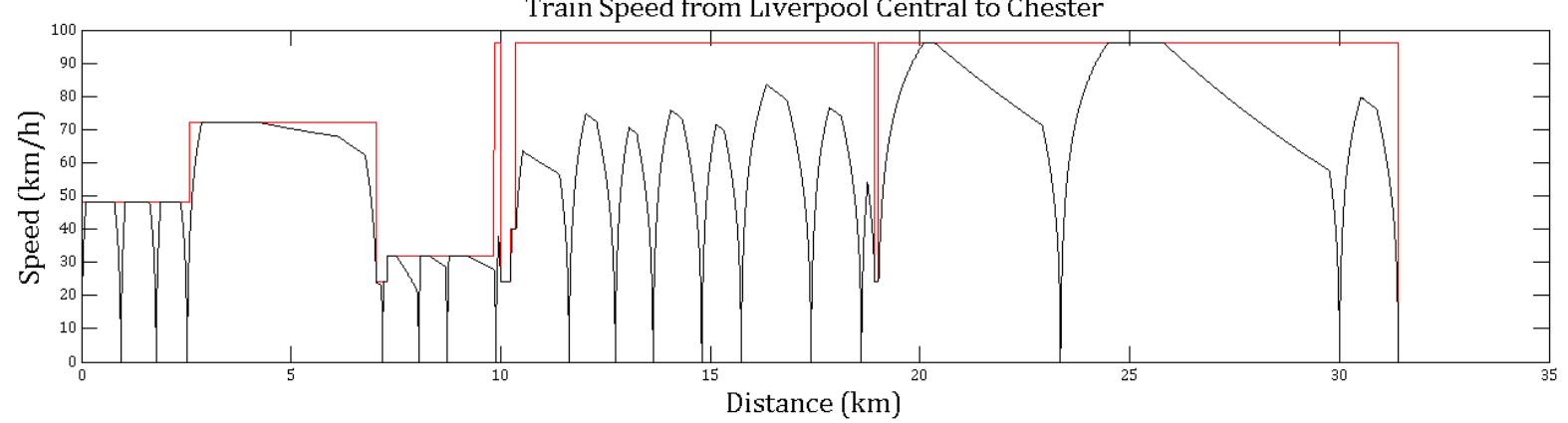

Figure 56: The MERS simulated speed-distance of a train travelling from Liverpool Central to Chester 


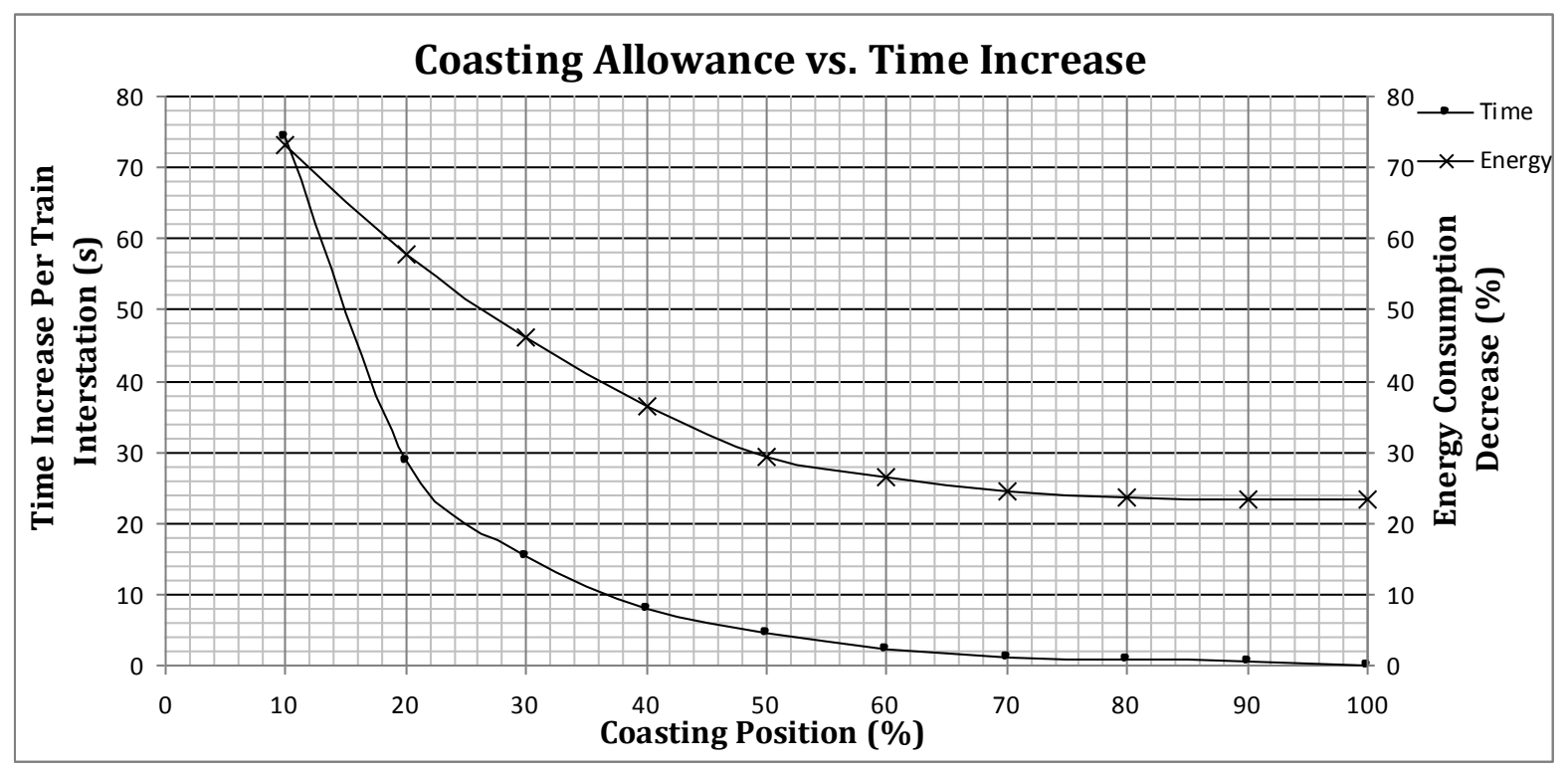

Figure 57: Simulation results of $\mathrm{C507/8}$ with boost converter, regeneration and coasting points showing the decrease in energy consumption and increase of run time

A railway capable of regeneration could have either onboard storage equipment, or wayside ESS (off-board). The difference in energy consumption is greater for onboard storage, due to the decreased storage capacity and increased train mass. However, transmission losses are evident for off-board storage. According to Chymera (2006a), the mass of a chopper is about $100 \mathrm{~kg}$, which is an insignificant increase compared to the mass of the batteries. Moreover, this is contrary to the chopper called HVI 500R Series, which is suitable for this application, weighing $2.2 \mathrm{~kg}$ this is more than twice the equivalent to the per unit weight of a rheostat of $1 \mathrm{~kg}$. 


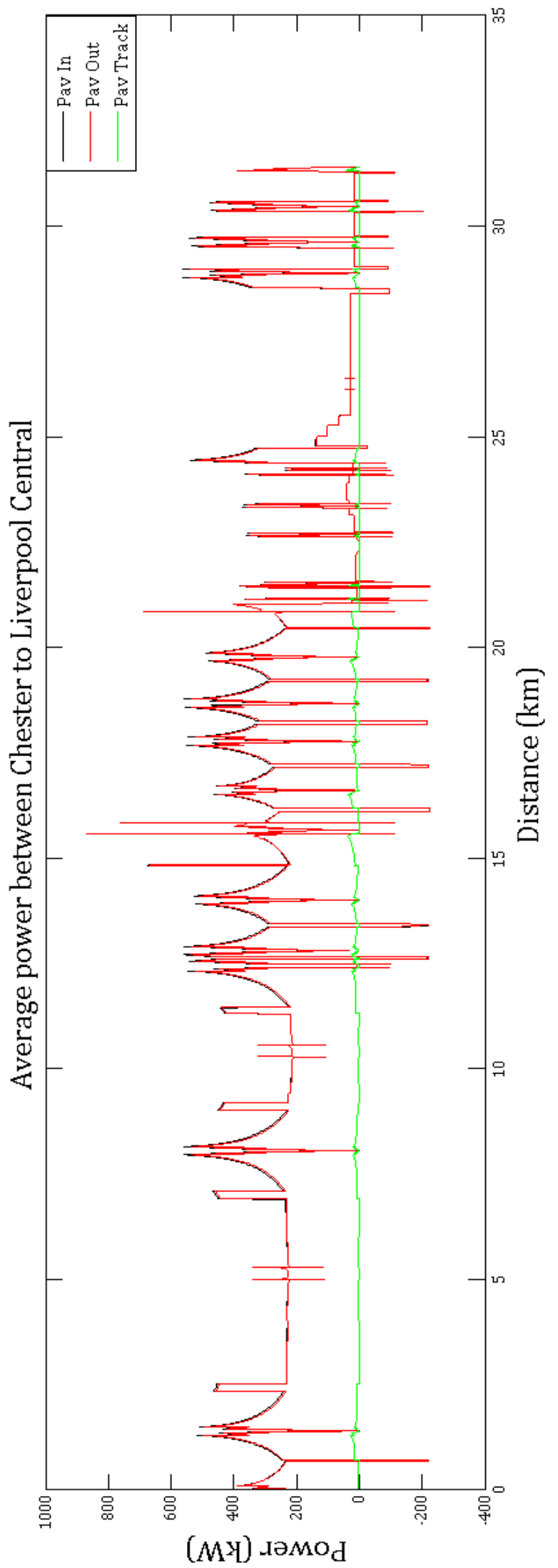

Figure 58: The average power of regenerating trains travelling between Chester and Liverpool Central 
Neglecting the extra mass and storage capacity, the regeneration of the braking force with an efficiency of $40 \%$ is simulated on Merseyrail (see Figure 58). The power has a minimum of $-200 \mathrm{~kW}$, this is when the train regenerates braking energy. In the simulator, the traction equipment is retrofitted with a boost converter, and with a rheostat to control the DC motors. Another simulation test is done with the inclusion of a buck converter to control the DC motors. This should increase the energy efficiency because it replaces the rheostat controller, which has major power losses. The final test is when the buck and boost converters are both retrofitted onto the C507/8 and regeneration and coasting is used.

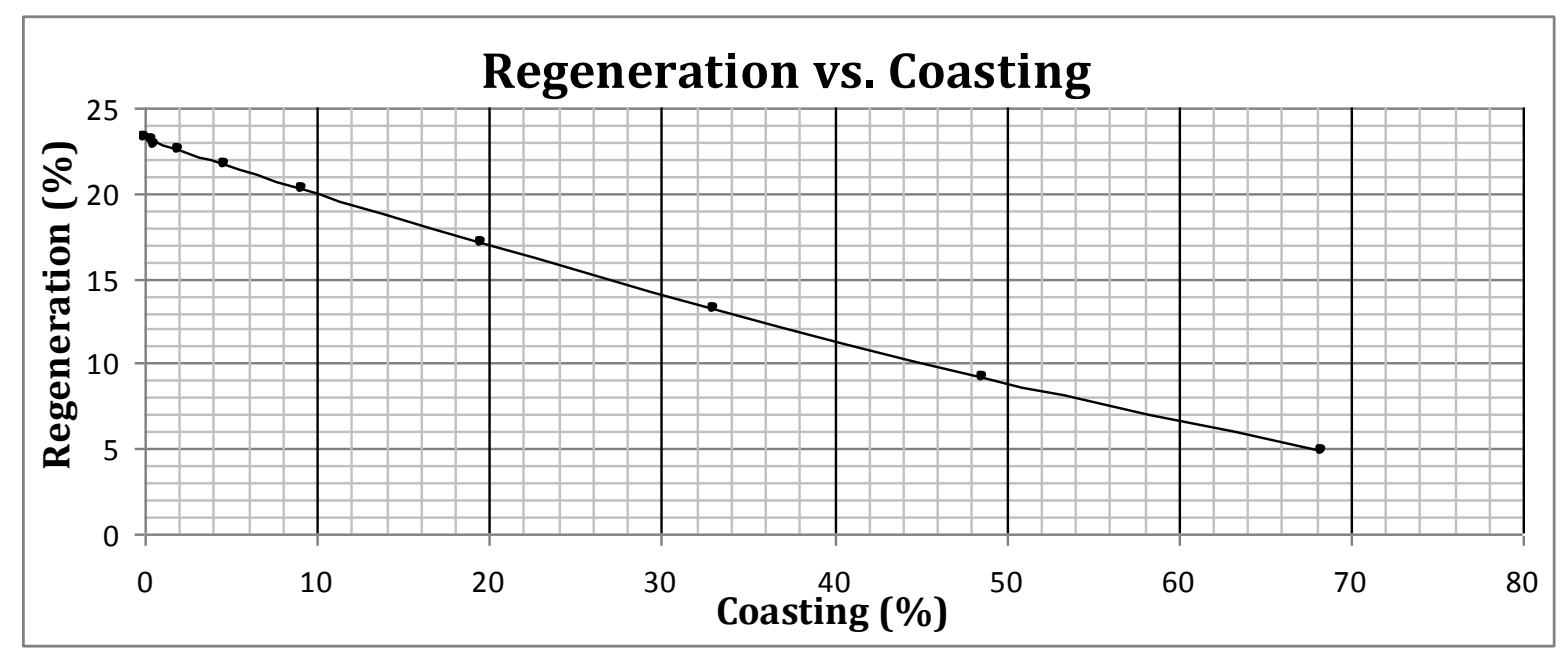

Figure 59: Regeneration against coasting showing the decrease in regenerated energy with an increase in energy saved by coasting

The MERS results from the C507/8 with a boost converter that regenerates braking energy into off-board storage are shown in Figure 57 and Figure 59. When no coasting points are used on the network, the regenerated energy saves $23 \%$ compared to the C507/8 operating flat-out. When coasting points are used, the energy efficiency increases further. However, as the percentage of energy saved from coasting increases, the percentage from regeneration decreases. The increase in run time of $10 \mathrm{~s}$ allows the 
energy efficiency to be increased by $40 \%$ and requires a coasting point at $36 \%$ between stations. Using regeneration with a coasting allowance of $10 \mathrm{~s}$ improves the energy efficiency further by $18 \%$.

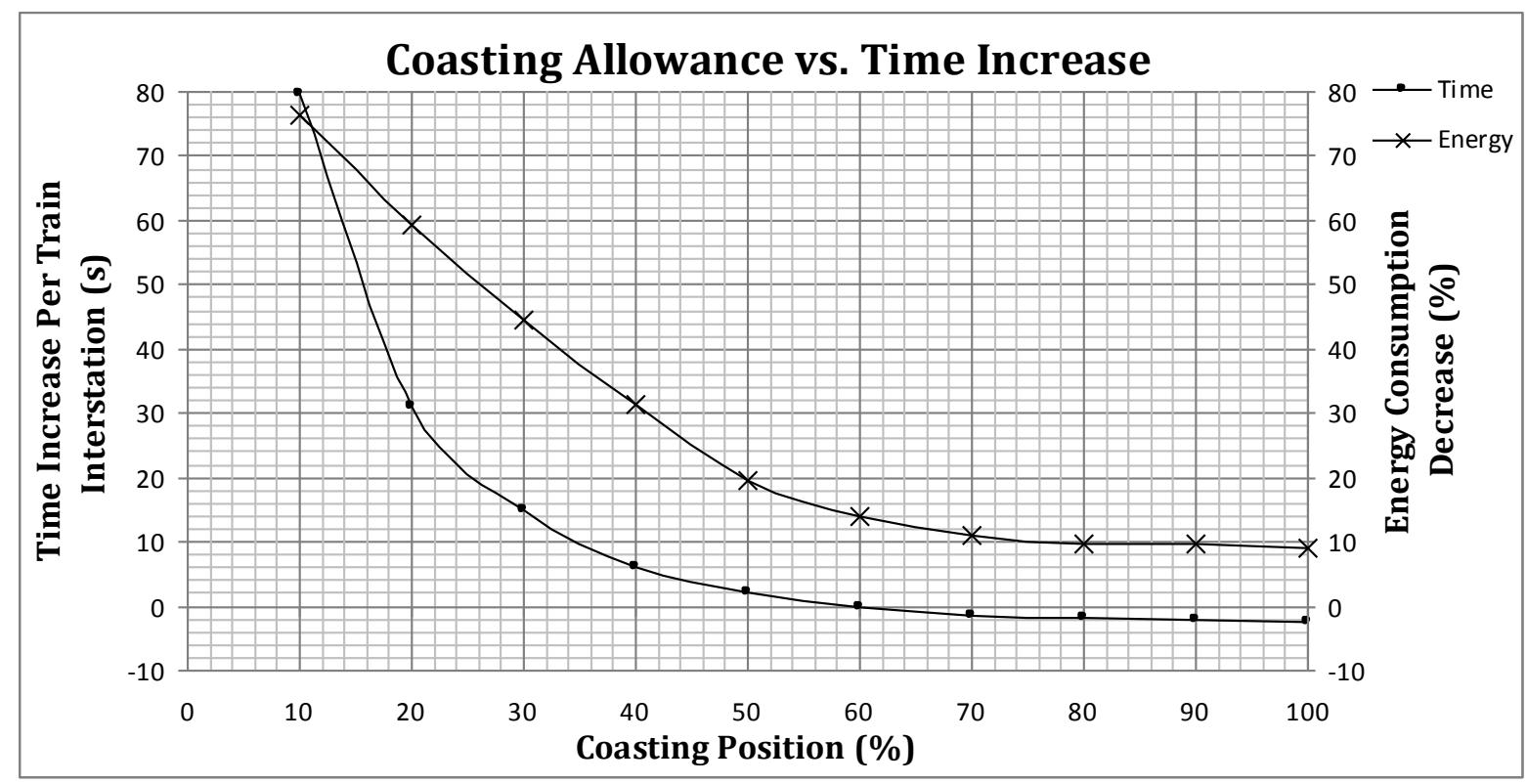

Figure 60: Simulation results of $\mathrm{C507/8}$ with buck converter and coasting points showing the decrease in energy consumption and increase of time compared to the C507/8 travelling flat-out

The results from the rheostat controlled C507/8 are shown in Figure 52 and the results from the buck converters controlling the C507/8 in Figure 60. This shows that when no coasting points are used (Coasting Position 100\%), the buck converter saves 9\% energy compared to the rheostat controller. The buck converter gives a smooth increase of current when accelerating, whereas the rheostat has a ripple in the acceleration waveform. This ripple gives an average acceleration that is slightly lower than the buck converter, which results in the C507/8 with a buck converter having a decrease in run time between stations of $2 \mathrm{~s}$. 


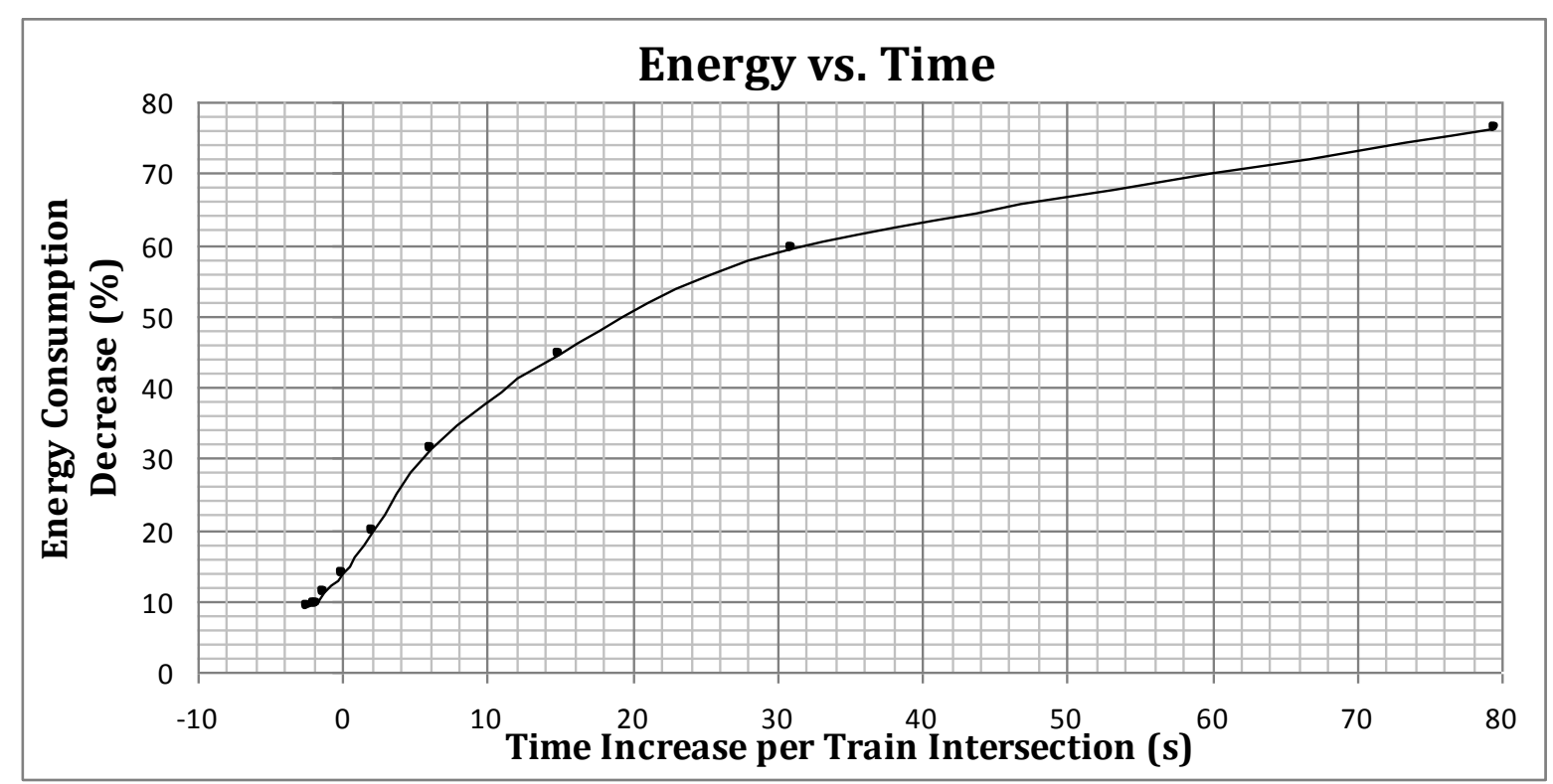

Figure 61: Energy against time graph of a C507/8 with a buck converter, showing percentage of energy saved for an increase of running time because of coasting points

The C507/8 with a buck converter will always have a 9\% energy efficiency improvement compared to the rheostat controlled C507/8. When a coasting allowance of $10 \mathrm{~s}$ is simulated the energy consumption decreases by 38\% (see Figure 61). This retrofitted C507/8 is capable of achieving 50\% energy efficiency improvement when the coasting allowance is increased to $19 \mathrm{~s}$ and coasting points are placed at $26 \%$ between each interstation. However, this would require a dwell time of $11 \mathrm{~s}$, which may not be enough time for the passengers to comfortably disembark and board the train. Alternatively, the time could be increased on the timetable for each station, which may be equally undesirable. 


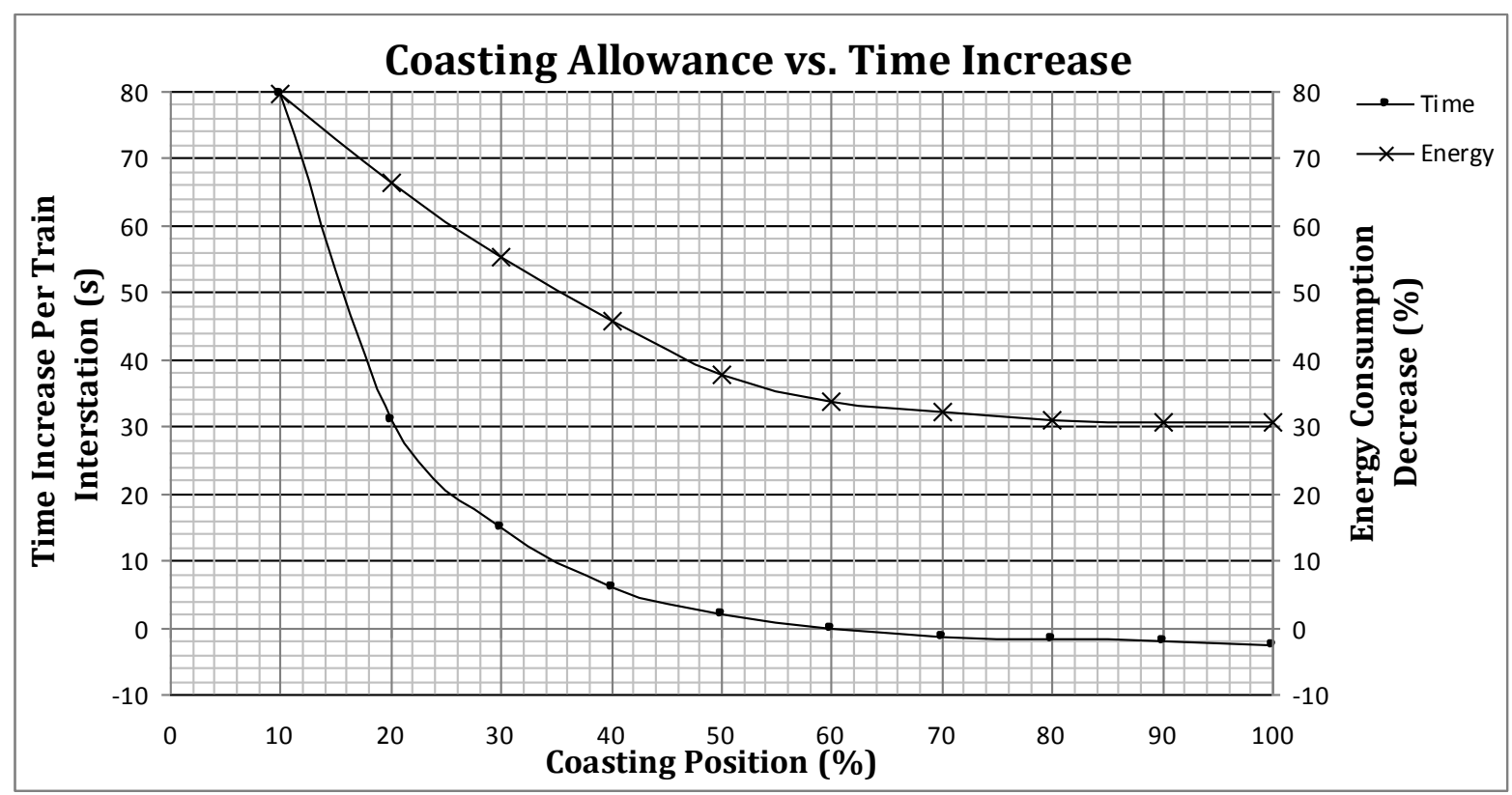

Figure 62: Simulation results of $\mathrm{C} 507 / 8$ with buck and boost converters, regeneration, and coasting points showing the energy consumption decrease and time increase

The retrofitting of a C507/8 with buck and boost converters enables it to regenerate energy into an ESS. This scenario was simulated in the MERS and the results are shown in Figure 62 and Figure 63. Without any coasting points used (Coasting Position 100\%) there is $31 \%$ energy efficiency improvement, this is a combined $9 \%$ from retrofitting with a buck converter and $22 \%$ from regeneration with a boost converter. Similar to other simulation tests, when coasting points are used the energy efficiency increases; however, the percentage of regenerated energy decreases. For a 10 s coasting allowance, coasting points are required at 35\% between stations, which gives an energy efficiency improvement of $51 \%$. This is $9 \%$ from the buck converter, $12 \%$ from regeneration, and $30 \%$ from coasting. 


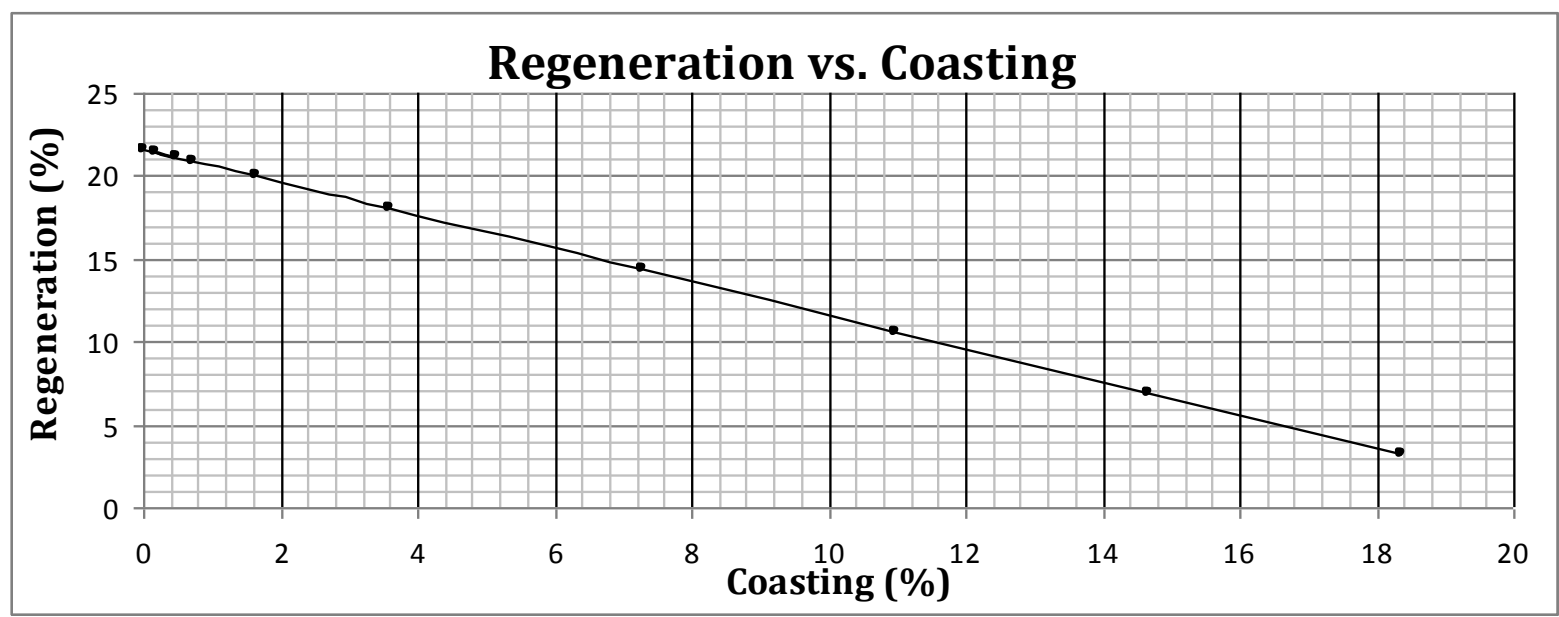

Figure 63: Regeneration against coasting of the $\mathrm{C} 507 / 8$ with buck and boost converters, showing regenerated energy decrease with energy saved by coasting increase

With consideration of the effect on operational time, regeneration with a C507/8 retrofitted with buck and boost converters is better compared to all other energy efficiency schemes. It has a very small increase in operational time and has the greatest energy savings. However, this is only beneficial for off-board storage; onboard storage would increase the running time due to the weight of the battery.

The ERRAC objective to improve energy efficiency and reduce pollutants for railway networks by $50 \%$ was achieved by using various methods. The cheapest method would be to use coasting points without retrofitting the $C 507 / 8$, but this increases the run time by 33 s. Another cheap method is to retrofit the C507/8 with a buck converter and to use coasting points, but this increases the running time by $18 \mathrm{~s}$. To stay within the limits of a reasonable coasting allowance, and to achieve 50\% energy efficiency improvement, it is necessary to retrofit the C507/8 with buck and boost converters, place ESS at strategic positions on the network and coast at $35.5 \%$ between stations (see Table 11). This reduces the energy consumption by 16.3 million $\mathrm{kWh} /$ year and requires an average $9 \mathrm{~s}$ increase in running time between stations. 


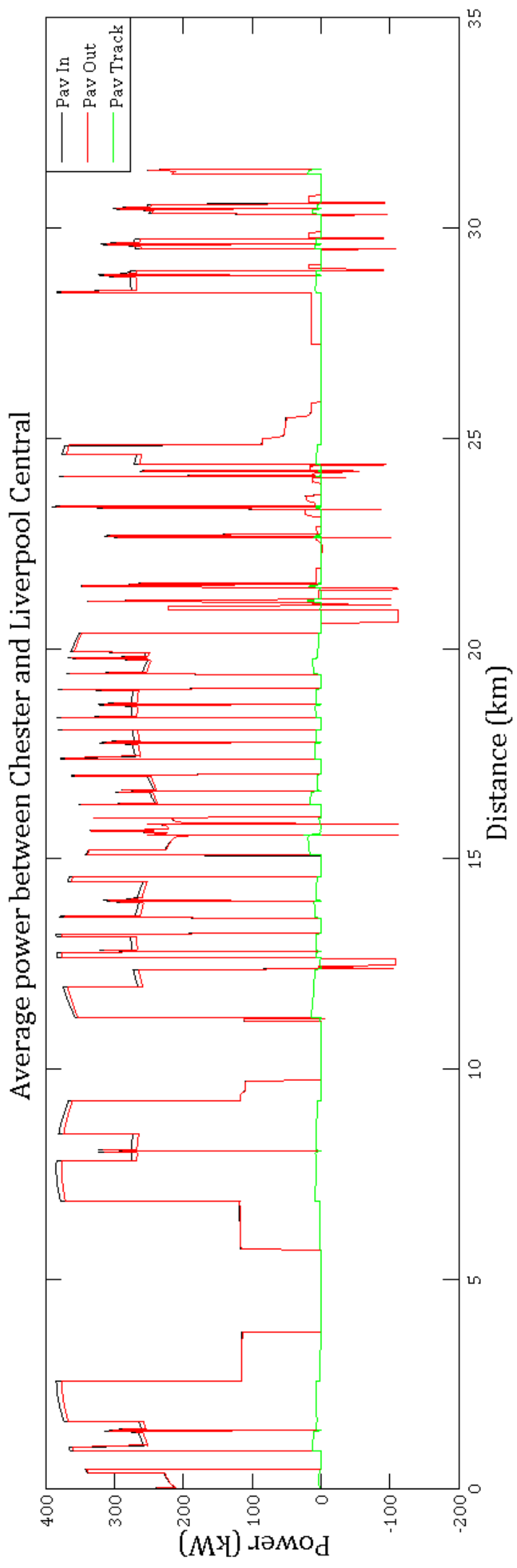

Figure 64: The average power results from the MERS between Chester and Liverpool Central for a $\mathrm{C507/8}$ retrofitted with buck and boost converters with regeneration and coasting points at $35.5 \%$ 
Coasting 35.5\%, \& Regeneration with Buck and Boost

\begin{tabular}{lr}
\hline Average time increase per interstation (s) & 8.91 \\
\hline Total Energy $\left(\times 10^{6} \mathrm{kWh} /\right.$ year $)$ & 16.27 \\
\hline Energy Efficiency Increase (\%) & 50.06
\end{tabular}

Table 11: Combination of three energy efficient techniques for the C507/8 with buck and boost converters

The configuration in Table 11 is the best combination of schemes to achieve a $50 \%$ energy efficiency improvement with minimal increase in time. Figure 64 shows the results from the MERS for this case between Chester and Liverpool Central. The peak power is below $400 \mathrm{~kW}$, which is less than the other cases because of the use of coasting points and the use of the buck converter. This energy efficiency improvement of $50 \%$ completes the most demanding objective set by ERRAC, and meets the target set by the CCC. The extra time would be acceptable if Merseyrail decreased the dwell time over all station stops by an average $9 \mathrm{~s}$. Each individual station stop requires more or less than $9 \mathrm{~s}$ decrease in the dwell time.

\subsection{Conclusion and Further Work}

The objectives of this thesis were to test the hypothesis that a combination of regeneration, coasting points, and driving style could improve the energy efficiency substantially. The target of $50 \%$ improvement, with minimal increase in operational time has been achieved using all three energy efficiency schemes. These also satisfy the objectives set by ERRAC and CCC. The result is an annual energy consumption decrease of 16 million $\mathrm{kWh}$ and 8 kilotonnes of $\mathrm{CO}_{2}$ emissions. This solution increases the total operational run time by $7 \%$, but is compromised with a reasonable decrease in dwell time. 
Regeneration alone increases energy efficiency by $23 \%$, which has a negligible effect on the operational time. This was using a $40 \%$ recuperation rate of the braking energy. A DC machine with a higher rated power would give a higher braking power and hence give a greater energy efficiency improvement. The cost and the effect of the extra weight if using onboard storage from the batteries are the main drawbacks of using this energy efficient scheme. Factors such as battery degradation, harmonic distortions and receptivity could be considered for further work.

Coasting was simulated at a fixed distance between stations. A coasting point can be ideal for one position between two stations, but that coasting point is not necessarily ideal for every interstation. To further improve the proficiency of coasting points on the Merseyrail network, an ideal coasting point should be chosen for each interstation throughout the network. Coasting algorithms calculate the coasting point for each interstation spacing iteratively, which for further work could be programmed into the MERS to find ideal coasting points for each interstation.

The driver controls of the C507/8 increase the difficulty of speed control, resulting in an increase in energy consumption. The improvement of the controls improves the energy efficiency, but decreases the operational time. This happens because the driver does not reach the speed limit. When driver performance is improved, the run time decreases and energy efficiency decreases. The results showed it is better to have a faster run time with greater driver accuracy because coasting points are a better utilisation of the available time 


\section{CONCLUSION AND FURTHER WORK}

This thesis shows that a combination of energy efficiency schemes can achieve a $50 \%$ energy efficiency improvement and meet the energy efficiency objectives set by ERRAC and CCC. The energy efficiency of commuter railways is affected by many factors. There is considerable scope to decrease the energy consumption of operating trains and hence reduce $\mathrm{CO}_{2}$ emissions. With so many variable factors, it is impractical to test the effectiveness of each energy efficiency factor without a simulator. The Merseyrail Simulator (MERS) was designed specifically to the Merseyrail network. As case studies the proficiency of regeneration, coasting allowances and driver technique were all tested in the MERS. This type of development testing is useful for Merseyrail and all other railway networks that are required to improve their energy efficiency.

\subsection{Railways and Merseyrail}

Merseyrail's distribution power network consists of substations, third rail conductors and return rails. Health and Safety regulations in Britain restrict the magnitudes of conductor voltage on third rail systems because of the short separation distance between the conductor and rail. This leads to a high current demand given the power rating of the traction equipment. Such low voltages and high currents result in greater losses on the conductors and rails. As a result, the spacing between substations is short, which incurs both a greater initial investment cost and higher periodic cost for maintenance. Operators of DC commuter railways should endeavour to reduce their operational costs, which is possible by implementing developments on their railways to improve energy efficiency. However, such developments can be expensive and sometimes outweigh the net cost benefit from reduced energy expenditure. 


\subsection{Single Train Simulator and Merseyrail Simulator}

The single train simulator models the journey of a train along a given route, with a tractive effort moving the train, accompanied by the gradient and against resistive forces.

A satisfactory set of parameters were given by reliable sources and some unknown parameters were developed specifically for the simulator. In this thesis, there is a development of an existing simulator with the inclusion of NPF and TEm models that are specific to the Merseyrail network and C507/8 traction equipment. These models were adapted to interact with the central model, which was based on the initial STS. The TEm model was integrated with the central model to simulate the journey of the train with the tractive effort governed by the performance of the DC series motor with camshaft control. This is the first available model of the C507/8.

The NPF model estimated the power flow from the substation, along the conductors, through the train and back down the return track, and processes data from the TEm model. The NPF model evaluates whether the train has enough power over the entire network. If the power demanded by the trains were greater than the power supplied, then the train would stall. A better representation of the movement of the train would include a dynamic terminal voltage. This would entail the integration of the NPF model with the central model and TEm model. The performance of the DC motor is dependent on the power supplied from the power distribution network. However, as long as the terminal power is above or equal to the rated power, the performance of the motor will be normal. 
The C507/8 trains can be improved to achieve greater energy efficiency in several ways. The results show that there is a greater power loss during the slower halves of the series and parallel regions. The driver can avoid this by operating the train with a high acceleration from standstill. The driver should then continue at constant speed either in the faster half of the series and parallel regions or in the weak field region. Retrofitting the traction equipment with a buck converter or powering the train in this region with auxiliary power supplies would have similar benefits. There is further work required to optimise the duty-cycle of the energy consumption between the motor and auxiliary power supply.

\subsection{Verification}

The MERS was compared with two other industry recognised simulators, the MTS and OSLO, which had similar results in a previous validation procedure. The verification test carried out between the MERS and OSLO considered the parameters of run time, energy consumption, and train voltage. The comparisons of the speed-distance graphs showed where the differences were between the verification test parameters. The differences were identified as between the different methods of operating the train. In OSLO, the ATO changes the speed of the train after the back of the train has passed the limit marker. The MTS simulates the ATO, with a change in speed after the front of the train has passed the speed limit. It will then travel at an average speed by mediating the speed controller up and down around the speed limit. Thus the train will frequently exceed the speed limit. The MERS simulates the change of speed at the speed limit from the front of the train similar to the MTS, but the train always travels below the speed limit. It 
mediates the speed control similar to the MTS, but this is underneath the speed limit and is at a slower rate compared to MTS.

\subsection{Simulation of Energy Efficiency}

Three known developments that improve the energy efficiency of a railway network are regeneration of braking energy, allocation of inter-station coasting points, and improvement of driving style. The implementation of the three energy efficient schemes showed that the ideal case is a combination of all three. A method to develop this could be to retrofit the traction equipment with a buck converter for speed control, a boost converter for converting the regenerated energy, and installing wayside Energy Storage Supplies (ESS). There would need to be coasting points within the inter-station spacing at $35.5 \%$ of the distance between each station. The driver would need to be retrained to operate the train with a chopper speed controller and be able to use coasting points with a high accuracy.

The ideal energy efficiency combination might allow Merseyrail to meet the requirements of the objectives set by ERRAC and CCC. A proposal to Merseyrail would be to implement these energy efficient schemes in time for their new rolling stock due in 2012. The results of the C507/8 rolling stock represent a benchmark of energy efficiency improvements that the new rolling stock should meet. The C507/8 would need to include a buck and boost converters to minimise the power loss from the starting resistors and to enable regeneration. The use of ESS is a more expensive solution than using onboard storage. However, onboard storage has a smaller capacity and increases the weight of the train. Therefore, the deciding factors which Merseyrail has to consider 
depend on the capacity of the onboard storage for improving the energy efficiency and whether ESS is economical.

The ideal energy efficiency combination had a constant coasting position of $35.5 \%$ between each station. However, as described in Section 5.3, coasting algorithms can approximate the ideal coasting position for each inter-station within a given coasting allowance. For any particular inter-station configuration, this may result in coasting points differing from $35.5 \%$. This will further increase the energy efficiency due to coasting. The coasting point locator could be positioned on the wayside of the Merseyrail track as signs, or the driver could be given a distance chart indicating when to begin coasting. The latter solution has greater difficulties as it requires the driver to frequently monitor the displacement of the train. A wayside coasting signal is easy to construct, however, other railway companies use the same route and would have a different coasting point. If they were all to use the same system then each railway company would need individual wayside coasting signals, which would cause clutter on the wayside.

\subsection{Further Work: Simulator Developments}

The MERS has built in assumptions and limitations on the non-modelled parameters, indicating that the technology used in industry would minimise their effect on the energy consumption of the train. However, further developments to the simulator could include:

- Armature reaction

- Delay of the movement of the camshaft

- Dynamic load for passenger utilities 
- Dynamic payload

- Earth-current leakage

- Individual driver for each train simulation

- Random delays

- $\quad$ Signalling

- Temperature variation of armature windings

- Underground aerodynamics

- Weather conditions

- Wheel slip protection

These are the extra factors that are not modelled in the MERS and if implemented would simulate all the influential factors of a railway power network. The majority of these have been quantified in the main text as having minimal effect on the total energy consumption due to technological developments.

\subsection{Further Work: Merseyrail Project}

An ongoing project that is in collaboration with this project is the monitoring of the rolling stock of Merseyrail, as carried out by the research department at the Birmingham Centre for Railway Research and Education (BCRRE). Present capabilities include the general location of the train using a GPS tracker, the movement of the train with a yaw, pitch, and roll using an electric gyroscope and speed sensing with an accelerometer. Further capabilities are presently in development.

BCRRE will have a current transducer connected to the main terminals of the DC motor sets for each motoring coach. In addition, a monitor will be placed on the serial bus to read information on the position of the camshaft. The project is developing a device to monitor the driver and their performance when operating the train. This 
would be able to classify the drivers who are monitored in terms of their energy consumption. All monitoring devices will store their data on a removable SD card or directly connect to a hard disk drive of a laptop. These allow the monitoring project to gather data on the acceleration, speed, displacement, voltage/current dynamics of the DC motors and camshaft positions.

The weight of the train will increase depending on how many passengers are onboard. Weight distribution depends on which cars the passengers are situated in. The weight distribution of the train can be monitored and the effect of this on energy consumption identified.

Two trains will be monitored using appropriate monitoring equipment. The MERS is capable of analysing the data and identifying the dynamics of the voltage and current of multiple trains. The MERS could give reasons for any anomalies in the data. For instance, in the event of a delay, the train stops or slows down. Therefore, if the monitored train is the cause of a delay, the energy consumption should increase for that section between stations. Alternatively, if that train is behind a delayed train, there might be an increase in time and energy. Therefore, when the MERS analyses the monitored data it can give insight into the cause and effect of a delayed train and other energy consumption deviations arising from the payload dynamics.

\subsection{Interoperability}

Merseyrail is similar to other railways in Britain such as Southern Rail, DLR, and Glasgow Subway. The MERS has already been tested for one DLR route with satisfactory results from the comparison of OSLO and the MTS. This increases the probability of 
producing similar results for Southern Rail and Glasgow Subway. The MERS could also simulate fifty-six other railways in countries worldwide, which also use the third rail system for urban railway transportation. 


\section{BIBLIOGRAPHY}

Acikbas ST, and Soylemez M. "Parameters Affecting Braking Energy Recuperation Rate in DC Rail Transit." ASME/IEEE Joint Rail Conference. Colorado, 2007.

Angel Trains. "Unpublished Information from Angel Trains." 2008.

ATKINS. "Unpublished information from ATKINS." 2009.

Avallone EA, Baumeister T, Sadegh A, and Marks LS. Marks' standard handbook for mechanical engineers. 11. McGraw-Hill Professional, 2006.

Barlow R. Statistics: a guide to the use of statistical methods in the physical sciences. Chichester, UK: John Wiley \& Sons Ltd., 1996.

BBC News. "Sizzling temperatures break UK record." BBC News. August 11, 2003. http://news.bbc.co.uk/1/hi/uk/3138865.stm.

Birkhoff G, and Rota G. Ordinary Differential Equations. 4. New York, Chichester, Bribane, Toronto, and Singapore: John Wiley \& Sons, 1989.

Bocharnikov YV, Tobias AM, Roberts C, Hillmansen S, and Goodman CJ. "Optimal Driving Strategy for Traction Energy Saving on DC Suburban Railways." IET Electrical Power Applications (IET) 1, no. 5 (2007): 675 - 682.

Buchwald P. "Mechanical transmission, energy saving potential - Experience with modern mechanical transmissions in DMUs." 2nd UIC Railway Energy Efficiency Conference. Paris: UIC, 2004.

Chapman SJ. Electric Machinery Fundamentals. 4. New York, US: McGraw-Hill, 2005.

Chou CJ, Hsiao YT, Wang JL, and Hwang YT. "Distribution of earth leakage currents in railway systems with drain auto-transformers." IEEE TRANSACTIONS ON POWER DELIVERY (IEEE-INST ELECTRICAL ELECTRONICS ENGINEERS Inc.) 16, no. 2 (April 2001): 271-275.

Chymera M, Renfrew A, and Barnes M. "Energy Storage Devices in Railway Systems." Manchester, UK: IEE, 2006a.

Chymera M, Renfrew AC, and Barnes M. "Analysis of Power Quality in a DC Tram System." The 3rd International Conference on Pwer Electronics, Machines and Drives. Dublin, Ireland: IEE Conference Publication, 2006b. 96-100.

Commitee on Climate Change. Building a low-carbon economy - The UK's contribution to tackling climate change. London: The Stationary Office (TSO), 2008. 
Davis JH. "Conservation of Electrical Energy for Automated Transportation Systems." Automated People Movers 2005. Moving to the Mainstream. 10th International Conference on Automated People Movers. Chantilly, Virginia, USA: American Society of Civil Engineers, 2005.

Department of Trade and Industry. A White Paper on Energy: Meeting the Energy Challenge. Norwich: TSO The Stationary Office, 2007, 128-129.

DFT. Rolling Stock Database, National Rail Trends Yearbook, Draft Evidence Pack 2007: Key Rail Operating Statistics. London: DFT, 2007.

Dixon J, and Morán L. "A Clean Four-Quadrant Sinusoidal Power Rectifier Using Multistage Converters for Subway Applications." IEEE TRANSACTIONS ON INDUSTRIAL ELECTRONICS 52, no. 3 (May 2005): 653 - 662.

Dorrian J, Hussey F, and Dawson D. "The Effects of Fatigue on Train Driving Performance: A Data Logger Study." Proceedings of the International Conference on Fatigue Management in Transportation, September 2005.

Dorrian J, Hussey F, and Dawson D. "Train driving efficiency and safety: examining the cost of fatigue." Journal of Sleep Research 16, no. 1 (2006).

ERRAC. A Joint Strategy for European Rail Research: Towards a Single European Railways System. Brussels: ERRAC, 2001.

European Union. Energy and Transport in Figures 2007/ 2008, Part 4: Environment. European Environment Agency, Directorate-General for Energy and Transport in cooperation with Eurostat, 2008.

Fam WZ, and Balachander MK. "Dynamic Performance of a DC Shunt Motor Connected to a Photovoltaic Array." (IEEE-INST Electrical Electronics Engineers) 3, no. 3 (September 1988): 613-617.

Fletcher RG. "Regenerative Equipment for Railway Rolling Stock." Power Engineering Journal (IEEE) 5, no. 3 (1991): 105 - 114.

Flinders F, and Oghanna W. "Energy Efficiency Improvements To Electric Locomotives Using PWM Rectifier Technology." International Conference on Electric Railways in a United Europe. Queensland: IEEE, 1995. 106 - 110.

Gawthorpe RG. "Aerodynamics in railway engineering: Aerodynamics of trains in the open air." Proceedings of the World Congress: Railway Engineering International (Institute of Mechechanical Engineers) 3, no. 3 (1978): 7 - 12.

GEC. "Unpublished Information from GEC." 2008. 
Golovitcher IM. "Energy Efficient Control of Rail Vehicles." Newark, USA: IEEE International Conference on Systems, Man and Cybernetics, 2001.

Goodman CJ, Siu LK, and Ho TK. "A Review of Simulation Models for Railway Systems." London, UK: IEE International Conference on Developments in Mas Transit Systems, 1998. 80 - 85 .

Griffith RJ, and Plunkett AB. Torque Analog of a Series Wound DC Traction Motor. Erie, Pennsylvania, USA Patent 4090119. May 16, 1978.

Hill RJ. "Electric Railway Traction: Part 1 Electric Traction and DC Traction Motor Drives." Power Engineering Journal (IEE-INST ELEC ENG) 1, no. 1 (1994a): 47 - 57.

Hill RJ. "Electric Railway Traction: Part 3 Traction Power Supplies." Power Engineering Journal (IEE-INST ELEC ENG) 8, no. 6 (December 1994b): 275-285.

Hill RJ. "Electric Railway Traction: Part 4 Signalling and Interlockings." Power Engineering Journal (IEE-INST ELEC ENG) 9, no. 4 (August 1995): 201-206.

Hillmansen S, and Roberts C. "Energy Storage Devices In Hybrid Railway Vehicles: A Kinematic Analysis." Proceedings of the Institution of Mechanical Engineers, Part F: Journal of Rail and Rapid Transit (Professional Engineering Publishing) 221, no. 1 (2006): $135-143$.

Hosseini SH, Shahnia F, Sarhangzadeh M, and Babaei E. "Power Quality Improvement of DC Electrified Railway Distribution Systems Using Hybrid Filters." Proceedings of 8th International Conference on Electrical Machines and Systems. Tabriz, Iran: ICEMS, 2005. $1273-1277$.

Jong J-C, and Chang E-F. "Model for Estimating Energy Consumption of Electric Trains." Eastern Asia Society for Transportatio Studies (Eastern Asia Society) 6 (2005): 278-291.

Jordan N. DC Power Supplies for Mainline and Underground Railways. MSc Railway Systems Engineering \& Integration, Birmingham: The University of Birmingham, 2007.

Kemp RJ. "Introduction of Chopper Controlled Trains on Established DC Railways." IEE PROCEEDINGS-B ELECTRIC POWER APPLICATIONS (IEE - INST ELEC ENG) 134, no. 3 (1987): 141 - 147.

Kirkland CJ. Engineering the Channel Tunnel. London, UK: Chapman \& Hall, 1995.

Kuphaldt TR. Lessons In Electric Circuits. ibiblio, 2008.

Lijun G, Zhenhua J, and Dougal RA. "An Actively Controlled Fuel Cell/Battery Hybrid To Meet Pulsed Power Demands." Journal of Power Sources (Elsevier B. V.) 130, no. 1 - 2 (2003): 202 - 207. 
Liu C, and Meerman E. "Increased recuperation efficiency by increment of the recuperation voltage to $1950 \mathrm{~V}$ in a $1500 \mathrm{~V}$ DC catenary system." 2007 EUROPEAN CONFERENCE ON POWER ELECTRONICS AND APPLICATIONS. Alborg, Denmark: IEEE SERVICE CTR, 2007. 5234-5237.

Lueg RE, and Reinhard EA. Basic Electronics for Engineers and Scientists. 2. New York, US: New York: International Textbook Company, 1972.

Mallet B. "French Train Breaks Speed Record in Champagne." Reuters. April 3, 2007. http://www.reuters.com/article/topNews/idUSL0364103520070403?pageNumber=1 \&virtualBrandChannel=0\&sp=true.

Marsden CJ. Traction Recognition. Surrey: Ian Allan Publishing Ltd, 2007.

Martin P. "Train Performance and Simulation." 31st Conference on Winter Simulation: Simulation - a Bridge to the Future. Pheonix, US: ACM, 1999. 1287 -1294.

McPherson G. Statistics in Scientific Investigation: its basis, application, and interpretation. Tasmania, Australia: Springer-Verlag New York Inc., 1990.

Mei TX, Yu JH, and Wilson DA. "A mechatronic approach for effective wheel slip control in railway traction." IMECHE PART F Rail and Rapid Transit (Professional Engineering Publications Ltd.) 223, no. 3 (May 2009): 295-304.

Merseytravel. $\quad$ "Rail Timetables." 2005. http://www.merseytravel.gov.uk/railindex.asp (accessed June 31, 2008).

Mohan N, Undeland TM, and Robbins WP. Power Electronics: Converters, Applications and Design. 3. Minneapolis: John Wiley \& Sons, Inc., 2003.

Morrison-Knudsen. Feasibility Study for Electrifying the Caltrain/PCS Railroad. Feasibility Study, California, US: Morrison Knudsen Corporation, 1992, 95 (5 - 6).

Network Rail. "Corporate Responsibility Report: Delivering for You." Annual Report, London, 2007a.

Network Rail. "Current Capability." Annual Report, London, 2007b.

—. "Unpublished information from Network Rail." 2007c.

Ogawa T, Yoshihara H, Wakao S, Kondo K, and Kondo M. "Energy consumption Analysis of FC-EDLC hybrid railway vehicle by dynamic programming." European Conference on Power Electronics and Applications. Aalborg: IEEE, 2007. 1 - 8.

Ribeiro PF, Johnson BK, Crow ML, Arsoy A, and Liu Y. "Energy storage systems for advanced power applications." Proceedings of the IEEE (IEEE-INST ELECTRICAL ELECTRONICS ENGINEERS INC) 89, no. 12 (December 2001): 1744-1756. 
Robles E, Zaragoza J, Merino M, Ceballos S, Vechiu I, and Curea O. "Innovative Permanent Magnet Generator for an easy Integration into Direct Drive Wind Turbines." European Wind Energy Conference and Exhibition. Milan, 2007.

Rochard BP, and Schmid F. "A review of methods to measure and calculate train resistances." Journal of Rail \& Rapid Transit (Proceedings of the Institution of Mechanical Engineers - Part F) 214, no. 4 (2001): 185 - 199.

Rus G, Nash C. "In What Circumstances is Investment in High Speed Rail Worthwhile?" Institute of Transport Studies (White Rose Research Online), 2007.

Sandia National Laboratories. "Energy Storage Systems Technology." Sandia. 2003. http://www.sandia.gov/ess/Technology/technology.html.

Schmid F. Fundamental Aspects of Train Performance and Design Issues. Lecture Notes, Birmingham: The University of Birmingham, 2008.

Schmid F, and Goodman CJ. Systems in Common Use Additional Notes. Lecture Notes, Birmingham, UK: University of Birmingham, 2007, 13.

Siemens. DC Motors: Sizes 100 to 630, $0.45 \mathrm{~kW}$ to $1610 \mathrm{~kW}$. Catalogue DA 12 - 2004. Siemens. Munich, Germany, 2004.

Siu LK, and Goodman CJ. "An Object-oriented Network Simulator for Multi-train Simulations." 4th International Conference on Computer Aided Design, Manufacture and Operation in the Railway and Other Advanced Mass Transit Systems. Madrid: CompRail 94, 1994.

Slemon GR. Electric machines and drives. Reading, Massachusetts, USA: Addison-Wesley, 1992.

Taskin T, and Goodman CJ. "Modelling of signalling in an Object-oriented Simulation Model." London: IRSE International Conference 'Aspect 91', 1991.

Wells C. Braking Systems for Railways: Friction Brake Selection, Adhesion Management and State of the Art. Lecture Notes, MSc Railway Systems Engineering, Birmingham: The University of Birmingham, 2008, 7 - 10.

Wen Q, Kingsley S, and Smith RA. "Energy Simulation of Hybrid Inter-city Trains." Proceedings of the Institution of Civil Engineers (Journal of Energy - Ice) 160, no. 3 (2007): 123 - 131.

Wikipedia. Railway Electrfication in Great Britain. June 7, 2009a. http://en.wikipedia.org/wiki/Railway_electrification_in_Great_Britain\#1500_V_DC.2C_O verhead_2. 
- Railway Electrification Systems. May 21, 2009b. http://en.wikipedia.org/wiki/Railway_electrification_system.

Wildi T. Electrical machines, drives, and power systems. 6. Upper Saddle River, New Jersey: Prentice Hall, 2006.

Wong KK, and Ho TK. "Coast Control for Mass Rapid Transit Railways with Searching Methods." (IEE) 151, no. 3 (2004).

Yu JG, Khan AMM, and Loring K. "Computer Simulation of Transit Power Systems." International Conference on Simulation '98. York, UK: IEE, 1998. 93 - 98. 


\section{APPENDIX A}

\begin{tabular}{|c|c|c|c|c|c|c|c|c|c|c|c|c|}
\hline $\mathrm{Z} / \mathrm{N}$ & 368 & & & & & & & & & & & \\
\hline$\omega$ & 145.56 & & & & & & & & & & & \\
\hline n & 1390 & & & & & & & & & & & \\
\hline I & 275 & & & & & & & & & & & \\
\hline \multicolumn{13}{|c|}{$\mathbf{K}$} \\
\hline Winding Type & turns (N) & 1 & 2 & 3 & 4 & 5 & 6 & 7 & 8 & 9 & 10 & 11 \\
\hline \multirow{2}{*}{ Lap } & simplex & 58.57 & 117.14 & 175.71 & 234.28 & 292.85 & 351.41 & 409.98 & 468.55 & 527.12 & 585.69 & 644.26 \\
\hline & duplex & 29.28 & 58.57 & 87.85 & 117.14 & 146.42 & 175.71 & 204.99 & 234.28 & 263.56 & 292.85 & 322.13 \\
\hline \multicolumn{13}{|c|}{$\mathbf{K}^{\prime}$} \\
\hline Winding Type & turns (N) & 1 & 2 & 3 & 4 & 5 & 6 & 7 & 8 & 9 & 10 & 11 \\
\hline \multirow{2}{*}{ Lap } & simplex & 6.13 & 12.27 & 18.40 & 24.53 & 30.67 & 36.80 & 42.93 & 49.07 & 55.20 & 61.33 & 67.47 \\
\hline & duplex & 3.07 & 6.13 & 9.20 & 12.27 & 15.33 & 18.40 & 21.47 & 24.53 & 27.60 & 30.67 & 33.73 \\
\hline $\mathbf{T}$ & 583.99 & & & & & & & & & & & \\
\hline \multicolumn{13}{|c|}{ Phi } \\
\hline Winding Type & turns $(\mathrm{N})$ & 1 & 2 & 3 & 4 & 5 & 6 & 7 & 8 & 9 & 10 & 11 \\
\hline Lap & $\begin{array}{l}\text { simplex \& } \\
\text { duplex }\end{array}$ & 0.04 & 0.02 & 0.01 & 0.01 & 0.01 & 0.01 & 0.01 & 0.00 & 0.00 & 0.00 & 0.00 \\
\hline \multicolumn{4}{|c|}{$\mathbf{E}$} & & \multicolumn{4}{|c|}{$\mathrm{T}$} & & & & \\
\hline Winding Type & Orientation & $\mathbf{K}$ & $\mathbf{K}^{\prime}$ & & Winding Type & Orientation & $\mathbf{K}$ & $\mathbf{K}^{\prime}$ & & & & \\
\hline \multirow{2}{*}{ Lap } & simplex & 309.11 & 309.11 & & \multirow{2}{*}{ Lap } & simplex & 583.99 & 61.16 & & & & \\
\hline & duplex & 154.56 & 154.56 & & & duplex & 292.00 & 30.58 & & & & \\
\hline \multicolumn{13}{|c|}{$\mathbf{K}$} \\
\hline Winding Type & turns $(\mathrm{N})$ & 1 & 2 & 3 & 4 & 5 & 6 & 7 & 8 & 9 & 10 & 11 \\
\hline \multirow{2}{*}{ Frog-leg } & simplex & 29.28 & 58.57 & 87.85 & 117.14 & 146.42 & 175.71 & 204.99 & 234.28 & 263.56 & 292.85 & 322.13 \\
\hline & duplex & 14.64 & 29.28 & 43.93 & 58.57 & 73.21 & 87.85 & 102.50 & 117.14 & 131.78 & 146.42 & 161.06 \\
\hline \multicolumn{13}{|c|}{ 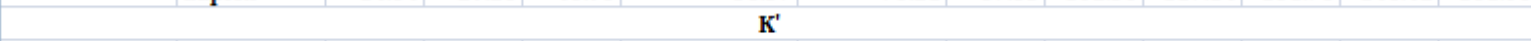 } \\
\hline Winding Type & turns (N) & 1 & 2 & 3 & 4 & 5 & 6 & 7 & 8 & 9 & 10 & 11 \\
\hline \multirow{2}{*}{ Frog-leg } & simplex & 3.07 & 6.13 & 9.20 & 12.27 & 15.33 & 18.40 & 21.47 & 24.53 & 27.60 & 30.67 & 33.73 \\
\hline & duplex & 1.53 & 3.07 & 4.60 & 6.13 & 7.67 & 9.20 & 10.73 & 12.27 & 13.80 & 15.33 & 16.87 \\
\hline $\mathbf{T}$ & 583.99 & & & & & & & & & & & \\
\hline \multicolumn{13}{|c|}{ Phi } \\
\hline Winding Type & turns $(\mathrm{N})$ & 1 & 2 & 3 & 4 & 5 & 6 & 7 & 8 & 9 & 10 & 11 \\
\hline Frog-leg & $\begin{array}{l}\text { simplex \& } \\
\text { duplex }\end{array}$ & 0.04 & 0.02 & 0.01 & 0.01 & 0.01 & 0.01 & 0.01 & 0.00 & 0.00 & 0.00 & 0.00 \\
\hline
\end{tabular}

Figure 65: Class 507 Motoring Curves (C507MC) with calculation of motor constant $(\mathrm{K})$ for lap and frog-leg windings, 1 to 11 turns on armature conductors and multiplex 


\section{APPENDIX B}

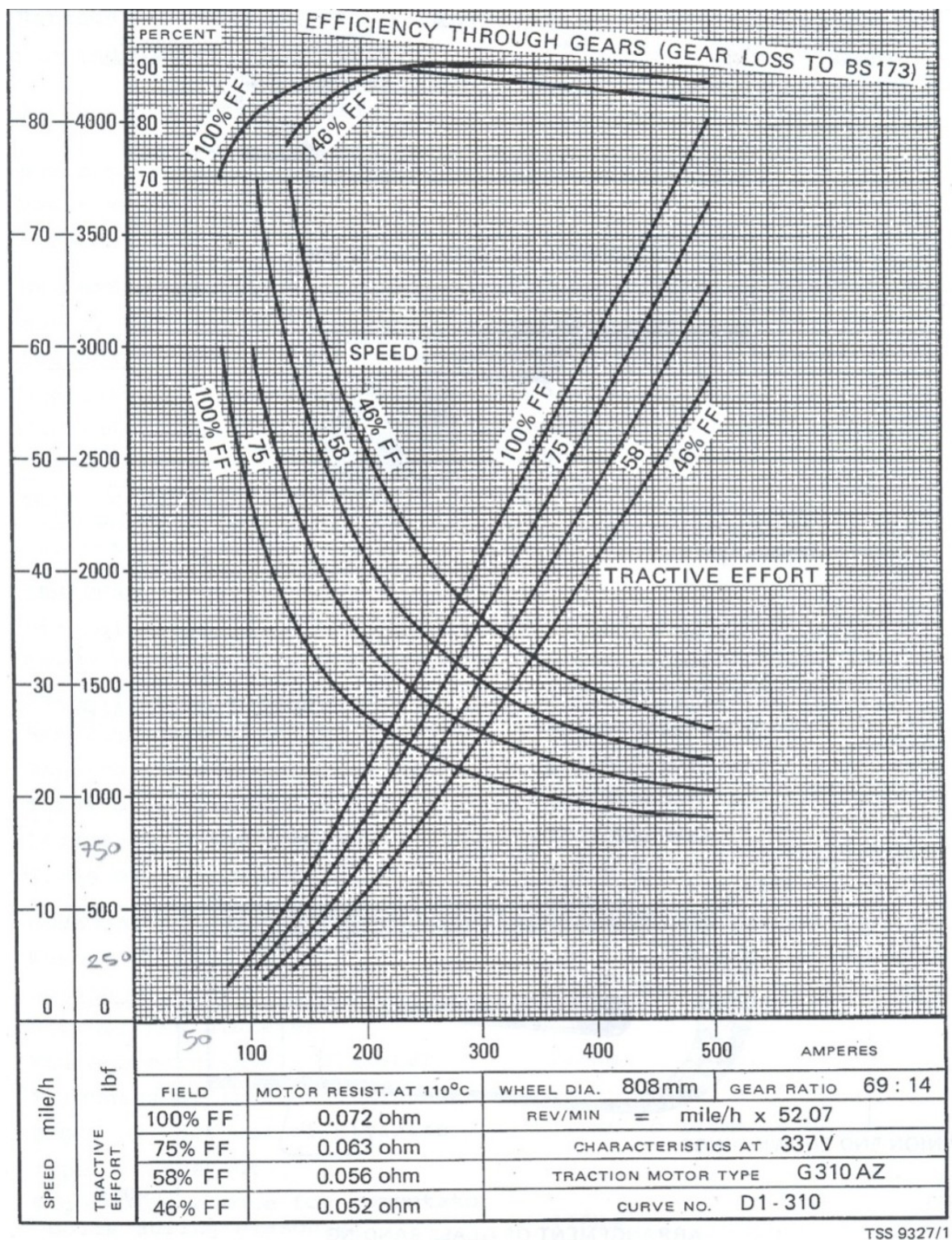

Page $4-133189$

Figure 66: Tractive Effort versus Current and Speed versus Current with indicated field weakening percentages 


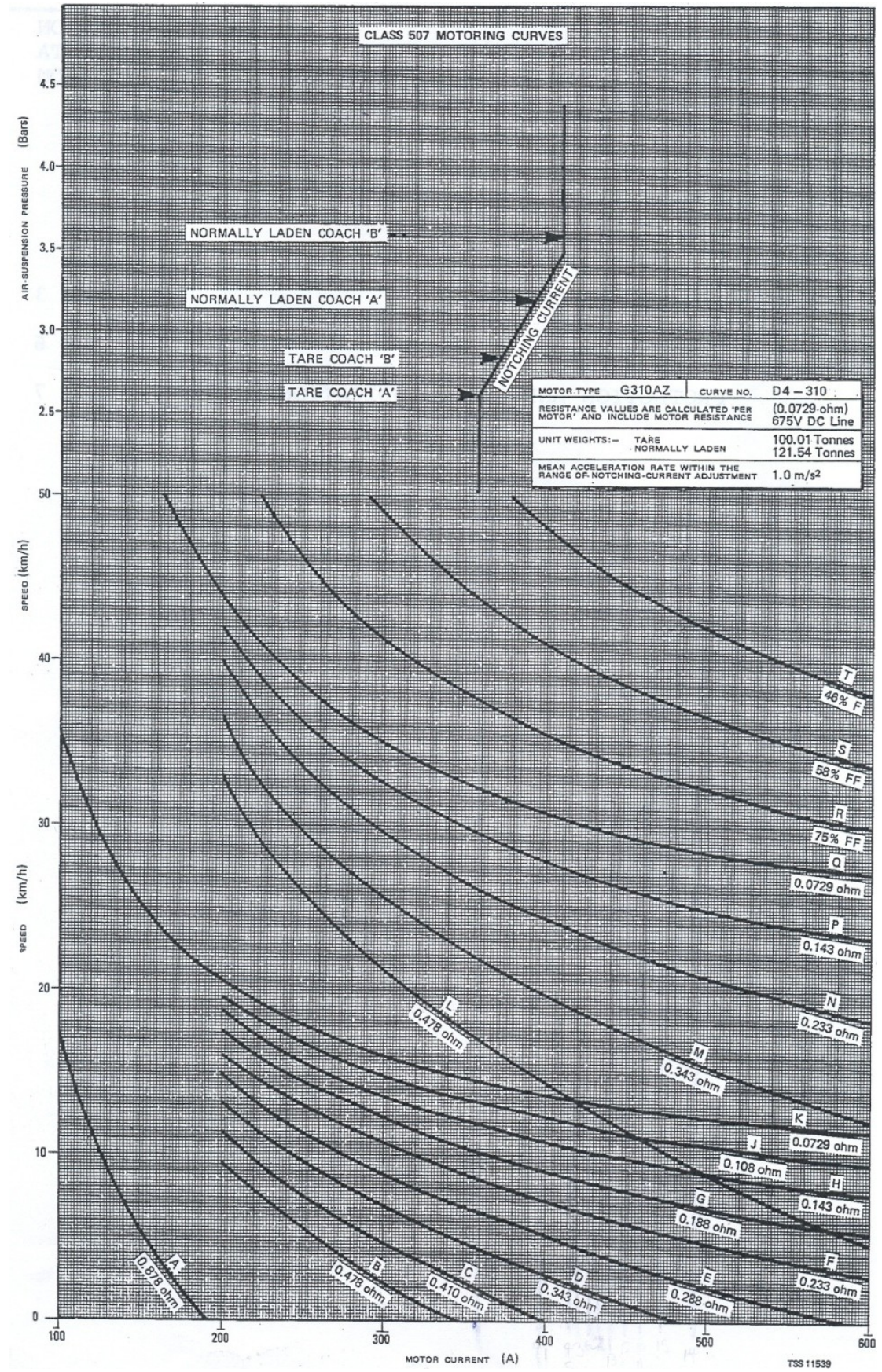

Figure 67: Speed versus Current curves for each camshaft position from A to T, with indicated resistance and field weakening percentages 


\section{APPENDIX C}
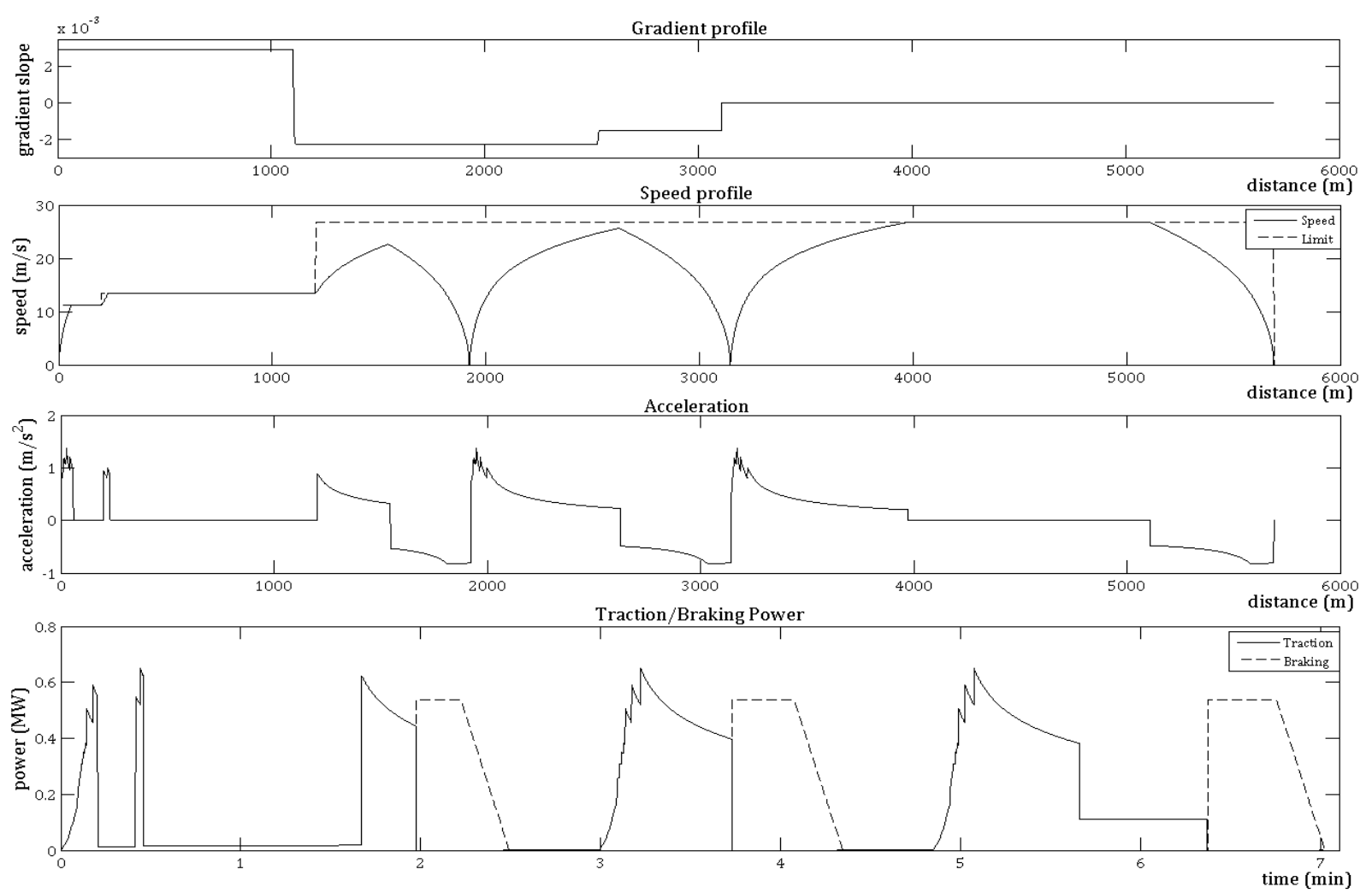

Figure 68: The MERS simulating one train from Ellesmere Port to Hooton
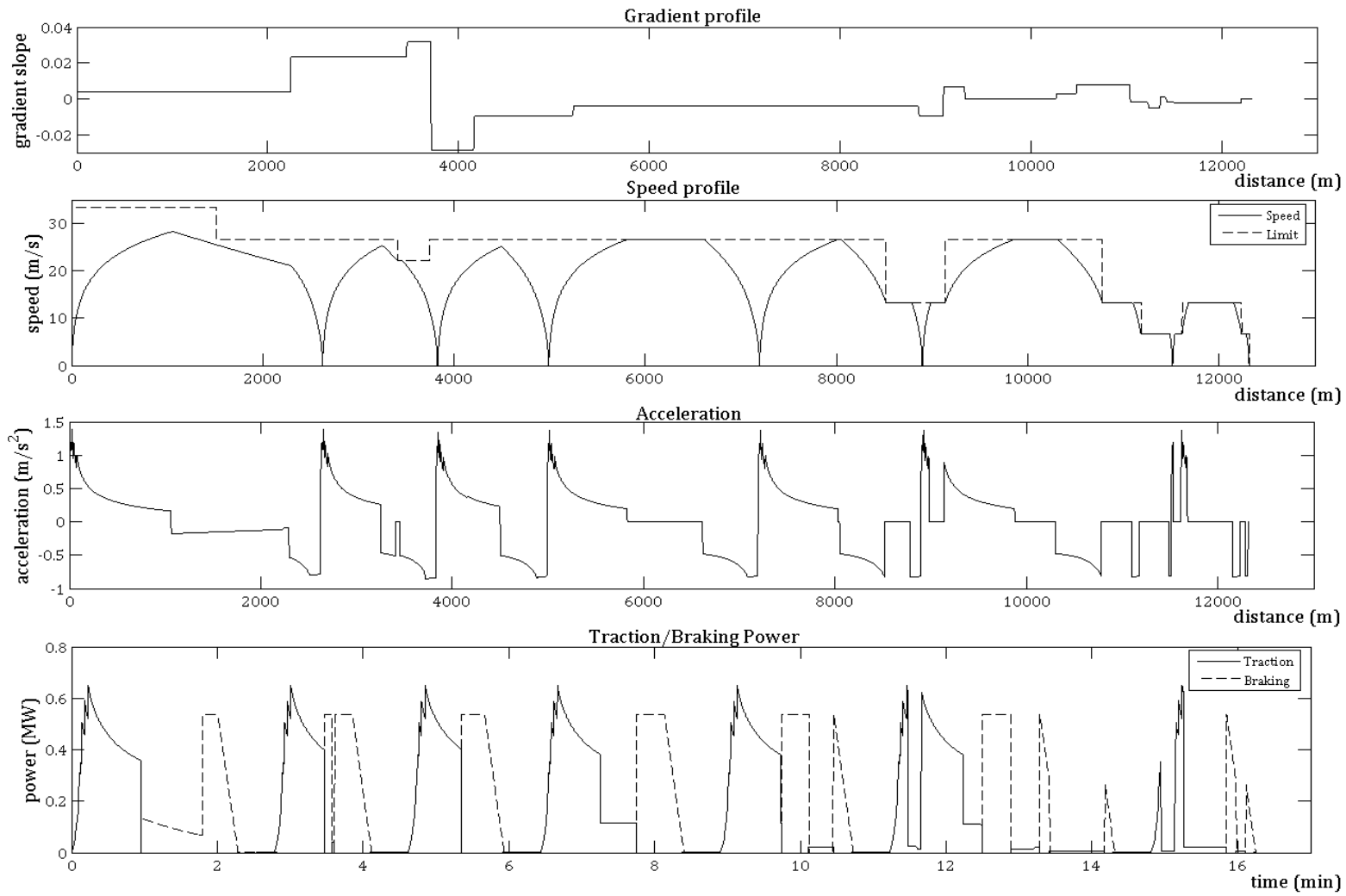

Figure 69: The MERS simulating one train from Hunts Cross to Moorfields 

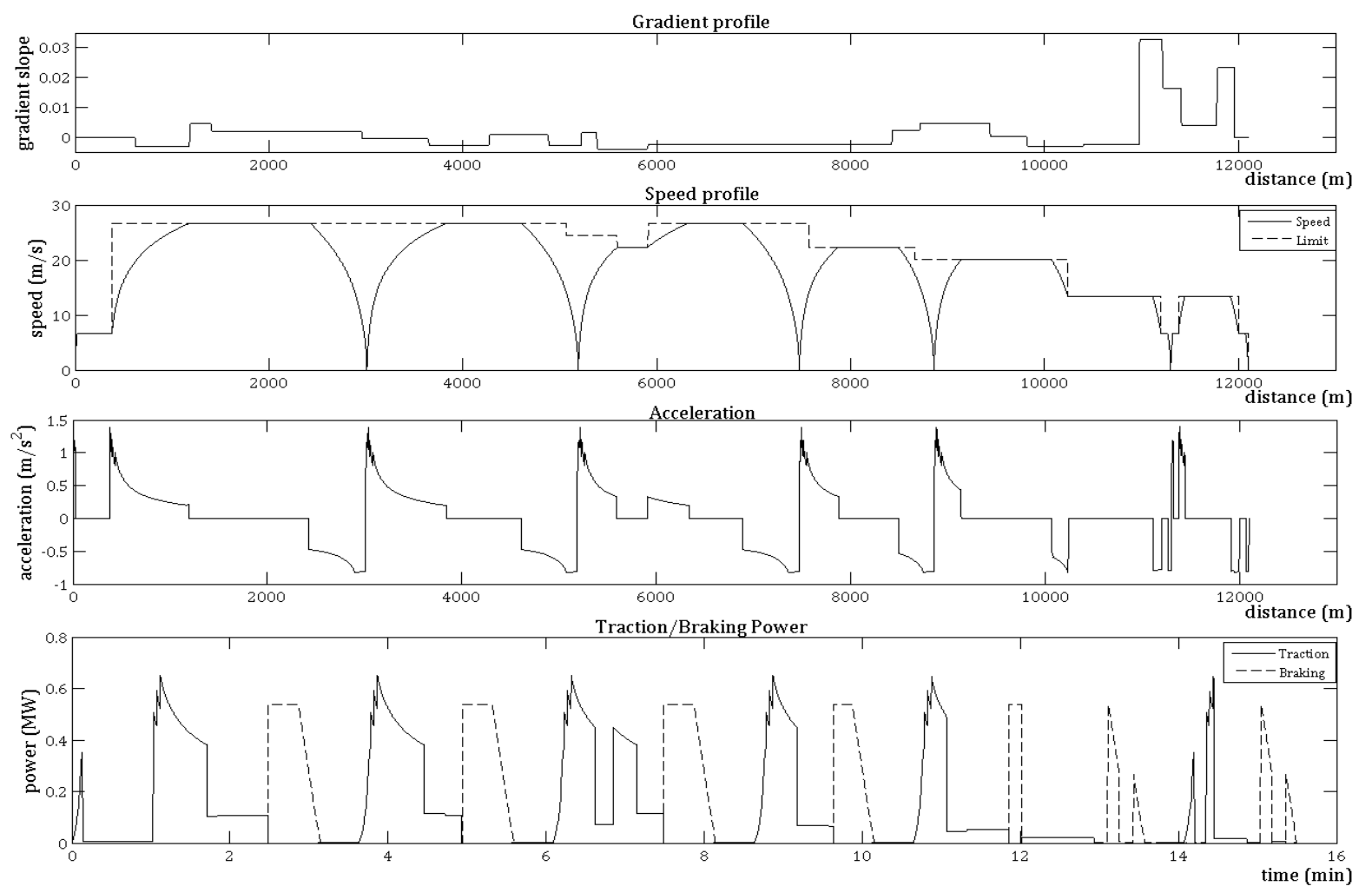

Figure 70: The MERS simulating one train from Kirkby to Liverpool Central
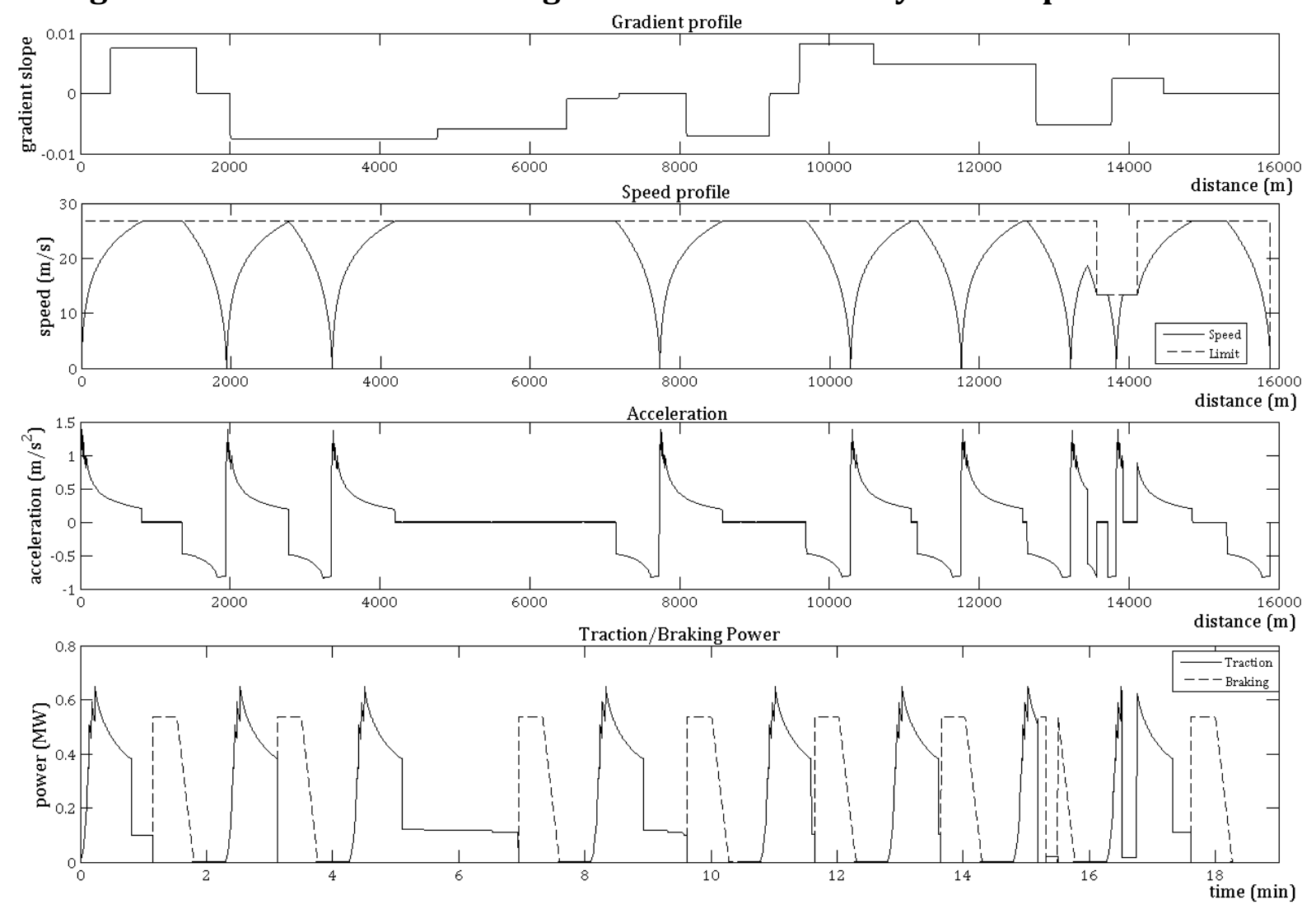

Figure 71: The MERS simulating one train from Ormskirk to Kirkdale 

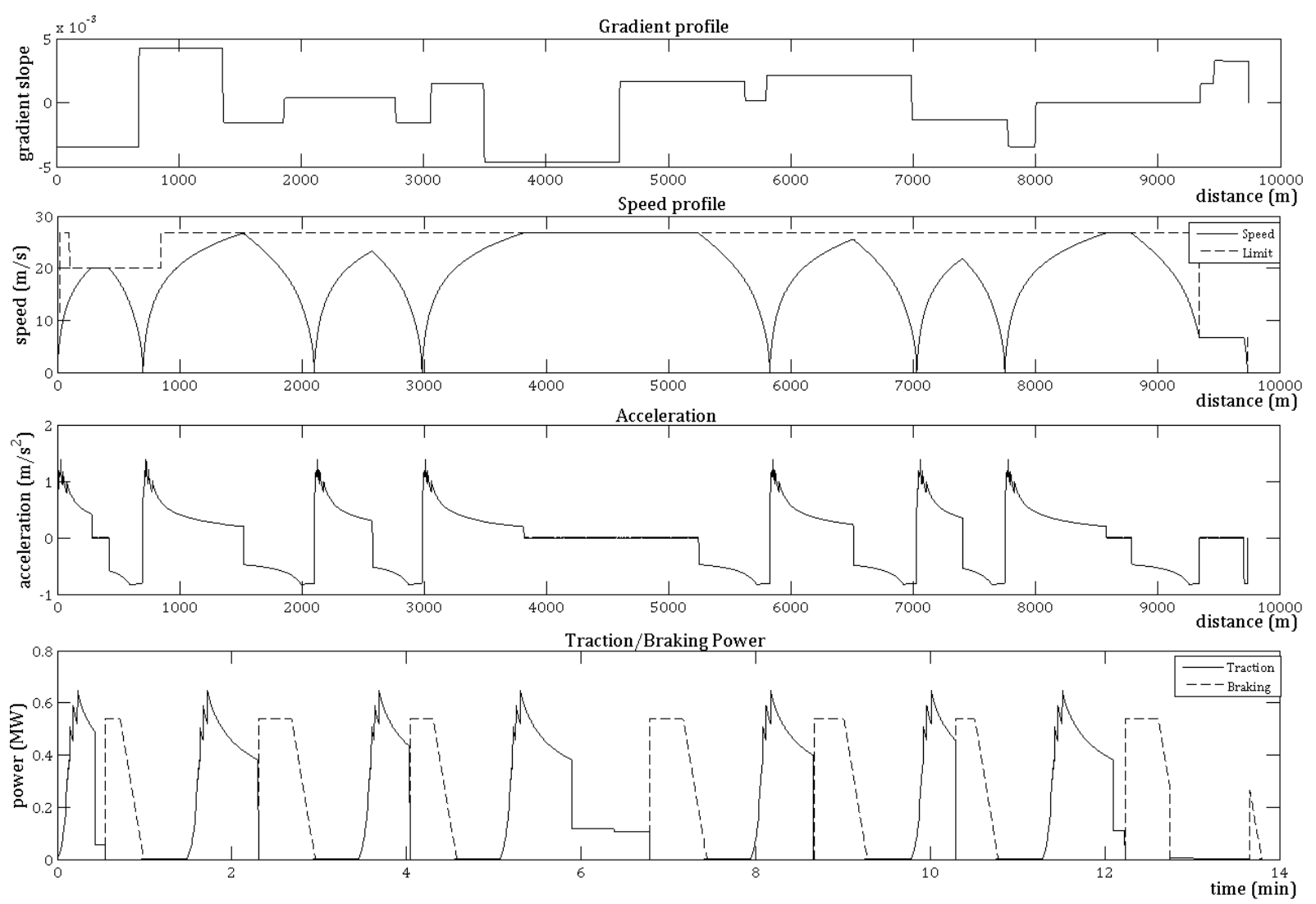

Figure 72: The MERS simulating one train from West Kirby to Birkenhead North
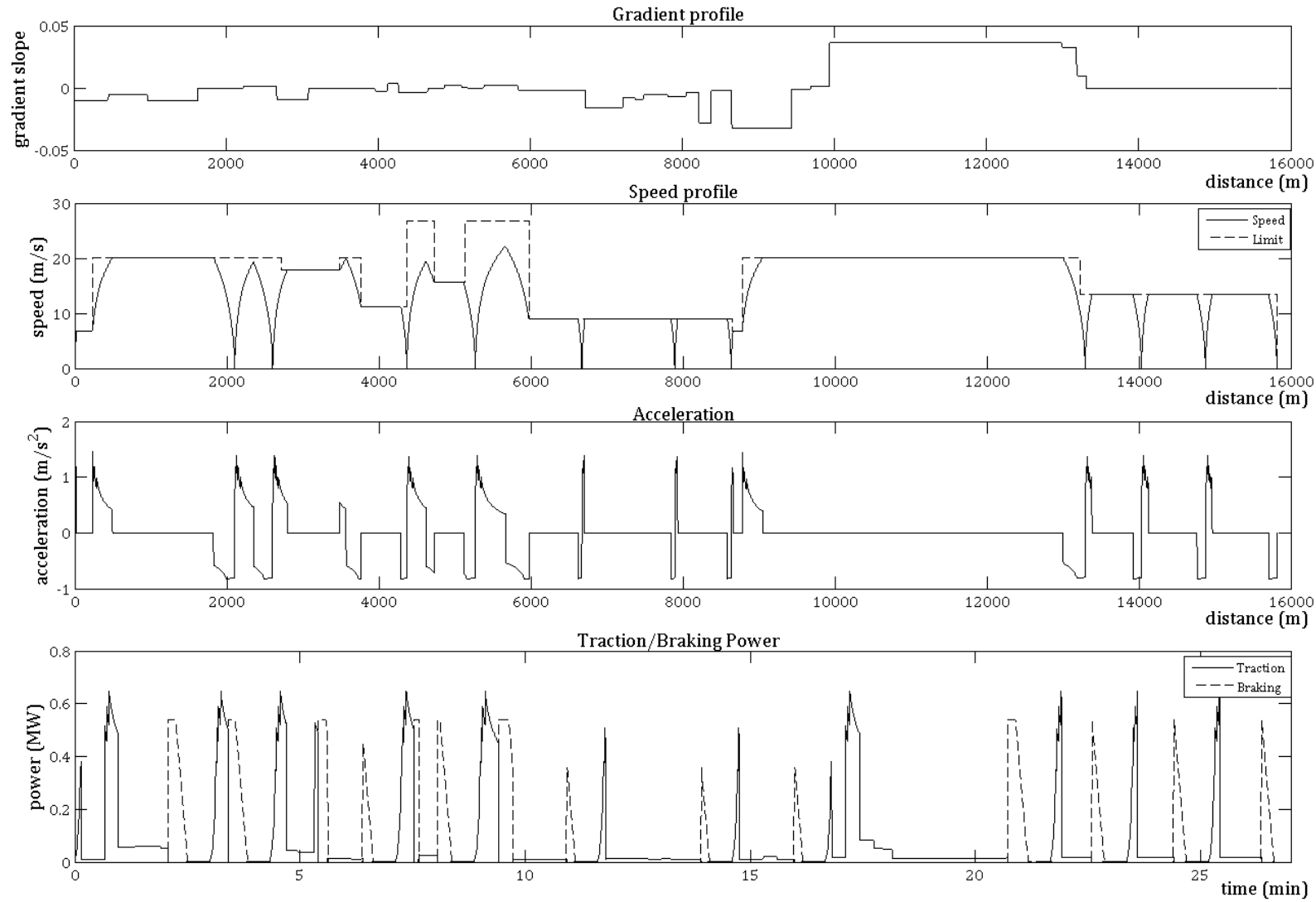

Figure 73: The MERS simulating one train from New Brighton to Liverpool Central 

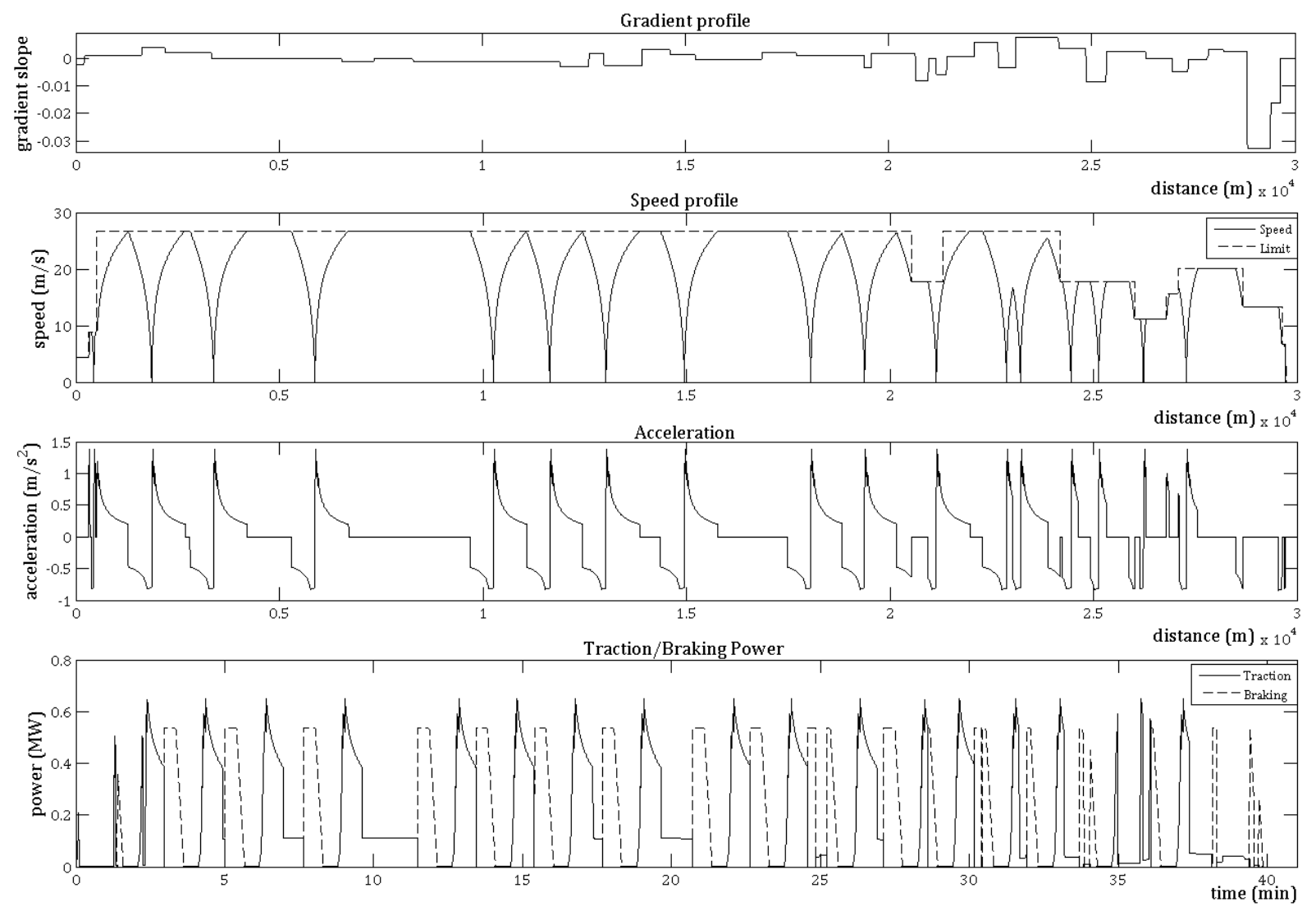

Figure 74: The MERS simulating one train from Southport to Moorfields 